\title{
Are Big Gods a big deal in the emergence of big groups?
}

\section{Quentin D. Atkinson, Andrew J. Latham \& Joseph Watts}

To cite this article: Quentin D. Atkinson, Andrew J. Latham \& Joseph Watts (2015) Are Big Gods a big deal in the emergence of big groups?, Religion, Brain \& Behavior, 5:4, 266-274, DOI: 10.1080/2153599X.2014.928351

To link to this article: https://doi.org/10.1080/2153599X.2014.928351

曲 Published online: 23 Jul 2014.

Submit your article to this journal $\pi$

Џll Article views: 575

Q View related articles $₫$

View Crossmark data $\nearrow$

Citing articles: 4 View citing articles $\sqsubset$ 


\title{
BOOK SYMPOSIUM: BIG GODS BY ARA NORENZAYAN
}

\section{Are Big Gods a big deal in the emergence of big groups?}

\author{
Quentin D. Atkinson $^{\mathrm{a} *}$, Andrew J. Latham ${ }^{\mathrm{b}}$ and Joseph Watts ${ }^{\mathrm{a}}$ \\ ${ }^{a}$ School of Psychology, University of Auckland, Auckland, New Zealand; ${ }^{b}$ Department of \\ Philosophy, The University of Sydney, Sydney, Australia
}

Establishing whether Big Gods helped drive the cultural evolution of large-scale cooperation requires the synthesis of multiple lines of evidence. Survey data and labbased studies suggest that belief in (or priming the concept of) a powerful moralizing god can increase individual prosocial behavior (Norenzayan, Henrich, \& Slingerland, 2013; Shariff \& Norenzayan, 2007, 2011), and point to the importance of the imagined presence of a supernatural monitor and the threat of punishment (Atkinson \& Bourat, 2011; Gervais \& Norenzayan, 2012; Norenzayan, Gervais, \& Trzesniewski, 2012; Shariff \& Norenzayan, 2011; Shariff \& Rhemtulla, 2012). However, these findings do not tell us whether such prosocial effects scale up to produce meaningful cooperative advantages at the societal level. One crucial piece of evidence in this regard has been cross-cultural comparative data on the distribution of types of Big God beliefs around the world (Brown \& Eff, 2010; Johnson, 2005; Norenzayan \& Shariff, 2008; Peoples \& Marlowe, 2012; Peregrine, 1996; Roes \& Raymond, 2003; Sanderson \& Roberts, 2008; Snarey, 1996; Stark, 2001; Swanson, 1960; Underhill, 1975). Put simply, if certain types of Big Gods help promote cooperation then, the argument goes, these gods should be associated with cooperation across societies.

In Big Gods, Norenzayan (2013) presents the most comprehensive treatment yet of the Big Gods question. The book is a commendable attempt to synthesize the rapidly growing body of survey and experimental research on prosocial effects of religious primes together with cross-cultural data on the distribution of Big Gods. There are, however, a number of problems with the current cross-cultural evidence that weaken support for a causal link between big societies and certain types of Big Gods. Here we attempt to clarify these problems and, in so doing, correct any potential misinterpretation of the cross-cultural findings, provide new insight into the processes generating the patterns observed, and flag directions for future research.

Attempts to statistically test "Big Gods" predictions using systematically coded ethnographic data can be traced back to the coding schemes outlined in Swanson's (1960) The Birth of the Gods. Swanson catalogued the presence or absence of omnipotent creator gods, termed "High Gods," in 39 societies. Swanson further categorized High Gods based on whether they were active, concerned with human affairs, and specifically supportive of human morality. Based on his initial coding, Swanson argued that larger societies with multiple layers of jurisdictional hierarchy were more likely to have High Gods (morally

*Corresponding author. Email: q.atkinson@auckland.ac.nz

(C) 2014 Taylor \& Francis 
concerned or not). Since 1960, Swanson's coding has been expanded to cover 168 societies from the Standard Cross-Cultural Survey (SCCS; Murdock \& White, 1969) and 748 societies from the Ethnographic Atlas (EA; Murdock, 1967). Like Swanson's initial survey, these larger data sets also show an association between the presence of High Gods and economic and political complexity (Sanderson \& Roberts, 2008; Underhill, 1975). ${ }^{1}$

Recently, a string of studies have sought to test the hypothesized monitoring and enforcement role of High Gods by examining the relationship between the presence of specifically moralizing High Gods (MHGs) and various measures of large-scale cooperation. Snarey (1996) found that across societies in the SCCS, MHGs were more likely to occur in regions of water scarcity where, he argued, there was a greater need for prosocial use of natural resources. Stark (2001) found that MHGs recorded in the Atlas of World Cultures (Murdock, 1981) correlate with various measures of cultural complexity (e.g., presence of domestic animals, agriculture, pottery, and existence of a state). Roes and Raymond (2003) showed that the presence of MHGs in the SCCS and EA correlates with "society size" (although the metric they used for society size was the number of "levels of jurisdictional hierarchy"). Johnson (2005) found that the presence of MHGs in the SCCS is correlated with various indices of societal cooperation such as taxation, policing, and measures of norm compliance. More recently, Brown and Eff (2010) applied a spatial autoregressive model (see below) to the SCCS data and found that animal husbandry, resource richness, external warfare, community size, and class stratification are associated with MHGs. Finally, Peoples and Marlowe (2012) have shown that MHGs in the SCCS tend to be found in societies with greater technological complexity and subsistence productivity.

The above relationships are variously cited as supporting the claim that shared belief in an MHG increases prosocial behavior and facilitates large-scale cooperation (Johnson, 2005; Norenzayan, 2013; Norenzayan \& Shariff, 2008; Peoples \& Marlowe, 2012; Roes \& Raymond, 2003; Snarey, 1996; Stark, 2001). The general patterns reported are also taken to support cultural group selection arguments that the competitive advantage provided by MHG beliefs has contributed to the gradual increase in human social complexity since the dawn of agriculture and the more recent expansion of the major world religions (Norenzayan, 2013; Norenzayan \& Shariff, 2008; Roes \& Raymond, 2003).

A major problem with almost all of the cross-cultural analyses of MHG data is that the statistical tests employed assume that the data points are independent when they are not. "Galton's problem," as it is known to anthropologists, has been recognized since 1888 when Sir Edward Tylor presented a correlation between patrilineal marriage systems and social complexity as evidence that complex societies gave rise to a patrilineal focus. Sir Francis Galton famously critiqued Tylor's argument, noting that the similarities between cultures could also arise due to common ancestry or more recent diffusion of ideas. The same critique can be applied to the similarities identified between societies with MHGs.

While some of the above studies acknowledge and attempt to address Galton's problem, none do so adequately and, to the extent that they are able to control for nonindependence, the conclusions of the studies are weakened. Stark (2001) and Peoples and Marlowe (2012) do not control for Galton's problem at all. Roes and Raymond (2003) and Johnson (2005) control for regional effects by including six world regions (Sub-Saharan Africa, Circum-Mediterranean, East Eurasia, Insular Pacific, North America, South America) as a factor in their regression models. Of the 19 predictions tested in Johnson (2005), only four remain significant after controlling for world region. 
Roes and Raymond (2003) report that their correlation between MHGs and society size remains significant when controlling for world region. We replicated this test using binary logistic regression and the EA data set $(p<0.001)$, but did not find a significant effect using the smaller SCCS data set $(p=.379)$.

Controlling for region effects in this way is a step in the right direction, but it still assumes that data points are independent within regions and that each region is independent. Neither of these assumptions holds. Figures 1 and 2 map the presence or absence of MHGs across societies in the SCCS and EA, respectively. The figures show that the global distribution of MHGs is highly spatially auto-correlated, with most MHGs around the circum-Mediterranean, the northern half of Africa and the Near East, clearly associated with the expansion of the Abrahamic faiths. These cultures will dominate any global analysis of the distribution of MHGs, and because their range cross-cuts the standard world regions in the SCCS and EA, controlling for regional effects does not account for non-independence due to the Abrahamic expansions. It is worth noting that the SCCS sample was initially designed as an attempt to overcome the problem of nonindependence between neighboring groups by sub-sampling cultures from the larger EA data set; however, even the cultures in the SCCS are known to be spatially auto-correlated (Dow \& Eff, 2008). The fact that Roes and Raymond's (2003) findings do not hold for the SCCS after controlling for regional differences therefore suggests that we should be cautious in interpreting their results.

A more principled approach to controlling for non-independence in the data is to explicitly incorporate possible dependencies into the regression model. Brown and Eff (2010) use a two-stage least-squared spatial autoregressive model to quantify and control for non-independence due to spatial diffusion as well as shared cultural ancestry. This enables them to estimate the relative contribution of spatial diffusion (as indicated by geographic proximity) and shared cultural ancestry (as indicated by linguistic affiliation) to variation in MHGs. They find spatial diffusion to be the dominant process - their

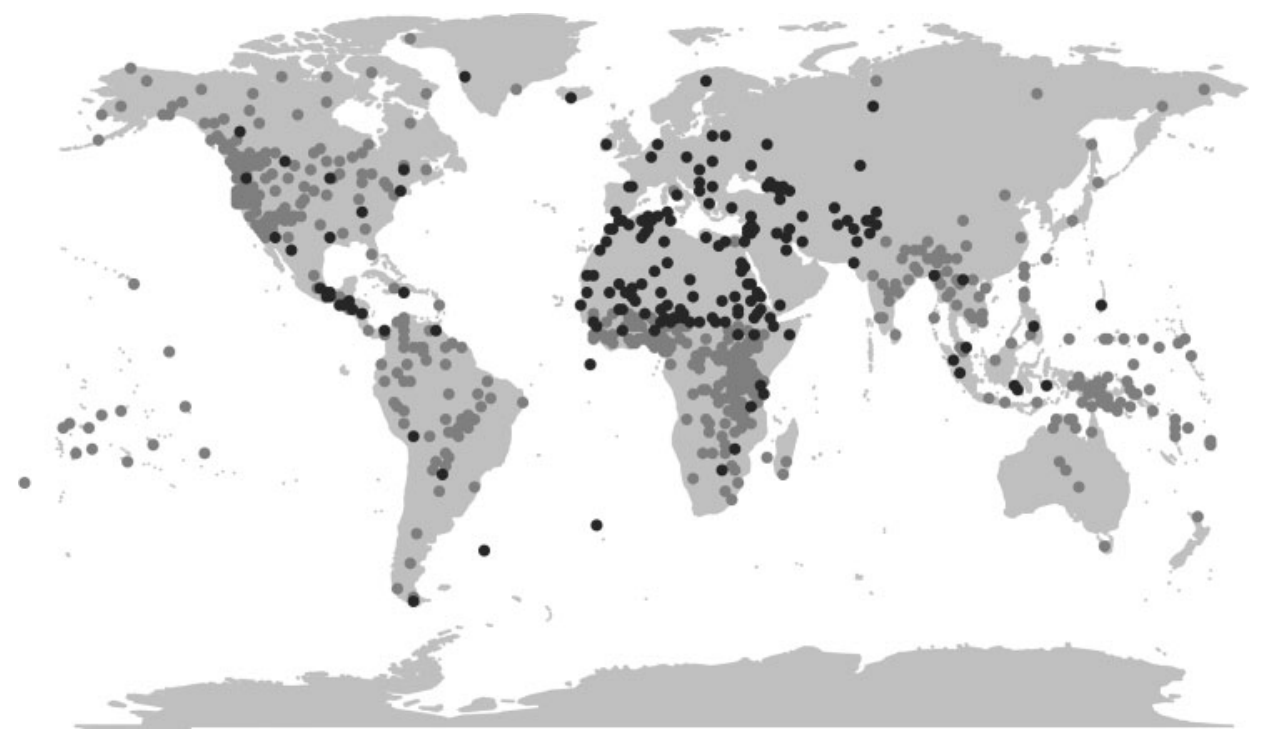

Figure 1. Map showing the location of moralizing high gods (black dots) in societies from the Ethnographic Atlas (Murdock, 1967); and (b) the Standard Cross Cultural Survey (Murdock \& White, 1969). 


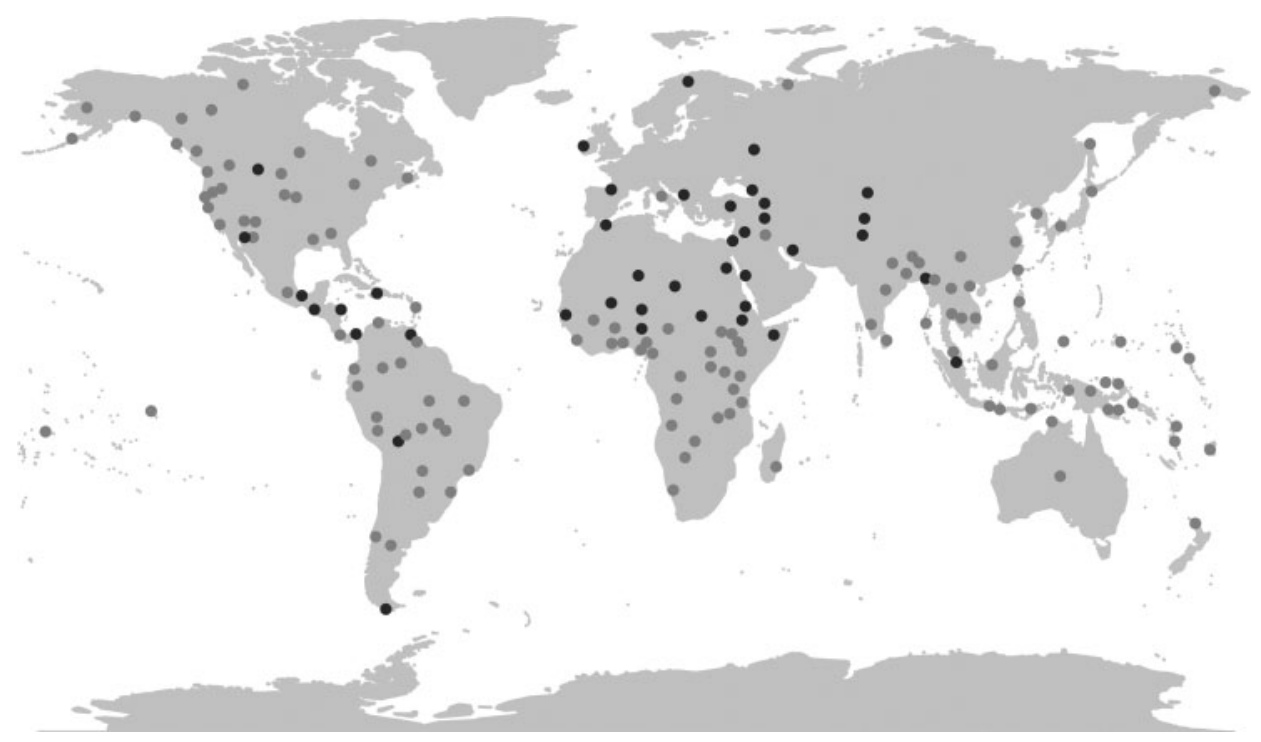

Figure 2. Map showing the location of moralizing high gods (black dots) in societies from the Standard Cross Cultural Survey (Murdock \& White, 1969).

cultural diffusion term is the single most important predictor in their final model, explaining $24 \%$ of the variance. The next best predictor in their model is animal husbandry (11\% of the variance), which they suggest may reflect a functional role for religion in the "protection of easily alienable property rights." Small but significant effects were also found for increased caste stratification, community size, lower frequency of external warfare, lower agricultural potential, and increased resource scarcity. Interestingly, for community size, Brown and Eff (2010) find that MHGs are most likely to occur in societies of moderate size, being relatively rare in the smallest and largest groups. While Brown and Eff (2010) control for cultural ancestry and the geographic spread of MHGs, they do not control for Abrahamic influence that has occurred through missionaries, trade networks, and colonization - processes that have not necessarily taken place between geographically contiguous cultures.

Several studies have attempted to control for influence of Abrahamic and other classical religions (e.g., Hinduism and Buddhism) using the SCCS "Religion" variable (v713). This variable classifies half the societies in the SCCS according to whether they are: (1) "Classical religion (Christianity, Islam, Hinduism, Buddhism);" (2) "Mixture of classical \& preclassical;" or (3) "Preclassical." After controlling for influence of classical religion and region, only two of Johnson's 19 predictions are supported (and another borderline significant effect is in the opposite direction to that predicted) (Johnson, 2005). Roes and Raymond (2003) claim that the correlation between MHGs and society size holds after controlling for classical religion, but we could not replicate this finding using the SCCS data (in an ordinal regression controlling for classical religion, the effect of society size [levels of jurisdictional hierarchy] is not significant, $p=.415$ ). Snarey (1996) coded a similar variable recording whether societies were exposed to Christian or Muslim missionaries. Excluding "missionized" societies, the relationship between water scarcity and MHGs remained significant. 
A favorable interpretation of these results is that after controlling for the influence of classical religions, the effect of MHGs on cooperation is weakened but still detectable. However, a closer look at the cultures outside the Abrahamic and other classical religious traditions challenges this conclusion. In Johnson (2005) and Roes and Raymond (2003), of the cultures judged "preclassical," only one is coded as having an MHG - the Papago. A more recent version of the "Religion" variable (v713rev) has a complete coding for all cultures in the SCCS, but only eight "preclassical" societies are coded as having MHGs. One of these, the Hebrews, practices Judaism, an early branch of the Abrahamic tradition. The Abkhaz are listed as "preclassical" but have been subject to Orthodox Christian and Muslim influence since the sixth century. The Lakher of southern Asia appear to have had an indigenous MHG (although early ethnographies followed on the heels of intensive missionary activity) (Levinson, 1991). In the Americas, the Papago, Cuna, Warrau, Gros Ventre, and Yaghan are all coded as having MHGs and as "preclassical," but information on the indigenous beliefs prior to missionary contact is limited, and for at least some of these groups the reported MHGs may well be recent innovations following contact with Christianity (Cooper, 1917; Levinson, 1991). It is worth noting that of these eight societies, only the Hebrews are coded above a 2 ("petty chiefdom") on the 1-5 scale of society size/complexity that is the focus of Roes and Raymond's (2003) study. The picture is similar for Snarey's (1996) findings. Of the nine cultures with MHGs judged by Snarey to be "pre missionization," the Hebrews follow an Abrahamic tradition, and the Bogo, Masaii, Somali, Basseri, and Rwala Bedouin have their own traditions but are all part of a geographically contiguous arid region that has been subject to influence from Abrahamic religions for centuries. The Gros Ventre and Yaghan cases are inconclusive, as mentioned above. Finally, the Yukaghir of Siberia are coded by Snarey as having a "preclassical" MHG, but early accounts describe a vague and distant entity (Jochelson, 1926), and moralizing elements may reflect direct or indirect influence from missionaries (Willerslev, 2011). ${ }^{2}$

Hence, there is little, if any, evidence from the SCCS that the reported correlates of MHGs apply outside the Abrahamic traditions. Data from the larger EA might seem a more promising prospect given its increased sample size (issues of non-independence not withstanding). However, the EA does not include measures of missionization or influence of classical religion, so their effect cannot currently be factored out. More detailed work is needed on the status of putative MHGs around the globe, but it seems clear that the independent innovation of an MHG is a rare event. The SCCS provides just one clear case of the major expansion of a religious tradition with MHGs - the expansion of the Abrahamic faiths. This is not to say that there are no non-Abrahamic MHGs - for example, the ancient Zoroastrian "good" and "bad" gods were outside the Abrahamic tradition, although not independent of it (Wright, 2009); the Lakher (mentioned above) are a credible case; and recent analysis of ancient Chinese texts suggests the independent development of MHG beliefs in China (Slingerland, 2013). However, outside of the Abrahamic tradition, the current cross-cultural data provide at best weak evidence for the predicted associations between MHGs and society size, complexity, resource scarcity, and norm compliance.

How, then, are we to interpret the cross-cultural evidence regarding MHGs? As discussed above, a failure to adequately account for Galton's problem calls into question much of the previous research on MHGs (Brown \& Eff, 2010; Johnson, 2005; Peoples \& Marlowe, 2012; Roes \& Raymond, 2003; Snarey, 1996; Stark, 2001). Nevertheless, Brown and Eff (2010) were able to identify a number of significant predictors of MHGs after controlling for geographic diffusion and cultural ancestry (although not Abrahamic 
influence). On the basis of their findings, it remains possible to argue that MHGs facilitate cooperation and the emergence of large groups, at least within the Abrahamic religions. The inferred curvilinear relationship between MHGs and community size fits with the suggestion that MHGs allow groups to grow, but only up to a point at which they "kick away the ladder" and other secular systems take over (Norenzayan, 2013). MHGs were also more likely to be found in pastoral societies that are large enough to face problems of defection, but have not yet developed efficient secular policing systems (Brown \& Eff, 2010). Finally, in line with Snarey's (1996) argument, MHGs were also found to be more likely in areas of resource scarcity and lower agricultural potential, where they may help promote the prosocial use of resources and contribute to survival.

Although these findings are broadly consistent with Norenzayan's (2013) argument, our examination of the cultures driving these correlations indicates that support for the "Big Gods for big groups" hypothesis needs to be qualified in several ways. First, the dominance of Abrahamic MHGs in the SCCS affects the implied chronology of the relevant Big Gods and big groups. While Norenzayan (2013) postulates that Big Gods may have facilitated the shift from smaller nomadic bands to large agricultural societies as far back as 10,000 years ago, the Abrahamic religions are only around 3000 years old. MHGs of some kind might have promoted increases in social complexity at the dawn of the Neolithic, but the patterns identified in the MHG data reflect a much more recent transition.

Second, a lack of evidence outside the Abrahamic tradition means that we cannot rule out likely alternative causal explanations for the observed patterns. Most obviously, the Abrahamic religions share a range of features beyond MHGs that differentiate them from most ethno-religions of smaller-scale societies. These include active proselytization, a universal rather than ethnocentric ideology, a sacred text containing a strict moral code, exhortations to be fruitful and multiply, and exclusivity of a single god. Previous studies attempted to rule out these potentially confounding factors by showing that the predicted correlates of MHG held even after controlling for missionary activity or influence from classical religion more generally (Johnson, 2005; Roes \& Raymond, 2003; Snarey, 1996). Here we have argued that in fact the ethnographic data currently provide little, if any, evidence that these correlations apply outside the Abrahamic tradition, making it impossible to tease apart the effects of MHGs from other features of the Abrahamic tradition. Indeed, it is also possible that other secular features of the cultures that carried Abrahamic religions are responsible for the correlations found. Like the spread of the English, Spanish, and Arabic languages, the Abrahamic faiths might have spread because of the expanding cultures that they found themselves in and the social, political, technological, and economic advantages that this afforded (Diamond, 1997), rather than because of features of the religions themselves.

Of course, these alternative explanations are not mutually exclusive (multiple factors may be at work) and they reflect a general problem with any correlational data correlation does not imply causation. And even if we were able to partial out plausible confounding variables, the direction of causation remains unknown. MHGs or universalism or proselytization may lead to big societies, but the reverse could also be true. The point that we wish to make here is not that any or all religious features are likely to be unimportant, but that, while the question is an interesting one, the current cross-cultural evidence cannot tease these different factors apart and the methods that have hitherto been applied are ill-suited for testing causal models. 
Rather than a reason to ignore cross-cultural comparative data or to dismiss the arguments put forward in Big Gods (which are built on much more than the cross-cultural evidence), we see these challenges as highlighting three key areas for future research. First, given the rarity of MHGs outside of the Abrahamic tradition, the few instances of their independent invention deserve more attention. Second, we need to move beyond Swanson's MHGs variable to develop systematically coded data on the presence or absence of a range of religious features hypothesized to promote cooperation, from supernatural agents to doctrine and ritual (Atkinson \& Whitehouse, 2011; Henrich, 2009; Slingerland, 2013; Valdesolo, Ouyang, \& DeSteno, 2010). Third, to tease apart alternative explanations, future cross-cultural studies need to explicitly model cultural transmission and test the direction of causation. One promising approach may be to borrow tools developed by evolutionary biologists to solve analogous problems in the study of species evolution. Evolutionary biologists routinely use comparative phylogenetic methods to infer evolutionary patterns and processes from extant species (Harvey \& Pagel, 1991). By reconstructing species ancestry and mapping traits onto their family tree, biologists can model the process of evolution as it plays out along the branches of the tree (Pagel, 1997). Phylogenetic methods developed in biology make it possible to test sequential models of change (Harvey \& Pagel, 1991) or test for the co-evolution of two features (Pagel, 1994; Pagel \& Meade, 2006), and provide a natural framework with which to control for non-independence in the data. These approaches have already been successfully applied to test competing models of cultural evolution using cultural genealogies derived from language relatedness (Currie, Greenhill, Gray, Hasegawa, \& Mace, 2010; Dunn, Greenhill, Levinson, \& Gray, 2011) and the methods are now beginning to be applied to model the process of religious evolution (Matthews, 2012). By combining these new methods with new comparative religious data, we should be able to explicitly test between competing theories and shed new light on how religion transformed cooperation and conflict.

\section{Acknowledgements}

We thank Oliver Sheehan for useful discussions about the material presented here.

\section{Funding}

This work was supported by a Rutherford Discovery Fellowship to Atkinson, administered by the Royal Society of New Zealand [grant \#RDF-UOA1101] and the John Templeton Foundation [grant \#28745].

\section{Notes}

1. An independent coding of 72 North American cultures found the same pattern (Peregrine, 1996).

2. In addition, the Yukaghir do not fit with Snarey's prediction, although Snarey (1996) attributes this to the fact that while their climate is not arid, subzero temperatures make water effectively inaccessible for much of the year.

\section{References}

Atkinson, Q.D., \& Bourrat, P. (2011). Beliefs about God, the afterlife and morality support the role of supernatural policing in human cooperation. Evolution and Human Behavior, 32(1), 41-49. doi:10.1016/j. evolhumbehav.2010.07.008

Atkinson, Q.D., \& Whitehouse, H. (2011). The morphospace of ritual form: Examining modes of religiosity cross-culturally. Evolution and Human Behavior, 32(1), 50-62. doi:10.1016/j.evolhumbehav.2010.09.002 
Brown, C., \& Eff, E.A. (2010). The state and the supernatural: Support for prosocial behavior. Structure and Dynamics, 4(1), 1-21.

Cooper, J.M. (1917). Analytical and critical bibliography of the Tribes of Tierra del Fuego and Adjacent Territory Bulletin 63, Bureau of American Ethnology, 1917. Washington, DC: Smithsonian Institution.

Currie, T.E., Greenhill, S.J., Gray, R.D., Hasegawa, T., \& Mace, R. (2010). Rise and fall of political complexity in island South-East Asia and the Pacific. Nature, 467, 801-804. doi:10.1038/nature09461

Diamond, J. (1997). Guns, germs and steel. New York, NY: Norton.

Dow, M.M., \& Eff, E.A. (2008). Global, regional, and local network autocorrelation in the standard crosscultural sample. Cross-Cultural Research, 42(2), 148-171. doi:10.1177/1069397107311186

Dunn, M., Greenhill, S.J., Levinson, S.C., \& Gray, R.D. (2011). Evolved structure of language shows lineagespecific trends in word-order universals. Nature, 473, 79-82. doi:10.1038/nature09923

Gervais, W.M., \& Norenzayan, A. (2012). Like a camera in the sky? Thinking about God increases public selfawareness and socially desirable responding. Journal of Experimental Social Psychology, 48, 298-302. doi:10.1016/j.jesp.2011.09.006

Harvey, P.H., \& Pagel, M. (1991). The comparative method in evolutionary biology. Oxford: Oxford University Press.

Henrich, J. (2009). The evolution of costly displays, cooperation and religion: Credibility enhancing displays and their implications for cultural evolution. Evolution and Human Behavior, 30, 244-260. doi:10.1016/j. evolhumbehav.2009.03.005

Jochelson, W. (1926). The Yukaghir and the yukaghized Tungus. New York, NY: American Museum of Natural History.

Johnson, D.D.P. (2005). God's punishment and public goods: A test of the supernatural punishment hypothesis in 186 world cultures. Human Nature, 16, 410-446. doi:10.1007/s12110-005-1017-0

Levinson, D. (1991). Encyclopedia of world cultures. Boston, MA: G.K. Hall.

Matthews, L. (2012). The recognition signal hypothesis for the adaptive evolution of religion. Human Nature, 23, 218-249. doi:10.1007/s12110-012-9138-8

Murdock, G.P. (1967). Ethnographic atlas. Pittsburgh, PA: University of Pittsburgh Press.

Murdock, G.P. (1981). Atlas of world cultures. Pittsburgh, PA: University of Pittsburgh Press.

Murdock, G.P., \& White, D.R. (1969). Standard cross-cultural sample. Ethnology, 9, 329-369. doi:10.2307/ 3772907

Norenzayan, A. (2013). Big Gods - How religion transformed cooperation and conflict. Princeton, NJ: Princeton University Press.

Norenzayan, A., Gervais, W.M., \& Trzesniewski, K.H. (2012). Mentalizing deficits constrain belief in a personal god. Plos One, 7, e36880. doi:10.1371/journal.pone.0036880

Norenzayan, A., Henrich, J., \& Slingerland, E. (2013). Religious prosociality: A synthesis. In P.J.Richerson \& M.H.Christiansen (Eds.), Cultural evolution: Society, technology, language, and religion (pp. 365-380). Cambridge, MA: MIT Press.

Norenzayan, A., \& Shariff, A.F. (2008). The origin and evolution of religious prosociality. Science, 322, 58-62. doi:10.1126/science. 1158757

Pagel, M. (1994). Detecting correlated evolution on phylogenies: A general method for the comparative analysis of discrete characters. Philosophical Transactions of the Royal Society of London B, 255, 37-45.

Pagel, M. (1997). Inferring evolutionary processes from phylogenies. Zoologica Scripta, 26, 331-348. doi:10.1111/j.1463-6409.1997.tb00423.x

Pagel, M., \& Meade, A. (2006). Bayesian analysis of correlated evolution of discrete characters by ReversibleJump Markov Chain Monte Carlo. The American Naturalist, 167, 808-825. doi:10.1086/503444

Peoples, H.C., \& Marlowe, F.W. (2012). Subsistence and the evolution of religion. Human Nature-an Interdisciplinary Biosocial Perspective, 23, 253-269. doi:10.1007/s12110-012-9148-6

Peregrine, P. (1996). The birth of Gods revisted: A partial replication of Guy Swanson's (1960) cross-cultural study of religion. Cross-Cultural Research, 30, 84-112. doi:10.1177/106939719603000104

Roes, F.L., \& Raymond, M. (2003). Belief in moralizing gods. Evolution and Human Behavior, 24(2), $126-135$. doi:10.1016/S1090-5138(02)00134-4

Sanderson, S.K., \& Roberts, W.W. (2008). The evolutionary forms of the religious life: A cross-cultural, quantitative analysis. American Anthropologist, 110, 454-466. doi:10.1111/j.1548-1433.2008.00078.x

Shariff, A.F., \& Norenzayan, A. (2007). God is watching you: Priming God concepts increases prosocial behavior in an anonymous economic game. Psychological Science, 18, 803-809. doi:10.1111/j.14679280.2007.01983.x

Shariff, A.F., \& Norenzayan, A. (2011). Mean Gods make good people: Different views of God predict cheating behavior. International Journal for the Psychology of Religion, 21(2), 85-96. doi:10.1080/10508619.2011. 556990

Shariff, A.F., \& Rhemtulla, M. (2012). Divergent effects of beliefs in heaven and hell on national crime rates. Plos One, 7, e39048. doi:10.1371/journal.pone.0039048

Slingerland, E. (2013). The evolution of prosocial religions. In P.J.Richerson \& M.H.Christiansen (Eds.), Cultural evolution: Society, technology, language, and religion (pp. 335-348). Cambridge, MA: MIT Press.

Snarey, J. (1996). The natural environment's impact upon religious ethics: A cross-cultural study. Journal for the Scientific Study of Religion, 35(2), 85-96. doi:10.2307/1387077 
Stark, R. (2001). Gods, rituals, and the moral order. Journal for the Scientific Study of Religion, 40, 619-636. doi:10.1111/0021-8294.00081

Swanson, G.E. (1960). The birth of the gods; the origin of primitive beliefs. Ann Arbor: University of Michigan Press.

Underhill, R. (1975). Economic and political antecedents of monotheism - cross-cultural study. American Journal of Sociology, 80, 841-861. doi:10.1086/225893

Valdesolo, P., Ouyang, J., \& DeSteno, D. (2010). The rhythym of joint action: Synchrony promotes cooperative ability. Journal of Experimental Social Psychology, 46, 693-695. doi:10.1016/j.jesp.2010.03.004

Willerslev, R. (2011). Frazer strikes back from the armchair: A new search for the animist soul. Journal of the Royal Anthropological Institute, 17, 504-526. doi:10.1111/j.1467-9655.2011.01704.x

Wright, R. (2009). The evolution of God (1st ed.). New York, NY: Little, Brown.

\title{
Big Gods can get in your head
}

\author{
Justin L. Barrett* and Tyler S. Greenway \\ School of Psychology, Fuller Theological Seminary, Pasadena, CA, USA
}

I (first author) once bought a pair of shoes from a gentlemen's shop in Oxford, England. I brought the shoes to the service desk and went to place them on the counter. To my surprise, the attendant immediately took them and, with care, placed them on the floor. He explained that his mother had taught him to never put shoes anywhere but on the floor. I did not see his mother anywhere, and I, the paying customer, had actually committed the transgression against his mother's code of conduct. Nevertheless, he could not tolerate this breech of etiquette. Why? The American colloquialism is that his mother had "gotten in his head." That is, his mother's behavioral code had been so drilled into him, that even as a grown man with no mother around, he would not violate her wishes. "Your mother may be watching" did not need to be primed in him. Human psychology works in this way: certain values and actions become so internalized or habitual that they no longer need policing or even, in many cases, conscious deliberation. In Robert McCauley's (2011) terms, they become part of practiced naturalness: fluent, automatic, and easy through direct tuition and rehearsal. So, too, we argue that attitudes, values, and behavioral directives derived from beliefs in morally interested, super-knowing gods or Big Gods (following Norenzayan, 2013) can become cognitively natural. Big Gods can get in your head.

Our thesis, then, challenges one element in Ara Norenzayan's (2013) thoughtful and much-needed synthesis of cognitive and evolutionary approaches to explaining the origins and persistence of theistic belief. Specifically, we challenge the second of eight principles that Norenzayan uses to structure the argument articulated in Big Gods: the claim that "Religion is more in the situation than in the person" (p. 39). While rejecting this "principle" leaves (in our estimation, at least) the bulk of Norenzayan's argument intact, it does impact the implications he wants to draw for the future of atheistic societies.

\section{Religion more in the situation?}

The second principle expresses a relative claim: that situational factors matter more than personal factors in influencing religious behavior. To support this claim Norenzayan

*Corresponding author. Email: jbarrett@fuller.edu 
begins by reviewing two studies, one within a Muslim context (Morocco; Duhaime, 2011) and the other within a Hindu context (Mauritius; Xygalatas, 2013). Both experiments presented religious individuals with an economic game situation in which they could be selfish or generous to some degree. Norenzayan relays that when religious reminders were present, participants were less selfish and more generous. Norenzayan is trying to make the point that as a result of situation effects, rather than personal factors, these individuals behaved generously. In other words, these religious individuals were reminded of their supernatural monitor, and as a result they acted in accordance with the actions expected of that supernatural monitor.

Whereas these studies may demonstrate that religious reminders may increase generosity and decrease selfishness, they do not, however, support the relative claim that situation matters more than the particulars of the person. Norenzayan mentions no consideration of personal factors in the study of Muslims and only notes that the relative degree of self-reported religious commitment "had little bearing" (p. 40) on the Hindu participants. ${ }^{1}$ Comparisons with non-Muslims and non-Hindus are wanted to make the strong relative claim. Indeed, given what Norenzayan reports about the Muslim shopkeepers opting to give all of a sum of money to charity $100 \%$ of the time when the call to prayer was sounded, it would be difficult for a sample of non-Muslim or atheist shopkeepers to be so generous: religious commitment (a personal factor) almost certainly mattered. In order to more accurately test the argument that religion is more situational than personal, non-religious participants would need to be involved as well.

This shortcoming applies to the famous Good Samaritan Study (Darley \& Batson, 1973) that Norenzayan uses as further evidence that "religion is in the situation more than the person." Darley and Batson failed to investigate whether the Princeton seminarians' rate of stopping to help a slumped confederate ( $40 \%$ of the time) would be matched by a less- or non-religious sample. These studies (and others like them) show that religious people are human: situations powerfully shape their actions. On this point Norenzayan is surely right. What we do not have is strong evidence that these situational demands are so much stronger than personal factors that they would motivate (or demotivate) prosocial activity if the people in question were not religious. Indeed, Norenzayan himself suggests otherwise. He writes: "[W]e find that nonconscious religious primes have reliable effects on believers. Interestingly, the results are mixed when it comes to nonbelievers. Some studies find priming effects for nonbelievers, while others do not" (p. 48). The personal factor of being religiously committed, then, influences whether situational factors have an impact.

As an instance of the long-standing person/situation debate in psychology, Norenzayan's second principle is largely intractable. Personal and situational factors cannot be cleanly dissociated. Further, when pitting these two classes of factors against each other, it is not easy to know whether both are being measured or manipulated to the same degree (e.g., how does self-reported "high" versus "moderate" degree of religious commitment compare in magnitude of difference to exposure to five religion-related words versus no religion-related words). Finally, we may wonder whether the momentary impact of situational priming is comparable to day-to-day differences in behavior due to personal factors. It may be impossible to marshal the sort of evidence required to accept Norenzayan's second principle with any confidence. 


\section{Two alternative ways for religion to motivate prosociality}

More important to Norenzayan's broader argument is the overall importance of religious situational factors, particularly needing to be reminded of supernatural monitoring, in motivating prosocial action. The basic idea that Norenzayan is attempting to convey from his second principle is that religion only has an effect on individuals when religious ideas particularly the idea that a morally interested god may be watching - are made salient. Norenzayan writes: "Believers have to think of God and His omniscience at any given moment if that belief is to have an impact on their actions" (p. 39). Such a claim is far too strong in at least two respects. First, even accepting strong situationism (i.e., that the situation drives action), it may be that other situational cues can impact religious people's actions without having to think of God specifically. Second, it is likely that previous thought about God can drive religious believers to internalize attitudes and values, and acquire behavioral habits, that require no situational priming at all. God can get in your head. We take up these two possibilities below.

\section{Changing one's environmental cues and support}

Constant thought about God's omniscience ${ }^{2}$ is not even required for religion to lead to prosociality, even if we accept the general idea that religious effects on action are situational. For instance, theists may form the belief that God wants people to care for the poor and so then work to establish church missions or charities (e.g., Oxfam, Red Cross, World Vision) through which they administer care for the poor. The institution becomes a cultural scaffold for benevolent action that does not require a constant reminder of divine omniscience in order for those working through the organization to persist at their prosocial activities.

This example illustrates that prosocial religious activities need not continue only because of thought about God. Perhaps the activities were initially engaged in because of a morally interested supernatural watcher, but they result in a changed cultural environment, one that continues to promote the prosocial motives without needing to constantly remind that God is watching. Other priming may be taking place, and this priming may weakly activate God concepts, but we lack evidence that God and God's omniscience is driving the prosocial activities at all moments. That is, believers do not have to think of God and God's omniscience at any given moment for the belief to have an impact on their actions. This "priming" may be of prosocial pursuits themselves or other correlates of them (e.g., "be a good Christian") that do not make direct reference to a supernatural watcher. Indeed, much of the evidence that Norenzayan cites concerning prosociality being primed by religious reminders (e.g., church buildings and calls to worship) is readily interpreted in this way. Religious people need not be primed that "God is watching" but only primed and scaffolded in their prosocial pursuits. As Norenzayan writes: "In the United States and other majority Christian countries, once a week on Sundays, many Christians naturally expose themselves to a high dose of religious priming" (p. 37). But "religious" priming is not the same as priming that God is watching, a distinction lost in Shariff and Norenzayan's (2007) landmark study, too.

The case is analogous to the actions of a married man who has arranged his life's patterns in such a way so as to avoid strip clubs and singles bars for the sake of preserving his marriage. He has created patterns of life that reflect marital commitments so that he does not have to constantly remind himself of his marital status in order to impact actions. Of course, it does not follow that he would not be even more dutiful in his marital commitments because of reminders of his marital status, let alone the presence 
(real or imagined) of his wife. Similarly, it may very well be, as Norenzayan demonstrates experimentally in various priming studies, that reminders of religion or God elevate some kinds of prosocial behavior; but it does not follow that prosocial behaviors of theists are only motivated by preceding cues that God may be watching.

\section{Internalized values and habituation}

Norenzayan's emphasis on situation leads to a neglect of the possibility that religious beliefs and practices really can be internalized to the point that they no longer require constant reminders that God is watching. That is, they become cognitively natural (McCauley, 2011). If we accept the general thesis common in cognitive science of religion that religious beliefs are cognitively natural and readily connected to moral considerations (see, e.g., Barrett, 2004, 2011; Boyer, 2001; McCauley, 2011), as Norenzayan seems to, then religious commitments and their accompanying values, attitudes, and behavioral routines should (in general) easily acquire a high degree of fluency and not require lots of external prompting. ${ }^{3}$ Not all of these values, attitudes, and behavioral routines will be prosocial, but the idea that there are no cross-situational differences between, say, Hasidic Jews and Southern Baptists is absurd. Consider this simple thought experiment: which would you trust more to not eat the bacon you just prepared?

This claim that religion is more in the situation than in the person also fails to account for some psychological findings unmentioned in Norenzayan's book that indicate that religion is not mostly situational. For instance, two of the traits within the Big Five personality scale, agreeableness and conscientiousness, are often positively correlated with religiosity (Saroglou, 2002). These findings, and others like them, present a problem for Norenzayan's thesis, as these major aspects of personality that promote prosocial behavior appear to be enduring, cross-situational, and not a product of supernatural monitoring being primed. It could be argued that, although indeed there are some personal factors that are associated with religiousnesss, the situational effects are greater than these personal factors. This defense, however, would require further articulation, as personality characteristics such as agreeableness and conscientiousness are arguably more influential on a daily basis then being lightly reminded of a supernatural monitor periodically.

\section{Implications for societies}

Norenzayan's commitment to the situational character of religiously motivated prosociality seems to grow from two desires articulated in his book: (1) to persuade us that you can be good without being religious (chapter 4); and (2) that we can have a Godless civil society without losing prosocial morality (chapter 10). If religious people are only "good" because they think God is watching, and someone else watching (e.g., government) will do the same job, then we do not need God to get along, and we do not need to be theists for this other watcher to help us be good. Contrariwise, if religious commitments really do lead to more moral, prosocial people, then the vision of a society of mostly atheists presents a problem: the baseline trustworthiness of such a society would be lower unless its citizens have internalized prosocial values via some non-religious indoctrination presumably governmental. Government would need to inculcate what is right and wrong to get the same level of prosociality of a theistic community. Such a prospect begins to sound Orwellian. 
Perhaps shadows of Big Brother keep Norenzayan shy of spending too much time applying his situationism to atheists. Norenzayan does note that when primed with words such as "civic, jury, and police" that serve as reminders of a government that can be trusted, participants respond similarly to how they respond when primed with religious words (pp. 35-36). If by "climbing the ladder of religion, then kicking it away" (p. 172), government monitoring is to take over in the place of supernatural monitoring, an equally constant stream of reminders of such monitoring should need to be in place, unless we have reason to think that the prospect of Government watching is more potent than God watching. Norenzayan gives us no evidence in this regard and is relatively silent about the need for priming that "Government is watching."

Norenzayan also ignores the reality that theological systems do promote certain values and moral codes that other theological systems and atheistic moralities do not embrace. Part of religious conflict and theists' mistrust of atheists (rightly or wrongly) surely stems from real differences in commitments about what it means to be good. For religious reasons, people oppose (or support) abortion, birth control, civil disobedience, euthanasia, genocide, homosexuality, infanticide, misogyny, polygamy, suicide, and vegetarianism. Until we have sufficient evidence that religious teachings and indoctrination really do not penetrate past situational effects, we must take seriously religious systems' roles as articulators and sustainers of social values. If government, instead, is to take the role of God in reminding people to "be good," whose good will they be? Can government comparably fill the shoes of moral arbitrator? We are not optimistic.

\section{A friendly amendment}

Norenzayan's central thesis appears promising. Naturally developing conceptual systems working in historically ordinary human environments incline people to be receptive to various ideas that we often call religious, including belief in supernatural agents of various sorts. Once part of our cognitive equipment, some of these god concepts promote actions such as religious rituals of various sorts that increase in-group trust and cooperation and prosocial attitudes and actions. The gods that are most effective in this way are likely to be morally interested gods with an observational reach beyond an immediate locality. These Big Gods then provide a mechanism for growing broader social connections and networks and, thereby, support larger human groups, and hence, could have played a pivotal role in human social and cultural evolution. So far, so good. Where we part company with Norenzayan is at the suggestion that Big Gods cannot get in your head and make an enduring, cross-situational impact on human values, attitudes, and actions, beyond the impact of situational factors.

Whereas this particular claim regarding the situational effects and personal factors of religion presents challenges that need to be addressed with more convincing data, Big Gods raises a number of stimulating questions that provide a worthwhile avenue for thinking about the nature of religion and its effects on society, past and present. Norenzayan produces an excellent attempt to synthesize a number of fields into a single coherent argument, for which we are grateful.

\section{Acknowledgements}

We thank the Templeton World Charity Foundation for a grant [grant number TWCF0020] to the first author that supported, in part, both authors' work on this paper. 


\title{
Notes
}

1. Failure to find a relationship is different than documenting that there is no relationship. An actual relationship may have not been found due to any number of challenges including measurement error (religiosity is not easy to measure reliably across faith traditions) and lack of variability in degree of religiosity (e.g., as when everyone is high on religiosity).

2. Indeed, Norenzayan frequently makes reference to "omniscience," but his view only requires the god in question to stand a good likelihood of knowing one's moral transgressions, not being all-knowing. The idea that at any given non-reflective moment a difficult theological abstraction such as omniscience is activated and used to drive actions as the result of priming runs counter to data investigating what gods implicitly know that suggest a less than omni-god (e.g., Barrett \& Keil, 1996; Purzycki, et al., 2012).

3. Some religious values may be largely counterintuitive, in which case they may never become entirely natural and would require priming or cultural scaffolding to be activated. Barrett (2011) has suggested that the Christian doctrine of grace (by which all humans are equally loved and repentant humans are all forgiven by God regardless of the apparent gravity of their sins) may be one of these counterintuitive religious values because it violates natural reciprocity and fairness intuitions.

\section{References}

Barrett, J.L. (2004). Why would anyone believe in God? Walnut Creek, CA: AltaMira Press.

Barrett, J.L. (2011). Cognitive science, religion, and theology: From human minds to divine minds. West Conshohocken, PA: Templeton Press.

Barrett, J.L., \& Keil, F.C. (1996). Anthropomorphism and God concepts: Conceptualizing a non-natural entity. Cognitive Psychology, 31, 219-247. doi:10.1006/cogp.1996.0017

Boyer, P. (2001). Religion explained: The evolutionary origins of religious thought. New York, NY: Basic Books.

Darley, J.M., \& Batson, C.D. (1973). "From Jerusalem to Jericho": A study of situational and dispositional variables in helping behavior. Journal of Personality and Social Psychology, 27(1), 100-108. doi:10.1037/ h0034449

Duhaime, E. (2011). Did religion facilitate the evolution of large-scale cooperative societies? Religious salience and the "Ritual Effect" on prosocial behavior (Unpublished MA thesis). Cambridge University, Cambridge.

McCauley, R.N. (2011). Why religion is natural and science is not. New York, NY: Oxford University Press.

Norenzayan, A. (2013). Big gods: How religion transformed cooperation and conflict. Princeton: Princeton University Press.

Purzycki, B.G., Finkel, D.N., Shaver, J., Wales, N., Cohen, A.B., \& Sosis, R. (2012). What does God know? Supernatural agents' access to socially strategic and non-strategic information. Cognitive Science, 36, 846-869. doi:10.1111/j.1551-6709.2012.01242.x

Saroglou, V. (2002). Religion and the five factors of personality: A meta-analytic review. Personality and Individual Differences, 32, 15-25. doi:10.1016/S0191-8869(00)00233-6

Shariff, A.F., \& Norenzayan, A. (2007). God is watching you: Priming god concepts increases prosocial behavior in an anonymous economic game. Psychological Science, 18, 803-809. doi:10.1111/j.14679280.2007.01983.x

Xygalatas, D. (2013). Effects of religious setting on cooperative behaviour: A case study from Mauritius. Religion, Brain, \& Behavior, 3, 91-102. doi:10.1080/2153599X.2012.724547

\section{Empirical problems with the notion of "Big Gods" and of prosociality in large societies}

\author{
Nicolas Baumard ${ }^{\mathrm{a}}$ and Pascal Boyer ${ }^{\mathrm{b} *}$ \\ ${ }^{a}$ Philosophy, Politics, and Economics Program, University of Pennsylvania, Philadelphia, PA, USA; \\ ${ }^{b}$ Department of Anthropology, Washington University, St. Louis, MO, USA
}

*Corresponding author. Email: pboyer@artsci.wustl.edu 
Ara Norenzayan's book and this précis weave together various strands of evidence and modeling into an impressive narrative or causal explanation for the appearance of both "Big Gods" and large-scale societies (Norenzayan, 2013). We sympathize with Norenzayan's evolutionary perspective and with his methods. The emergence of religions and their common features should be explained in terms that combine human evolved psychology and specific historical conditions. However, we also consider that the specific causal story proposed here, although coherent and intuitively compelling, requires a highly implausible reading of the evidence from several distinct fields.

Specifically, Norenzayan's argument puts forward the following propositions:

(1) People behave in more prosocial ways when they think (or intuit) that their behavior is being scrutinized.

(2) Powerful gods are construed by people as agents that scrutinize their cooperative behavior.

(3) People in societies with Big Gods tend to be more prosocial (from (1) and (2)).

(4) There is cultural group selection where groups with more efficient norms survive (culturally) and absorb, eliminate, etc. the others.

(5) Large-scale societies require large-scale cooperation based on prosocial behavior.

(6) Groups with increased prosocial behavior win over groups with less prosocial norms.

We would argue that (1) is a profound and interesting empirical result, supported by many studies, notably by Norenzayan and his colleagues and students (Gervais \& Norenzayan, 2012; Shariff \& Norenzayan, 2011). A large body of evidence suggests that people do engage in more cooperative behaviors and are become less tolerant of misdemeanors when scrutinized, even with very subtle implicit cues (Bateson, Nettle, \& Roberts, 2006; Bourrat, Baumard, \& McKay, 2011; Haley \& Fessler, 2005), a phenomenon that appears early in development (Leimgruber, Shaw, Santos, \& Olson, 2012). Conversely, people monitor other agents' behavior and intuitively estimate the potential costs and benefits of cooperating with them (Delton \& Robertson, 2012). This is consistent with the notion that reputation is an essential aspect of human cooperation (Sperber \& Baumard, 2012).

The trouble starts with proposition (2). In our view, Norenzayan's assumption that large societies came with powerful, punishing gods conflates two very different historical developments.

First, with the emergence of large polities, there appeared groups of religious specialists promoting notions of powerful gods with quasi-universal jurisdiction, as opposed to tribal notions of spirits and ancestors concerned with local matters (Boyer, 2001). These large-society superhuman agents were sometimes represented as intensely interested in human behavior, in the form of sacrifices and general obedience to the gods' will. The evidence for such religious representations comes from places as diverse as the Mayan empire, Rome, Greece, Sumer and Akkad, Egypt, China and India (Burkert \& Trad, 1985; Kramer, 1961; Poo \& Pu, 1998; Tedlock, 1985). There is little or no evidence that people in these societies represented the gods as concerned with people's own cooperative or prosocial behavior toward fellow members of their groups.

Second, during the so-called Axial Age (Jaspers, 1953), there appeared in a limited number of places a new kind of religious and secular movement, promoting new values, among which were the notions of cosmic justice and of gods concerned with people's moral behavior (Bellah, 2011). Examples include Jainism, Orphism, second-Temple 
Judaism and Christianity. These movements all emphasized the idea of proportionality or Golden Rule, a prescription to engage in mutually profitable interactions by treating others as one would wish to be treated (Neusner \& Chilton, 2008). This reciprocity was accompanied by the notion that the gods themselves would scrutinize people's behavior and reward those with a record of cooperative or altruistic behavior. This notion of cosmic justice for cooperation could be expressed in terms of reincarnation (Obeyesekere, 2002), or in the afterlife (Bernstein \& Katz, 2010; Brandon, 1969). But note that this was an entirely new development - and that large-scale societies had appeared thousands of years before and subsisted in many places without this emphasis on prosocial behavior (Baumard \& Boyer, 2013).

So, against proposition (2), most gods of early large-scale societies were not concerned with whether one behaved in prosocial ways.

This in turn challenges the validity of proposition (3), that people in groups with "Big Gods" cooperate more than those with local deities or spirits. True, some studies seem to show that people are more cooperative when primed with religious themes (Gervais \& Norenzayan, 2012), but this evidence comes from places where gods are construed as, precisely, interested in people's prosocial behavior. Indeed, the effect is modulated by people's belief that the gods in question punish selfish behavior (Shariff \& Norenzayan, 2011). In terms of cultural comparisons, some limited comparative evidence suggests a small effect in the direction of more cooperation in societies with Big Gods (Henrich et al., 2010). But again, this stems from places where the gods in question happen to be moralistic gods - and the religious difference in this case is also confounded with economic conditions anyway (Baumard, Boyer, \& Sperber, 2010). The same remark applies to Richard Sosis's comparative study of religious communes, showing that groups with rigorous religious norms are more stable than those with lax standards (Sosis \& Bressler, 2003). Given that in both kinds of communities gods are said to monitor prosocial behavior, the difference does not lie in concepts of superhuman agency. Indeed, a broader comparison of voluntary association groups, secular and religious, suggests that stability is generally associated with efficient monitoring and punishment, more than the kinds of ideologies that bring people together (Hechter, 1987).

The narrative's dependence on cultural group selection, proposition (4), is problematic too. Cultural group selection was originally put forward, not on the basis of empirical evidence, archaeological or ethnographic, that such selection actually occurred, but as a proposed theoretical solution to the apparent "mystery" of human cooperation (Boyd \& Richerson, 2006). The latter is indeed mysterious, if we consider human social exchange as a set of iterated prisoner's dilemma encounters, where one cannot choose one's partners; will never interact with the same partner twice; and must therefore minimize the costs of a partner's defection (West, Griffin, \& Gardner, 2007). But that was never a realistic model of human sociality, which is more accurately depicted as a biological market, where agents can choose between potential partners and easy communication allows for the monitoring of reputation (Baumard, André, \& Sperber, 2013; Noe \& Hammerstein, 1994). In this more realistic model of human interaction, it is likely that people will meet again, so that generous strategies are advantageous and evolutionarily stable (Delton, Krasnow, Cosmides, \& Tooby, 2011). The competition between potential cooperators also ensures that mutually profitable arrangements win over exploitation (André \& Baumard, 2011). In fact, there does not seem to be any specific behavior in human cooperation that could be explained only by the very un-parsimonious notion of group selection (West, El Mouden, \& Gardner, 2011). 
Proposition (5) assumes that large-scale societies can subsist only when people have more intense prosocial motivations than in small-scale groups. This is proposed as a conceptual argument (scaled-up groups are logically impossible without trust), rather than an empirical generalization about historical processes. But there is a straightforward alternative explanation, this one with considerable empirical support, namely that (some) large-scale polities subsist because of the efficiency of their institutions. The Roman Empire for instance remained a coherent entity, over centuries, because of relatively efficient military and fiscal institutions. When the latter became dysfunctional, the empire collapsed (Hopkins, 1980). Comparative research suggests that large-scale polities differ from small groups in their institutions, not in the overall level of prosocial motivation (Acemoglu, Johnson, \& Robinson, 2002; Greif, 1998; North, 1990). Ethnographic research, for example, by Ostrom and others, suggests that stable cooperation depends on efficient monitoring, reputation management and low-cost punishment (Ostrom, 1990, 2005). Such institutions allow social groups to achieve "cooperation without trust" (Cook, Hardin, \& Levi, 2005).

Similarly, there does not seem to be much anthropological or historical evidence to support proposition (6), that groups with more prosocial norms would or did defeat less prosocial ones. What we know of the history of empires would suggest either that such values either are historically neutral (e.g., the Meso-American empires with little prosociality triumphed over surrounding tribal groups), or seem detrimental (e.g., the Roman Empire triumphed when it had largely amoral gods, and it collapsed after adopting a clearly moralistic and prosocial religion). In the destiny of nations, quantitative historical scholarship suggests that institutions, comparative advantage, technological edge and geography explain enough of the variance (Burbank \& Cooper, 2011; Morris, 2013) that the effect of different levels of prosociality, if any, would be marginal.

Against each of the arguments presented here, it is of course possible to defend the narrative - especially so, as we painted all the processes involved in a few broad strokes. But it seems to us that, at each point, the overall causal story put forward by Ara Norenzayan requires too much special pleading or speculative leaps away from the historical and anthropological evidence.

\section{References}

Acemoglu, D., Johnson, S., \& Robinson, J.A. (2002). The rise of Europe: Atlantic trade, institutional change and economic growth. Cambridge, MA: National Bureau of Economic Research.

André, J.-B., \& Baumard, N. (2011). The evolution of fairness in a biological market. Evolution, 65, 1447-1456. doi:10.1111/j.1558-5646.2011.01232.x

Bateson, M., Nettle, D., \& Roberts, G. (2006). Cues of being watched enhance cooperation in a real-world setting. Biology Letters, 2, 412-414. doi:10.1098/rsbl.2006.0509

Baumard, N., André, J.-B., \& Sperber, D. (2013). A mutualistic approach to morality: The evolution of fairness by partner-choice. Behavioral and Brain Sciences, 36(1), 1-36.

Baumard, N., \& Boyer, P. (2013). Explaining moral religions. Trends in Cognitive Sciences, 17, 272-280. doi:10.1016/j.tics.2013.04.003

Baumard, N., Boyer, P., \& Sperber, D. (2010). Evolution of fairness: Cultural variability. Science, 329(5990), 389-390. doi:10.1126/science.329.5990.388-b

Bellah, R.N. (2011). Religion in human evolution: From the Paleolithic to the axial age. Cambridge, MA: Harvard University Press.

Bernstein, A., \& Katz, P. (2010). The rise of postmortem retribution in China and the West. The Medieval History Journal, 13, 199-215. doi:10.1177/097194581001300202

Bourrat, P., Baumard, N., \& McKay, R. (2011). Surveillance cues enhance moral condemnation. Evolutionary Psychology, 9, 193-199.

Boyd, R., \& Richerson, P.J. (2006). Solving the puzzle of human cooperation. In S.C. Levinson \& P. Jaisson (Eds.), Evolution and culture (pp. 105-132). Cambridge, MA: The MIT Press.

Boyer, P. (2001). Religion explained. Evolutionary origins of religious thought. New York, NY: Basic Books. 
Brandon, S.G.F. (1969). The judgment of the dead: The idea of life after death in the major religions. New York, NY: Scribner.

Burbank, J., \& Cooper, F. (2011). Empires in world history: Power and the politics of difference. Princeton, NJ: Princeton University Press.

Burkert, W.R.J. (1985). Greek religion archaic and classical. Oxford: B. Blackwell.

Cook, K.S., Hardin, R., \& Levi, M. (2005). Cooperation without trust? New York, NY: Russell Sage Foundation.

Delton, A.W., Krasnow, M.M., Cosmides, L., \& Tooby, J. (2011). Evolution of direct reciprocity under uncertainty can explain human generosity in one-shot encounters. PNAS Proceedings of the National Academy of Sciences of the United States of America, 108, 13335-13340. doi:10.1073/pnas.1102131108

Delton, A.W., \& Robertson, T.E. (2012). The social cognition of social foraging: Partner selection by underlying valuation. Evolution and Human Behavior, 33(60), 715-725. doi:10.1016/j.evolhumbehav.2012.05.007

Gervais, W.M., \& Norenzayan, A. (2012). Like a camera in the sky? Thinking about God increases public selfawareness and socially desirable responding. Journal of Experimental Social Psychology, 48, 298-302. doi:10.1016/j.jesp.2011.09.006

Greif, A. (1998). Historical and comparative institutional analysis. American Economic Review, 88(2, Papers and Proceedings of the Hundred and Tenth Annual Meeting of the American Economic Association), 80-84.

Haley, K.J., \& Fessler, D.M.T. (2005). Nobody's watching? Subtle cues affect generosity in an anonymous economic game. Evolution and Human Behavior, 26, 245-256. doi:10.1016/j.evolhumbehav.2005.01.002

Hechter, M. (1987). Principles of group solidarity. Berkeley: University of California Press.

Henrich, J., Ensminger, J., McElreath, R., Barr, A., Barrett, C., Bolyanatz, A., ... Ziker, J. (2010). Markets, religion, community size, and the evolution of fairness and punishment. Science, 327, 1480-1484. doi:10.1126/science. 1182238

Hopkins, K. (1980). Taxes and trade in the Roman Empire (200 B.C.-A.D. 400). The Journal of Roman Studies, 70, 101-125. doi:10.2307/299558

Jaspers, K. (1953). The way to wisdom: An introduction to philosophy. New Have, CT: Yale University Press.

Kramer, S.N. (1961). Mythologies of the ancient world (1st ed.). Garden City: N.Y., Doubleday.

Leimgruber, K.L., Shaw, A., Santos, L.R., \& Olson, K.R. (2012). Young children are more generous when others are aware of their actions. PLoS ONE, 7, e48292. doi:10.1371/journal.pone.0048292

Morris, I. (2013). The measure of civilization: How social development decides the fate of nations. Princeton, NJ: Princeton University Press.

Neusner, J., \& Chilton, B. (2008). The golden rule: The ethics of reciprocity in world religions. New York, NY: Continuum

Noe, R., \& Hammerstein, P. (1994). Biological markets: Supply and demand determine the effect of partner choice in cooperation, mutualism and mating. Behavioral Ecology and Sociobiology, 35(1), 1-11. doi:10.1007/BF00167053

Norenzayan, A. (2013). Big gods: How religion transformed cooperation and conflict. Princeton, NJ: Princeton University Press.

North, D.C. (1990). Institutions, institutional change, and economic performance. Cambridge and New York, NY: Cambridge University Press.

Obeyesekere, G. (2002). Imagining karma ethical transformation in Amerindian Buddhist, and Greek rebirth. Los Angeles: University of California Press.

Ostrom, E. (1990). Governing the commons: the evolution of institutions for collective action. Cambridge and New York, NY: Cambridge University Press.

Ostrom, E. (2005). Understanding institutional diversity. Princeton, NJ: Princeton University Press.

Poo, M., \& Pu, M. (1998). In search of personal welfare: A view of ancient Chinese religion. Buffalo, NY: SUNY Press.

Shariff, A.F., \& Norenzayan, A. (2011). Mean gods make good people: Different views of God predict cheating behavior. International Journal for the Psychology of Religion, 21(2), 85-96. doi:10.1080/ 10508619.2011 .556990

Sosis, R., \& Bressler, E.R. (2003). Cooperation and commune longevity: A test of the costly signaling theory of religion. Cross-cultural Research: The Journal of Comparative Social Science, 37, 211-239. doi:10.1177/ 1069397103037002003

Sperber, D., \& Baumard, N. (2012). Moral reputation: An evolutionary and cognitive perspective. Mind \& Language, 27, 495-518. doi:10.1111/mila.12000

Tedlock, D. (1985). Popol vuh: The definitive edition of the Mayan book of the dawn of life and the glories of gods and kings. New York, NY: Simon and Schuster.

West, S.A., El Mouden, C., \& Gardner, A. (2011). Sixteen common misconceptions about the evolution of cooperation in humans. Evolution and Human Behavior, 32, 231-262. doi:10.1016/j. evolhumbehav.2010.08.001

West, S.A., Griffin, A.S., \& Gardner, A. (2007). Social semantics: Altruism, cooperation, mutualism, strong reciprocity and group selection. Journal of Evolutionary Biology, 20(2), 415-432. doi:10.1111/j.14209101.2006.01258.x 


\title{
Hyper-cooperation is deep in our evolutionary history and individual perception of belief matters
}

\author{
Agustin Fuentes* \\ Department of Anthropology, University of Notre Dame, Notre Dame, IN, USA
}

For all its virtues in binding strangers together, religious cooperation is born out of competition and conflict between groups... Big God religions are both the fire department and the arsonist. (Norenzayan, 2013, p. 140)

The archaeological record clearly demonstrates a significant ratcheting up of societal complexity, group size, economic/political systems, and intergroup conflict in humans over the last 12,000 years. Why and how this happened is the focus of a long debate by archaeologists and other anthropologists, historians, some biologists, and even the occasional psychologist. The most popular causal assertion has to do with the interface between increased efficiency of domestication/agriculture and increased sedentism, birth rates, and population sizes leading to more complex political and economic systems that ratcheted up via feedback from increasingly stratified social and economic systems and diversified material cultures.

Most anthropologists and archaeologists see large-scale, hierarchical religions as part of the social complexity emerging from these increasingly stratified social systems and material cultures. Ara Norenzayan has a revised version of this scenario. He proposes the thesis that particular Big Gods (the moralizing and interventionist deities associated with large-scale religions) emerged alongside the initial increases in social complexity and coordination. As these populations became more complex their Gods became more moralizing, interventionist, and powerful and the belief-ritual complexes associated with these Gods are what facilitated the large-scale hyper-cooperation and coordination that enabled the emergence of large-scale, complex societies (states). As Norenzayan puts it, "Big God" religions are responsible for "Big Groups" - modern human hyper-complex social structures, including large-scale intragroup coordination (civil society) and largescale intergroup warfare.

This is not a wholly new proposal. Dominic Johnson and Jesse Bering (2006), and others, propose specific adaptive scenarios for the emergence of Big Gods and the role of supernatural punishment in facilitating hyper-cooperation in human groups (and conflict between them). However, unlike Johnson and Bering's proposals, Norenzayan does not argue that these major religions and their strong tendency for moral policing and punishing $\operatorname{God}(\mathrm{s})$ are the product of the natural selection of specific cognitive (neurological and perceptual) characteristics. Rather, he argues that strong cultural evolutionary processes have resulted in a system that links prosociality, morality, ritual, and "deep commitment" to what he terms "Big Gods" who are powerful, interventionist, punishing, and require hardto-fake commitment. He argues that because of these characteristics the "Big God" religions outcompeted their cultural rivals and have become the dominant religious force in humans today.

*Email: afuentes@nd.edu 
Norenzayan's perspective and contribution are important and his book does an eloquent job in laying out the argument and implications of his position. Here I would like to add a few correctives, modifying and complementing Norenzayan's proposal, by noting that complex cooperation is deeper and more ingrained in human evolution than he, and many others, assume. Then I will briefly highlight a major problem in much (but not all) of the evolutionary approaches to religion: the lack of inclusion of the actual experience and perceptions of believers as a salient and relevant factor.

First, the correctives. I propose that Norenzayan's, and most other, treatments of human cooperation and religion make two critical errors. They assume that large and complex cooperative groups in humans are a conundrum due to the predictions of kin selection and reciprocal altruism, and they place the appearance/timing of significant hyper-cooperation too late in our evolutionary history. I suggest that kin selection and reciprocal altruism are not the primary explanations for developing complex cooperation and reciprocity in small-scale early human groups. I also suggest that consideration of the emergence of a particular human niche, specifically in the last quarter of the Pleistocene, can give us a deeper insight into infrastructure of human hyper-cooperation and the social and cognitive patterns implicated in the emergence of religious belief systems. This system/niche has to be considered more fully before one can accept a primacy of the causal argument for the role of Big Gods in human social complexity and hyper civil cooperation (big groups).

It is too often assumed that the basal concepts of kin selection and reciprocal altruism (see Hamilton, 1964; Trivers, 1971) are the primary explanatory factors in all levels of cooperation and reciprocity: all things being equal, organisms should extract as much benefit as possible for themselves (and their genetic kin) (e.g., Dugatkin, 2006; Wilson, 1975). Thus, any high frequency of costly cooperation, or even more costly altruism, requires a specific evolutionary explanation for its occurrence. This perspective mandates that we establish how any such system avoids the successful invasion of free-riders, cheaters, and other selfish actors. However, if over its evolutionary history a system arrives at a node wherein cooperation becomes a basal aspect of its adaptive niche, explaining why cooperation occurs frequently in the subsequent evolution of its social system may be unnecessary (e.g., MacKinnon \& Fuentes, 2011; Sussman \& Cloninger, 2011).

For example, we do not attempt to explain the morphology of the hand in humans via current selection pressures since it is a mammalian pattern modified during the primate, anthropoid, and hominoid lineages, and then again (slightly but importantly) during Pliocene hominin evolution. The same is true for basal sociality: anthropoids exhibit a complex sociality and cognition, which ratcheted up during the Miocene in multiple branches of the hominoids (apes) and even more so in the Plio-Pleistocene hominins (Herrmann, Call, Hernandez-Lloreda, Hare, \& Tomasello, 2007; Malone, Fuentes, \& White, 2012). Thus, we are not tasked with explaining why humans live in highly social groups with complex social relationships and networks that cut across biological kinship with relatively high levels of cooperation, as this is a pattern found in the hominoids and thus evolutionarily basal for hominins (Malone et al., 2012). However, we are tasked with explaining the extreme level of large-group hyper-cooperation and social coordination in humans as it reflects a substantive departure from other hominins and hominoids. But that explanation is not at the basal level of why individuals would cooperate; rather, it requires us to explain why cooperative and social complex groups would become even more cooperative as they grow in size. This is what the Big Gods hypothesis does, but it starts too late in the game. 
Norenzayan makes some assumptions about the dating and extent of cooperation in the human lineage and the costs of cooperation. He, like many others, assumes that kin selection and reciprocity are the main endemic reasons for cooperation and therefore large-scale cooperation between unrelated individuals who might have limited opportunities for direct reciprocity is highly unlikely. Thus, moralizing and punishing gods are necessary to foster large-scale cooperation in big groups (Big Gods enable big groups). I think it is more complex than that. It is in the final transition from archaic forms of our genus (Homo spp.) into the current form (Homo sapiens sapiens) morphologically and behaviorally (approximately 400-100,000 years ago) that we can find core clues as to why we are able to cooperate in the context of such big groups: it is an expected outcome of increased population densities in the human niche.

A niche is the structural, social, and temporal context in which a species exists. It includes space, nutrients, and other physical factors and social actors as they are experienced, and restructured, by organisms and also shaped by the presence of competitors, collaborators, and other agents in a shared environment (Fuentes, 2010; Wake, Hadley, \& Ackerly, 2009). The human socio-cognitive niche is a cognitive and behavioral configuration that is derived relative to the socio-behavioral contexts of previous hominins. This modern human niche includes hyper-cooperation, theory of mind, cultural transmission and innovation, teaching, and language (Sterelny, 2012; Whiten \& Erdal, 2012). This niche is characterized by a rapidly increasing rate and density of innovations and concomitant ratcheting shifts in the pace and content of cultural and behavioral change and complexity resulting in new and more effective ways of engaging and changing local ecologies (Kendal, Tehrani, \& Olding-Smee, 2011; Sterelny, 2012; Tomasello, 2009; Whiten \& Erdal, 2012). Following many others, I suggest that it is a system of intensive and complex cooperative patterns that both facilitated the appearance of, and continued to emerge from, this human niche as population sizes/densities began to grow (e.g., Powell, Shennan, \& Thomas, 2009; Premo, 2012).

Looking at the paleoanthropological and archaeological evidence for the latter Pleistocene and the current capabilities of human beings, it is obvious that increasing capabilities for hyper-cooperative behavior are characteristic of the human lineage (Andersson, Törnberg, \& Törnberg, 2014; Fuentes, 2013; Gamble, Gowlett, \& Dunbar, 2011; Hrdy, 2009; Nowak \& Highfield. 2011; Sterelny, 2012). Between c. 500,000100,000 years ago, the genus Homo is characterized by minor changes in bones and bodies but probably by substantive neural reconfiguration (Aiello \& Anton, 2012; Gamble et al., 2011). Brain size reaches modern levels and material toolkits begin to diversify at a much greater pace than earlier in the Pleistocene. Hunting patterns and targets expand, complex foraging patterns become common, and raw material transport includes long-distance transfer $(>120 \mathrm{~km}$ ) (Marwick, 2003). During this time the use of fire becomes ubiquitous and likely begins to have substantive impacts on social and physiological evolution in humans (Wrangham \& Carmody, 2010).

Particularly evolutionarily relevant aspects of behavioral patterns that emerge before and expand during this period include intensive cooperative childrearing (likely involving intensive allocare and complex parenting) and the enhancement of 'kinship' relations that extend well beyond biological relationships but co-opt biological systems of bonding (Bell, Hinde, \& Newson, 2013; Fuentes, 2013; Hrdy, 2009). The pattern of facing ecological challenges (predation, foraging, area defense, childrearing, use and control of fire, etc.) predominantly as a community, and not mainly as individuals, is characteristic of our direct ancestors by the later Pleistocene (tens of thousands of years before the advent of social hierarchies associated with sedentism and domestication - Fuentes, 2013; 
Gamble et al., 2011). The manufacture and use of increasingly complex stone, wood, and bone tools, and the emergence of non-tool material cultures ("art" and other symbolic representations), require extensive cooperative interactions and coordination within, and likely between, communities. In this time period there is mounting evidence that ritualistic behavior is associated with the toolmaking and the social and ecological landscapes of early humans (Bedarnik, 2003; McBrearty, 2012; Pope, Russel, \& Watson, 2006; Rossano, 2009; Sterelny, 2012). This places hyper-cooperation and social coordination, even in smaller groups, as central to the genus Homo and as a core adaptation in the human niche by the later Pleistocene.

Although there is substantive debate over the timing of the emergence of language and a fully developed theory of mind, both are impossible without an extremely cooperative and mutually integrated social system (Coward \& Gamble, 2008; Dean, Kendal, Shapiro, Thierry, \& Laland, 2012). It is increasingly evident that this system was in place substantially before 12,000 years ago. Once even rudimentary aspects of complex semiotic communication and the use of symbol are present (likely earlier than 100,000 years ago Wadley, 2013), one can expect the development of socially contextualized, and coordinated, ritual behavior that may in turn have adaptive significance.

My point in providing this very brief overview of terminal Pleistocene human evolution and the human niche is that Norenzayan's contentions about where and when extremely complex cooperation emerges and how it is assisted by Big Gods overlooks the possibilities that much of the infrastructure for such systems was already in place as basal aspects of the human niche - likely by 100,000 years ago and certainly well before 20,000 years ago. Norenzayan and others are probably correct in their suppositions that patterns of cultural evolution associated with domestication, agriculture, and increasing inequality over the last 12,000-15,000 years facilitated the emergence of particular religious systems typified by Big Gods. But it is a more tenuous assertion that the Big Gods are the key structural factor that facilitated the social complexity of large-scale civil societies - although I do agree that they likely play major roles in structuring and expanding them.

The explanations that Norenzayan invokes for the emergence of Big Gods overemphasize the need for human communities to develop methods of coordinating cooperative interactions on larger scales. I suggest that the core aspects of these processes were already in place well before the advent of full-blown material hierarchies, agriculture, and sedentism in patterns such as increasingly diversified intragroup social structures, trade networks, complex symbolic systems, and so on. It could be that only a slight expansion of extant systems of cooperation would be enough to initiate the coordination cascade associated with population growth that resulted in civil society and state formation (e.g., Bell, Richerson, \& McElreath, 2009).

Unfortunately we have a version of the "chicken and egg" scenario here. The presence and structure of Big God religions are effectively understood as the outcomes of social complexity and inequity as they are the force behind evolutionary shifts fostering civil control, punishment, and intergroup conflict. Norenzayan is aware of this dilemma and notes the problem of co-occurrence and causality throughout the book, providing a succinct nod to it via the historical record (2013, pp. 132-133). So my critique here is not aimed at refuting his assertions, but is rather an attempt to re-situate where we should start looking for the precursors and infrastructures that enabled both Big Gods and big groups.

In sum, I suggest that we need to more fully assess whether or not religion per se, and Big Gods specifically, can be so clearly identified as a driving force (whether in cultural, 
biological, or gene/culture co-evolutionary scenarios) and separated from the diverse forms of social complexity that ratchet up in unison as groups get bigger and socially and materially more complex. Economic, political, and ecological systems are becoming more and more complex before the emergence of towns, cities, and states. One might not need to invoke a supernatural threat of punishment via interventionist deities and a symbolic and structural hyper-xenophobia as the primary way that humans could have developed, and maintained, large-scale societies (which is not to say that these elements do not help facilitate or maintain such societies).

My final point is not about cooperation, at least not directly; it is about religious experience. I think that a core aspect missing from Norenzayan's book, and in much of the literature on this topic, is the absence of the individual believer's experience of religious faith and their interpretation of what that faith means. The cognitive, physiological, and perceptual realities of people who believe in Big God religions vary and in that variation there might be an evolutionarily relevant complexity that is missed in the larger-scale functional treatment of what religion does.

One could state that the economic games conducted and reviewed by Norenzayan and colleagues are indicators of personal beliefs and reflective of the influence that religious belief has on individuals. I think that this is only partially correct. These games focus on quantifiable measures of material exchange, largely based on monetary interactions or perceptions of value, and thus may reflect individuals' responses to the shared general structures of the religion (or those of the larger society) in question, but not necessarily the perceptions and actions in the religious experience of that person's actual daily life.

For example, the God of the Abrahamic faiths is used as the key example of a Big God who is punishing, interventionist, and so on. At a surface level, many basic structures and paradigms of these religions (Christianity, Islam, and Judaism) support that interpretation. However, for many believers practicing those faiths' specific core values, those of caring, love, compassion and especially altruism outweigh the punishment/ control elements (Hell, penance, sin, etc.) in everyday life and in their interpretation of the meaning of the religion. Here I am not being an apologist for religions, or naive about the history of how religious entities have manipulated/impacted societies; rather, I mean to assert that there are significant variations in how individuals experience and respond to the edicts, values, and structures of Big God religions. The focus solely on the overarching punishment/enforcement structure of religions as a functional entity might obscure the very important diversity and dynamism of experience and practice of belief at the individual level. The level of the individual can be extremely relevant when attempting to model patterns of behavior that have direct impacts in both cultural and biological evolutionary processes. My point is that we have to more seriously ask if we can disregard the lived experience of religion in favor of providing overarching structural and adaptationist explanations. I think that the two are more integrated than that, and that our models and approaches need to keep this in mind (e.g., Rappaport, 1999).

\section{Funding}

This essay is based in part on work supported by the Center of Theological Inquiry at Princeton's Inquiry on Evolution and Human Nature 2012-2013.

\section{References}

Aiello, L.C., \& Anton, S.C. (2012). Human biology and the origin of homo. Current Anthropology, 53(6), 269-277. 
Andersson, C., Törnberg, A., \& Törnberg, P. (2014). An evolutionary developmental approach to cultural evolution. Current Anthropology, 55(2), 154-174.

Bedarnik, R.G. (2003). Earliest evidence of paleoart. Rock Art Research, 20, 89-135.

Bell, A.V., Hinde, K., \& Newson, L. (2013). Who was helping? The scope for female cooperative breeding in early homo. PLoS One, 8, e83667. doi:10.1371/journal.pone.0083667

Bell, A.V., Richerson, P.J., \& McElreath, R. (2009). Culture rather than genes provides greater scope for the evolution of large-scale human prosociality. Proceedings of the National Academy of Sciences of the United States of America, 106, 17671-17674.

Coward, F., \& Gamble, C. (2008). Big brains, small worlds: Material culture and the evolution of the mind. Philosophical Transactions of the Royal Society B, 363, 1969-1979.

Dean, L.G., Kendal, R.L., Shapiro, S.J., Thierry, B., \& Laland, K.N. (2012). Identification of the social and cognitive processes underlying human cumulative culture. Science, 335, 114-118. doi:10.1126/science.1213969

Dugatkin, L.A. (2006). The altruism equation: Seven scientists search for the origins of goodness. Princeton: Princeton University Press.

Fuentes, A. (2010). Naturecultural encounters in Bali: Monkeys, temples, tourists, and ethnoprimatology. Cultural Anthropology, 25, 600-624. doi:10.1111/j.1548-1360.2010.01071.x

Fuentes, A. (2013). Cooperation, conflict, and niche construction in the genus homo. In D. Fry (Ed.), War, peace, and human nature (pp. 78-94). Oxford: Oxford University Press.

Gamble, C., Gowlett, J., \& Dunbar, R.I.M. (2011). The social brain and the shape of the paleolithic. Cambridge Archaeological Journal, 21(1), 115-136. doi:10.1017/S0959774311000072

Hamilton, W.D. (1964). The genetical evolution of social behavior. Parts I and II. Journal of Theoretical Biology, 7, 1-52. doi:10.1016/0022-5193(64)90038-4

Herrmann, E., Call, J., Hernandez-Lloreda, M.V., Hare, B., \& Tomasello, M. (2007). Humans have evolved specialized skills of social cognition: The cultural intelligence hypothesis. Science, 317, 1360-1366. doi:10.1126/science. 1146282

Hrdy, S.B. (2009). Mothers and others: The evolutionary origins of mutual understanding. Cambridge, MA: Harvard University Press.

Johnson, D., \& Bering J.M. (2006). Hand of God, mind of man: Punishment and cognition in the evolution of cooperation. Evolutionary Psychology, 4, 219-233.

Kendal, J., Tehrani, J.J., \& Odling-Smee, J. (2011). Human niche construction in interdisciplinary focus. Philosophical Transactions of the Royal Society B, 366, 785-792. doi:10.1098/rstb.2010.0306

MacKinnon, K.C., \& Fuentes, A. (2011). Primates, niche construction, and social complexity: The roles of social cooperation and altruism. In R.W. Sussman \& R.C. Cloninger (Eds.), Origins of altruism and cooperation. Developments in primatology: Progress and prospects (volume 36, part 2, pp. 121-143). New York, NY: Springer.

Malone, N., Fuentes, A., \& White, F.J. (2012). Variation in the social systems of extant hominoids: Comparative insight into the social behaviour of early hominins. International Journal of Primatology, 33, 1251-1277. doi:10.1007/s10764-012-9617-0

Marwick, B. (2003). Pleistocene exchange networks as evidence for the evolution of language. Cambridge Archaeology Journal, 13(1), 67-81. doi:10.1017/S0959774303000040

McBrearty, S. (2012). Sharpening the mind. Nature, 491, S31-S32. doi:10.1038/nature11751

Norenzayan, A. (2013). Big gods: How religion transformed cooperation and conflict. Princeton: Princeton University Press.

Nowak, M.A., \& Highfield, R. (2011). Supercooperators: Altruism, evolution, and why we need each other to succeed. New York, NY: Free Press.

Pope, M., Russel, K., \& Watson, K. (2006). Biface form and structured behavior in the Acheulean. Lithics, 27, 44-57.

Powell, A., Shennan, S., \& Thomas, M.G. (2009). Late Pleistocene demography and the appearance of modern human behavior. Science, 324, 1298-1301. doi:10.1126/science.1170165

Premo, L. (2012). Local extinctions, connectedness, and cultural evolution in structured populations. Advances in Complex Systems, 15(1-2), 1-18. doi:10.1142/S0219525911003268

Rappaport, R.A. (1999). Ritual and religion in the making of humanity. Cambridge: Cambridge University Press. doi:10.1017/CBO9780511814686

Rossano, M.J. (2009). Ritual behavior and the origin on modern cognition. Cambridge Archaeological Journal, 19, 243-256. doi:10.1017/S0959774309000298

Sterelny, K. (2012). The evolved apprentice: How evolution made humans unique. Cambridge, MA: MIT Press.

Sussman, R.W., \& Cloninger, R.C. (Eds.). (2011). Origins of altruism and cooperation. Developments in primatology: Progress and prospects. Volume 36, Part 2. New York, NY: Springer.

Tomasello, M. (2009). Why we cooperate. Cambridge, MA: MIT Press.

Trivers, R. (1971). The evolution of reciprocal altruism. Quarterly Review of Biology, 46(10), 35-57. doi:10.1086/406755

Wadley, L. (2013). Recognizing complex cognition through innovative technology in stone age and palaeolithic sites. Cambridge Archaeological Journal, 23, 163-183. doi:10.1017/S0959774313000309

Wake, D.B., Hadley, E.A., \& Ackerly, D. (2009). Biogeography, changing climates, and niche evolution. Proceedings of the National Academy of Science, 106, 19631-19636. doi:10.1073/pnas.0911097106 
Whiten, A., \& Erdal, D. (2012). The human socio-cognitive niche and its evolutionary origins. Philosophical Transactions of the Royal Society B, 367, 2119-2129. doi:10.1098/rstb.2012.0114

Wilson, E.O. (1975). Sociobiology: The new synthesis. Harvard: Belknap Press.

Wrangham, R., \& Carmody, R. (2010). Human adaptation to the control of fire. Evolutionary Anthropology, 19, 187-199. doi:10.1002/evan.20275rrbb20

\title{
Big Gods, small wonder: supernatural punishment strikes back
}

\author{
Dominic D.P. Johnson* \\ Department of Politics and International Relations, University of Oxford, Oxford, UK
}

\begin{abstract}
Ara Norenzayan's book Big Gods argues that the problem of maintaining cooperation in burgeoning human civilizations since the agricultural revolution was solved by the cultural evolution of omniscient, omnipotent, and moralizing "supernatural watchers" who could monitor good and bad behavior better than humans. Norenzayan's theoretical and experimental work in the new field of evolutionary religious studies has been inspirational and groundbreaking, and Big Gods represents a significant advance in the debate. To the audience of this journal, however, I do not need to further extol the many virtues of Big Gods and Norenzayan's remarkable contributions. Instead, I focus on critiquing Big Gods from the perspective of its main "rival" - the Supernatural Punishment Hypothesis (Johnson, in press; Johnson \& Bering, 2006; Johnson \& Krüger, 2004; Schloss \& Murray, 2011). I argue that, in fact, they are not different theories at all. They differ in their emphasis on evolutionary mechanism (biological vs. cultural selection) and era of focus (Pleistocene vs. Holocene), but they both argue that belief in supernatural punishment fosters cooperation. The Supernatural Punishment Hypothesis is, however, more general on several dimensions and thus Big Gods can be seen as a subset of it. But this overlap is a good thing rather than bad. The key role of supernatural punishment is strongly corroborated by both approaches, they are complementary rather than conflicting, and a fuller understanding of the evolution of religion is likely to come from their integration.
\end{abstract}

\section{Toothless gods: the primacy of punishment}

Big Gods centers on the idea of "supernatural watchers," "supernatural monitoring," and "supernatural surveillance." The key concept is observation, because "watched people are nice people." But this is an odd hook on which to hang the theory, because observation on its own is toothless. In this framing, gods are more perverts than police. Whatever perspective one takes - game theory, natural selection, rational choice - being observed is irrelevant. The only thing that matters is consequences - that is, anticipated rewards or punishments. Only consequences can change expected payoffs and thus alter people's behavior. In fact, Norenzayan goes on to agree that punishment is key, and that it is punishment, rather than rewards, that is the more powerful of the two possible forms of supernatural consequences. As he puts it, "the action is in the fear of supernatural punishment" (p. 45) and he presents copious evidence of exactly this. Even where

*Email: dominic.johnson@politics.ox.ac.uk 
cheating declines and punishment becomes rare, observation alone is not enough because the threat of punishment must remain as a credible deterrent. History has shown numerous times and in numerous ways that observation is not enough to maintain social cooperation - you also need some form of policing and sanctions (Sigmund, 2007). Britain has two million CCTV cameras on its streets, yet plenty of crimes are committed under their gaze. What the cameras do is help the police to find and punish perpetrators. Experimental studies support this basic point: agents with the capacity to punish can alter people's behavior, but agents that just watch have no effect (Purzycki et al., 2012).

Perhaps the reason for this difference in focus is disciplinary. As a social psychologist, Norenzayan thinks in terms of people's social context, and how they are seen by others, whereas as (originally) a biologist, I think in terms of fitness consequences, and how people perform in competition with others. But it is not just a matter of perspective if we are exploring the evolution of religion. Social context is part of the problem, but fitness consequences provide the Darwinian bottom line. Punishment appears to be key, and what is striking is that, after much independent research and reflection, Norenzayan has come to exactly the same conclusion. Supernatural "watchers" offers new packaging, but Big Gods is the Supernatural Punishment Hypothesis with a nicer name.

\section{Beyond god: other sources of supernatural punishment}

Big Gods stands on another shaky pillar: it argues that supernatural monitoring and punishment come from gods (or just God). However, although this is the most obvious and most discussed form of supernatural agency, it is merely one source of supernatural consequences of our actions. Numerous other sources are found in spirits, ancestors, ghosts, angels, demons, animals, witches, sorcerers, jinns, and a variety of other beings Sometimes they are not even personified agents at all. Many cultures believe that behavior is rewarded and punished by impersonal forces governing the universe, such as karma, not by any particular agent. Big Gods are the exception, not the norm. Once this is recognized, supernatural punishment - from all sources - suddenly becomes a good explanation for a wide range of formidable anomalies for Norenzayan's theory, including: (1) major world religions that do not have an omniscient, omnipotent God, such as Buddhism and Hinduism; (2) small-scale societies, many of whom do not believe in a God or gods, or even any personified rewarding or punishing agents, but rather supernatural forces that nevertheless have powerful effects on behavior, such as mana among the Hawaiians or orenda among the Iroquois; and (3) even atheists who, despite lacking religious beliefs, nevertheless have underlying cognitive tendencies to anticipate supernatural causes and consequences of behavior (hence phenomena such as just world theory and immanent justice). Our undue focus on gods as agents of doom only gives us half the picture. With a fuller range of supernatural agents and consequences, many of these anomalies fall into place. People expect payback, but only sometimes from gods. Big Gods does not represent the big picture.

\section{Small gods punish too}

A core claim of Big Gods is that powerful, moralizing, punishing gods only emerged recently in human societies with the agricultural revolution some 10,000 years ago. Norenzayan therefore derives the reverse prediction that, among small-scale societies typical of the Pleistocene in which we evolved: (1) supernatural punishment is absent or rare; and (2) gods are amoral. I think that these claims are false. First for the claim that 
supernatural punishment is absent or rare in small-scale societies. There are in fact numerous traditional societies that believe in direct supernatural consequences of behavior - and again punishment looms large. For example, a study of economic behavior in Burkina Faso found that traditional beliefs increased cooperative behavior, because "people believe spirits and ancestors enforce the moral code... Supernatural forces punish anyone who violates the moral code, whether [by] severe illnesses, accidents or death" (Hadnes \& Schumacher, 2012, p. 692). And this is not unique to the region. Supernatural consequences for violating social norms is a widespread feature of sub-Saharan religions, and can be found among many or even most small-scale and traditional societies around the globe. Ironically, Norenzayan himself gives us plenty of examples of supernatural punishment in small-scale societies. For example, he describes the Kwaio of the Solomon Islands as having "interventionist spirits who are constantly monitoring and meddling" (p. 130) and "help those who follow social norms, and punish transgressors" (p. 26).

Even in parts of the book where Norenzayan becomes conscious of the contradiction, he acknowledges that supernatural punishment is, in fact, a common feature of small-scale societies. For example, he cites Boehm's (2008) study of 18 hunter-gatherer societies - a subsample of small-scale societies selected to better represent the types of societies in which we evolved during the Pleistocene - as evidence that many such societies do not believe in supernatural punishment for moral transgressions. He notes, for instance, that in 11 of them gods do not "prohibit murder" (p. 137). But that means that seven of them do. And there are similar beliefs in supernatural sanctions for a variety of other behaviors. Overall, all of these societies had supernatural sanctions of one sort or another "to enforce moral codes," 12 state the importance of supernatural punishment in general, and 16 state specific offenses that trigger it (all of which are antisocial). The only question is how such different conclusions can be drawn from the same evidence. Norenzayan wants to see no supernatural punishment in small-scale societies, since that is what the Big Gods idea predicts, so he emphasizes the proportion of societies that lack supernatural sanctions. But one can just as well point to the proportion that do have supernatural sanctions.

Supernatural punishment may not be universal (why should it be?), but quantitative and qualitative evidence from a variety of large-sample cross-cultural studies, in both early and recent literature, show that supernatural sanctions - of one form or another - are widespread among small-scale and traditional societies (Hartberg et al., in press; Johnson, 2005; Malinowski, 1935; Murdock, 1980; Swanson, 1960; Whitehouse, 2008). The often-cited idea that it is absent appears to be a myth. The myth, I believe, stems from our Western bias to look for gods as the source of supernatural punishment, and to look for violations of our own form of morals. This latter problem I address next.

\section{Small gods are not amoral}

Big Gods argues that supernatural agents in small-scale societies are not concerned with moral behavior. However, the term and common conceptualization of "morality" is a recent and Western phenomenon. Indeed, it is a feature of the very WEIRDos (Western, educated, industrialized, rich, democratic people) that Norenzayan warns us about. He explicitly points out that WEIRDos have "a narrow conception of morality that revolves around caring/not harming, fairness, and justice" (p. 53). Yet this same pitfall is evident in Norenzayan's own interpretation of evidence. He says, for example, that among Boehm's 18 societies, gods and spirits "typically care little about human affairs that we would consider falling under the label moral" (p.126, original emphasis). But this is exactly the point. We should be asking whether supernatural punishment affects people's adherence to 
the norms of their society - whatever those norms may be. Whether those norms conform to our own "morals" or not is irrelevant in the eyes of evolution. What matters is how belief in supernatural punishment affects Darwinian fitness. Sometimes this can be through "prosocial" behavior and cooperation, which is what Norenzayan is looking for. But sometimes it may be through dominance, stealing or killing. Why would (evolutionarily adaptive) gods necessarily condemn behavior if it is in one's own, or indeed the group's, genetic interest? Prosocial behavior is not synonymous with adaptive behavior.

Our own cultural perspective traps us into thinking that religion and gods are about morality. The error is striking, because Norenzayan cites Swanson on exactly this point (p. 131), but it pervades the pages of Big Gods despite an awareness of the danger. Certainly, moralizing gods may have spread and strengthened in recent millennia, but supernatural punishment for norm transgressions is clearly evident in many hunter-gatherer societies as well. Human cognitive dispositions underlying supernatural punishment beliefs have not changed, but norms have. If we want to understand the evolution of religion, it is not morality that we should be looking for but adaptive behavior, and adaptive behavior just like predation, fighting, or coercion - may appear "immoral" rather than "moral" to us. WEIRDos might care about the difference, but natural selection does not.

\section{Big Gods and the Supernatural Punishment Hypothesis: two theories or one?}

\subsection{Differences between Big Gods and the Supernatural Punishment Hypothesis}

There are differences between Big Gods and the Supernatural Punishment Hypothesis, but these are primarily differences of emphasis and scope of application (see Table 1). It is a shame that Big Gods does not engage with the extensive debate on evolutionary theories of supernatural monitoring and punishment published in this journal in 2011 (Schloss \& Murray, 2011, and commentaries). Schloss and Murray's target article quite usefully explored distinctions between the Big Gods argument and the Supernatural Punishment Hypothesis. They distinguished them by their function: the Supernatural

Table 1. Differences between Big Gods and the Supernatural Punishment Hypothesis. The latter is more general on several dimensions.

Supernatural Punishment

Big Gods Hypothesis

Evolutionary problem

Era

Mechanism

Source of supernatural punishment

Applies to major world religions

Applies to small-scale societies

Applies to atheism cooperation in large groups

Holocene

cultural selection

moralizing gods

yes (but not all, e.g., Buddhism, Hinduism) selfishness in small groups

Pleistocene and Holocene

natural selection and cultural selection

gods, other supernatural agents, and impersonal agency

yes

yes

yes 
Punishment Hypothesis was argued to be essentially about "punishment avoidance" in small-scale societies (a mind-guard to avoid real-world punishment for selfish behavior and norm transgressions), while the Big Gods idea was argued to be essentially about "cooperation enhancement" in large societies (boosting cooperation in the face of anonymity). This suggests that there are two different puzzles at issue, not two rival theories. Puzzle 1 is the evolutionary origins of religion in the Pleistocene (what problems, if any, did it emerge to solve?). Puzzle 2 is the spread of large-scale religions in the Holocene (why did some religious forms spread and others die out?). Norenzayan focuses on the second puzzle and explicitly excludes the former. By contrast, the Supernatural Punishment Hypothesis focuses on the first puzzle, but does not exclude the latter and in fact explicitly included it (Johnson, 2011; Johnson \& Krüger, 2004). Norenzayan's focus is solely on the problem of anonymity in big societies - how do you achieve trust and cooperation among strangers? From this perspective, hunter-gatherer societies seem qualitatively different - for one thing, no one is anonymous. But there is a bigger, broader, and older biological problem in the real-world consequences of selfish behavior. This problem emerged long ago with the advent of theory of mind and complex language, but it did not end with the Pleistocene. A parsimonious theory has to deal with both eras and both puzzles.

\subsection{Similarities between Big Gods and the Supernatural Punishment Hypothesis}

Despite variations in emphasis, the similarity between Big Gods and the Supernatural Punishment Hypothesis is much more striking than any differences - and certainly would be to people outside the field of evolutionary religious studies. Both say, basically, that cooperation is enhanced by a fear of supernatural punishment. Figure 1 sets out the elements of each theory, revealing that they are essentially saying the same thing. Although the motivating puzzle may be different, the explanandum and explanans are the same.

\begin{tabular}{|c|c|c|c|c|c|c|}
\hline & $\begin{array}{c}\text { Evolutionary } \\
\text { "problem" }\end{array}$ & $\begin{array}{c}\text { Independent } \\
\text { variable }\end{array}$ & & $\begin{array}{l}\text { Proximate } \\
\text { mechanism }\end{array}$ & & $\begin{array}{c}\text { Dependent } \\
\text { variable }\end{array}$ \\
\hline Big Gods & $\begin{array}{l}\text { cooperation in } \\
\text { large groups }\end{array}$ & $\begin{array}{c}\text { fear of } \\
\text { supernatural } \\
\text { punishment* }\end{array}$ & $\rightarrow$ & $\begin{array}{c}\text { religious } \\
\text { cognitive } \\
\text { dispositions }\end{array}$ & $\rightarrow$ & cooperation \\
\hline $\begin{array}{l}\text { Supernatural } \\
\text { Punishment } \\
\text { Hypothesis }\end{array}$ & $\begin{array}{l}\text { selfishness in } \\
\text { small groups }\end{array}$ & $\begin{array}{c}\text { fear of } \\
\text { supernatural } \\
\text { punishment }\end{array}$ & $\rightarrow$ & $\begin{array}{c}\text { religious } \\
\text { cognitive } \\
\text { dispositions }\end{array}$ & $\rightarrow$ & cooperation \\
\hline
\end{tabular}

Figure 1. Similarities between Big Gods and the Supernatural Punishment Hypothesis.

*The focus and language in Big Gods is on supernatural "watchers," "surveillance," and "monitoring," but it is explicitly stated that negative consequences - punishment - is the key driver of behavioral change. 
The only big difference is the emphasis on cultural selection instead of natural selection. But that leaves little to argue about, because the origins and development of the cognitive dispositions underlying religious beliefs - during the Pleistocene - is bound to be a natural selection story, whereas the emergence and spread of cultural manifestations of religious beliefs - during the Holocene - is obviously going to be a cultural evolution story. What else could it be? This is precisely why I also advocated a role for cultural evolution throughout the development of the Supernatural Punishment Hypothesis. The reason we pushed the individual selection approach is because explaining costly behavior with group selection is easy, but explaining costly behavior in terms of individual selection is harder. Although both may ultimately be at work, identifying individual Darwinian fitness benefits should be the first goal, and is likely to have been the stronger form of selection in human evolution (West, El Mouden, \& Gardner, 2011; Williams, 1966). Nevertheless, we also pointed out that cultural selection effects could be rapid and powerful when the necessary conditions are present.

Starting with the original "Good of Wrath" paper in 2004, Oliver Krueger and I explicitly pointed out that "[n]atural selection, then, may have favoured epigenetic predispositions receptive to religious norms of behavior that promoted cooperation" and "more specifically, a combined product of human adaptation and culture (i.e. genetic and/or cultural selection)" (Johnson \& Krüger, 2004, p. 169, 169 fn. 42). Again in 2005, I wrote:

Group selection [biological or cultural] may be at work as well (if supernatural punishment promotes cooperation, groups with it would do better than those without), but while certainly adding significantly to a selective process, group selection need not be relied upon for the mechanism to operate. (Johnson, 2005, p. 433)

In 2006, Jesse Bering and I again emphasized that although we focused on individual selection, "any group selection effects, though they are not necessary, would help drive the system" (Johnson \& Bering, 2006, p. 221). We also wrote:

[A]lthough we have highlighted a central role for individual selection in our theory, which we believe could drive the system on its own, any inter-group advantages leading to the group selection of such morally bound cooperative behavior would augment the process [refs]. Indeed, group selection would lead to a much more rapid dominance of god-fearing strategies, since groups with Machiavellians will suffer by comparison. (Johnson \& Bering, 2006, p. 228)

These recurrent nods to cultural group selection are precisely the Big Gods' point.

\section{God genes? Mischaracterizing the Supernatural Punishment Hypothesis}

Big Gods and the Supernatural Punishment Hypothesis are, in fact, so similar that in order to distinguish them Norenzayan was led to construct a straw man. Norenzayan depicts the Supernatural Punishment Hypothesis as claiming "an innate fear of divine retribution" which is a "genetic adaptation" (p. 136) and that "supernatural punishment is a human universal," which leads to "the wholesale suppression of selfish behavior." None of these is true. The notion of a genetic, innate fear of "divine retribution" is obviously ludicrous. There can be no gene for a complex cultural idea. There is also absolutely no biological reason whatsoever to imagine that belief in supernatural punishment - even if it were somehow "genetic" - would be a human universal. Epigenetics, individual variation, and ecological conditions, not to mention cultural factors, mean that even 
hardwired traits can be expressed in markedly different ways, or not at all. Supernatural punishment may be common but it need not be universal. Finally, Bering and I carefully explained that it was not about the "wholesale suppression" of selfish behavior - such an inflexible strategy would be outcompeted by Machiavellians (Johnson \& Bering, 2006). The trick is to increase prudence in the face of social transparency, to balance the costs of mistakes with the costs of missed opportunities (Johnson, 2009).

What can be genetic, of course, are the underlying cognitive mechanisms that give rise to "religious"-like beliefs and expectations of supernatural consequences in the first place. But only cultural evolution can fill in the details of whence these consequences come and what they are - whether karma, ghosts, or God, and reincarnation, misfortune, or Hell. The Holocene did not herald the emergence of beliefs in supernatural consequences; it was merely a new landscape in a longer evolutionary story. Norenzayan is on precisely the same page with regard to the underlying - and genetically based cognitive mechanisms, and yet unwilling to recognize supernatural punishment at work in human beings that live outside big societies. It is odd to claim that these remarkable cognitive dispositions had zero effect on fitness for tens of thousands of years prior to the Holocene, and then suddenly did.

As we have come to understand in recent years, any perceived dichotomy between genetic and cultural evolutionary theories is a false dichotomy. Most human traits are complex and influenced by both nature and nurture, and "multi-level selection" holds the key to understanding the relative contributions of different mechanisms of the evolutionary process. Norenzayan treads an unnecessarily adversarial path in pitching the argument as genes vs. culture. It is clearly both. Big Gods suggests that human cooperation is promoted by supernatural agents, and that punishment is the key driver of the relationship. This argument is big, bold, important, and, I think, correct. But it is not new. It is the Supernatural Punishment Hypothesis at work in big groups.

\section{The bigger the gods, the smaller the theory}

Recent years have seen an explosion of theories on the evolution of religion. The problem is typically couched in terms of a puzzle: how can we explain religious beliefs and behaviors within the logic of Darwinian natural selection, given that they are costly in terms of time, effort, and missed opportunities? Today, however, the problem is less about unearthing a good explanation and more about sifting through the multitude of existing explanations - is a given feature of religion better explained by supernatural punishment, costly signaling, elite manipulation, ritual cohesion, group identity, competition, or numerous other proposals? The evolution of religion is, therefore, "over-determined." We have good explanations already that appear to account for much of the variance, and the acid test for any new theory is what, if anything, does it add? Does it explain variation that other theories cannot? From this perspective, Big Gods is rather limited.

To me, Big Gods actually limits and hobbles the explanatory power of supernatural punishment, rather than extending it, because: (1) it narrows the scope by explaining cooperation in the Holocene alone; (2) it weakens the logic by focusing on toothless "monitoring", rather than the game-changing power of punishment; (3) it reduces generality by limiting the sources of supernatural punishment to gods (excluding other supernatural agents and impersonal sources such as karma and superstition); and (4) it limits the evolutionary logic by resorting to group selection (albeit the "safe" kind, in 
cultural group selection). The challenge of the Supernatural Punishment Hypothesis has been to transcend such limitations - to offer an account of the origin of religious beliefs (as well as their spread), to explain why punishment has such leverage (compared to monitoring or rewards alone), to account for widely different sources of supernatural consequences (gods are only one means to an end), and to identify individual fitness benefits of costly religious beliefs and behaviors - over and above any group selection story.

This does not mean that the issue is resolved, of course. Many outstanding questions demand attention, not least the role of elites and power in originating and maintaining supernatural punishment beliefs. After all, it is the perfect instrument of subordination (Cronk, 1994; Schloss \& Murray, 2011). This is an especially important problem indeed, a rival theory - in the Holocene, and yet is hardly discussed in Big Gods. And this brings us to a final point: the rise of "Big Gods" is inextricably linked with Western dominance and expansion. As Abrahamic religions and their cultures spread around the world, so too did technology, governance, science, and numerous other cultural traits. Big Gods are evidently a feature of big societies, but there is little reason to assume that they are a cause of them, and many reasons to believe that they are in fact a consequence. If so, which way do the causal arrows of Big Gods point?

\section{References}

Boehm, C. (2008). A biocultural evolutionary exploration of supernatural sanctioning. In J. Bulbulia, R. Sosis, C. Genet, R. Genet, E. Harris, \& K. Wyman (Eds.), The evolution of religion: Studies, theories, and critiques (pp. 143-150). Santa Margarita, CA: Collins Foundation Press.

Cronk, L. (1994). Evolutionary theories of morality and the manipulative use of signals. Zygon, 4, 117-135.

Hadnes, M., \& Schumacher, H. (2012). The gods are watching: An experimental study of religion and traditional belief in Burkina Faso. Journal for the Scientific Study of Religion, 51, 689-704. doi:10.1111/j.14685906.2012.01676.x

Hartberg, Y., et al. (in press). Supernatural monitoring and sanction in community based resource management. Religion, Brain \& Behavior.

Johnson, D.D.P. (2005). God's punishment and public goods: A test of the Supernatural Punishment Hypothesis in 186 world cultures. Human Nature, 16, 410-446. doi:10.1007/s12110-005-1017-0

Johnson, D.D.P. (2009). The error of God: Error management theory, religion, and the evolution of cooperation. In S.A. Levin (Ed.), Games, groups, and the global good (pp. 169-180). Berlin: Springer.

Johnson, D.D.P. (2011). Why God is the best punisher. Religion, Brain \& Behavior, 1(1), 77-84. doi:10.1080/ 2153599X.2011.558714

Johnson, D.D.P. (in press). The good of wrath: Supernatural punishment and the evolution of cooperation. New York, NY: Oxford University Press.

Johnson, D.D.P., \& Bering, J.M. (2006). Hand of God, mind of man: Punishment and cognition in the evolution of cooperation. Evolutionary Psychology, 4, 219-233.

Johnson, D.D.P., \& Krüger, O. (2004). The good of wrath: Supernatural punishment and the evolution of cooperation. Political Theology, 5, 159-176. doi:10.1558/poth.2004.5.2.159

Malinowski, B. (1935). The foundations of faith and morals: An anthropological analysis of primitive beliefs and conduct with special reference to the fundamental problem of religion and ethics. London: Oxford University Press.

Murdock, G.P. (1980). Theories of illness: A world survey. Pittsburg: HRAF, University of Pittsburgh Press.

Purzycki, B.G., Finkel, D.N., Shaver, J., Wales, N., Cohen, A.B., \& Sosis, R. (2012). What does God know? Supernatural agents' access to socially strategic and non-strategic information. Cognitive Science, 36, 846869. doi:10.1111/j.1551-6709.2012.01242.x

Schloss, J.P., \& Murray, M.J. (2011). Evolutionary accounts of belief in supernatural punishment: A critical review. Religion, Brain \& Behavior, 1(1), 46-99. doi:10.1080/2153599X.2011.558707

Sigmund, K. (2007). Punish or perish? Retaliation and collaboration among humans. Trends in Ecology \& Evolution, 22, 593-600. doi:10.1016/j.tree.2007.06.012

Swanson, G.E. (1960). The birth of the gods. Ann Arbor: University of Michigan.

West, S.A., El Mouden, C., \& Gardner, A. (2011). Sixteen common misconceptions about the evolution of cooperation in humans. Evolution and Human Behavior, 32, 231-262. doi:10.1016/j.evolhumbehav.2010. 08.001 
Whitehouse, H. (2008). Cognitive evolution and religion; cognition and religious evolution. In J. Bulbulia, R. Sosis, C. Genet, R. Genet, E. Harris, \& K. Wyman (Eds.), The evolution of religion: Studies, theories, and critiques (pp. 19-29). Santa Margarita, CA: Collins Foundation Press.

Williams, G.C. (1966). Adaptation and natural selection. Princeton: Princeton University Press.

\title{
The problems and origins of belief in Big Gods
}

\author{
Jordan Kiper* and Jacqueline Meier \\ Department of Anthropology, University of Connecticut, Storrs, CT, USA
}

Once in a great while, an intellectual comes along and provides a story that makes sense of the "big" questions within a discipline. We are fortunate enough that Norenzayan (2013) has done just that in Big Gods: How Religion Transformed Cooperation and Conflict. This book not only synthesizes the decade's most important studies in the cognitive science of religion (CSR) and the evolutionary study of religion (ESR), it also delivers a compelling account regarding two long-standing puzzles in the social sciences:

(1) How did large-scale anonymous societies emerge?

(2) Why did moralizing gods come to dominate so many religions?

These are indeed puzzles. In order for large-scale societies to emerge, there must have been a mechanism for widespread cooperation, but that would have required "scaled-up" costs (p. 6). Put simply, cooperation demands punishing free-riders, overcoming collective-action problems, and instilling widespread trust. But what mechanism could accomplish these on a large scale? Turning to religion, it is mysterious that moralizing gods came to "colonize the minds of so many people" during the Holocene and thereafter (p. 8), given that spirits and deities of hunter-gatherer societies do not have widespread moral concerns. How and why did this shift in belief happen?

According to Norenzayan, the answer to both puzzles is the emergence of "Big Gods" that is, "gods who watch, intervene, and demand hard-to-fake loyalty displays" (p. 8). To defend this thesis, Norenzayan draws from the most important studies in CSR and ESR, including the byproduct thesis (e.g., Boyer, 2001), minimally counter intuitive concepts (MCIs) (e.g., Barrett \& Nyhof, 2001), the supernatural punishment hypothesis (e.g., Norenzayan \& Shariff, 2008), costly signaling theory (e.g., Bulbulia \& Sosis, 2011), credibility signals (CREDs) (e.g., Henrich, 2009), and the co-emergence of prosocial religion and agriculture (e.g., Cauvin, 1994). Besides synthesizing these into a compelling narrative, Norenzayan brings them together to make the following argument, comprised of seven premises:

(1) Human beings inherit cognitive functions whose byproducts are religious intuitions (pp. 15-19).

(2) Sometime around the Holocene, these intuitions engendered the belief in interventionist Big Gods (pp. 7, 19-32, 118-124).

(3) Because these beliefs discouraged free-riding, those who held them could be trusted more than those who did not (pp. 33-93).

*Corresponding author. Email: jordan.kiper@uconn.edu 
(4) Trustworthy persons then grouped together and, to prevent free-riding, adopted hard-to-fake commitments, such as costly signals and CREDs (pp. 94-117)

(5) Through the solidarity-promoting mechanisms of costly signals and CREDs, prosocial religions emerged, giving rise to large-scale societies (pp. 124-139).

(6) Over the centuries, however, prosocial religions and large-scale societies brought about secular governments, which are replacing the need for Big Gods (pp. 170-192).

(7) Thus, although Big Gods were necessary for the emergence of prosocial religions and large-scale societies, they may no longer be needed in the contemporary secular world (pp. 12, 172-175, 192).

This is a valid argument that Norenzayan convincingly defends, and in so doing captures the current paradigm in the science of religion. However, like any good argument, it makes clear which premises are potentially unsound or in need of further justification. In what follows we engage with those points (viz., premises 2 and 3 from above), identifying several ideas that require clarification or highlight avenues for future research.

\section{The problem of belief}

Norenzayan argues that the necessary precondition for large-scale cooperation and prosocial religions is the belief in interventionist Big Gods who punish wrongdoers: "Belief in certain kinds of supernatural watchers - Big Gods - is an essential ingredient that, along with rituals and other interlocking sets of social commitment devices, glued together total strangers into ever-larger moral communities" (p. 10). This is certainly a justified claim. Many of the most advanced theories in the evolution of religion, including Wilson's (2002) group-selectionist model and Whitehouse's (2004) modes theory, are based on it. Furthermore, as cogently argued by Norenzayan, an overwhelming amount of evidence supports the claim that people who are socially monitored (e.g., Bateson, Nettle, \& Roberts, 2006) or undertake hard-to-fake commitments (e.g., Sosis, 2005) are more prosocial than those who do otherwise. Hence, once the human mind produced the idea of interventionist Big Gods, belief in that idea catalyzed rituals and social commitments that brought about large-scale cooperation and prosocial religions (p. 106).

To be sure, Norenzayan argues that belief preceded hard-to-fake commitments (see premises 2 and 3). After all, the conception of interventionist Big Gods must have come prior to the rituals made on their behalf (p. 6). It is important to stress here that Norenzayan uses the term "belief" in the same sense as other cognitive scientists of religion - that is, as a mental image or idea rather than a knowledge claim (e.g., "a talking tree" vs. " $2+2=4$," respectively). These early beliefs were therefore not propositional assertions but rather intuitions that were themselves byproducts of evolved cognition (p. 16). Yet, because these intuitions were so catchy and encouraged prosocial behavior, they quickly propagated from one mind to the next, eventually spreading to larger populations (pp. 106-110). Nevertheless, to solidify these beliefs, communities began to engage in worship, ritual, and other religious actions, which also served as hard-to-fake commitments and the foundations for large-scale societies (p. 99).

Hence, it was religious belief that drastically changed human environments: belief catalyzed ritual, ritual united communities, and united communities engendered largescale societies - to the extent that belief in Big Gods produced the agricultural revolution, 
and not vice versa (p. 120), a point we return to in the next section. With so much of his argument resting on "belief," Norenzayan thus offers several important caveats about belief, which deflate traditional epistemic problems (e.g., foundationalism, coherentism, reliabilism, etc.). For instance, Norenzayan shows that beliefs depend upon context (p. 39), require enculturation to be held across the life span (p. 113), and need ritual to produce shared intentionality (p. 114). Yet, despite these caveats, Norenzayan leaves several other points about belief unexplored, which render premises 2 and 3 needing further qualification.

Above all, there is a gap in Norenzayan's account about the onset of believing in interventionist gods as "contagious ideas" (p. 106) and "passionate commitments" (p. 110). While the former is holding an MCI (i.e., remembering something counterintuitive), the latter is being in a dispositional state to behave as if the MCI were true. One of the problems is determining the link between the two with respect to the emergence of interventionist Big Gods. According to Norenzayan (p. 8), the belief in such gods arose as a "mutant" byproduct of cognition, meaning that it was an MCI. He goes on to say, however, that people who believed this would have been trusted more than nonbelievers, implying that some were in a dispositional state such that they were passionately committed to the idea (pp. 60-61). This begs the question: which of the two mental states was it? Was it catching the "contagious idea" of interventionist Big Gods? Or was it seeing oneself as being in the purview of such gods? Although Norenzayan often equivocates between the two, his overall account puts a great deal of stress on the latter (p. 10), leading to the following questions that beg clarification regarding premises 2 and 3: how did the earliest believers transition from simply holding a "contagious idea" about interventionist Big Gods to having a "passionate commitment" toward them? Moreover, how would others have known who simply held the contagion and who had passionate commitments?

These queries underscore the following problem of belief: because belief is an internal mental-state subjectively known only (if at all) to the self, it is a private affair that is objectively difficult for others to discern. Yet religion evolved to find a way around this problem. As anthropologist Roy Rappaport (1999, pp. 119-120) has observed, the solution is ritual, which serves the dual function of (1) signaling commitments to others and (2) accepting for oneself the beliefs associated with the rituals in question (Sosis, 2003). Although Norenzayan (p. 103) recognizes the first function, he neglects to consider the second. Importantly, it is the second that is necessary for turning MCIs into passionate commitments, for it is through participation in ritual that participants accept whatever is encoded in the ritual itself, thus amplifying beliefs, constructing ideologies, and reifying social orders (Rappaport, 1999, pp. 129-130). If the idea of interventionist Big Gods arose among people already engaged in religious rituals, which is likely (e.g., Alcorta \& Sosis, 2005), those rituals would have been the necessary and sufficient conditions for converting a "contagious idea" into a "passionate commitment." This conditional not only qualifies premises 2 and 3, but also changes Norenzayan's overall account in an important way. It was ritual - not belief - that drastically changed human environments, transforming MCIs into passionate commitments and thus engendering hard-to-fake commitments. Thus, the cornerstone of prosocial religion - and all religion for that matter - would be ritual, not belief (Rappaport, 1999, p. 26).

By focusing so much on belief, Norenzayan faces yet another problem. This is to characterize religion and the lack thereof as ways of believing or not believing, respectively (p. 47). However, as anthropologists repeatedly find through fieldwork, religion is less about believing a set of propositions and more about forging social 
commitments and maintaining social identities (e.g., see Rappaport, 1999). Nowhere is this point more clearly needed than with Norenzayan's discussion of atheism. Although Norenzayan provides a brilliant analysis of the varieties of atheism (mind-blind atheism, analytic atheism, incredulous atheism, and apatheism; see pp. 178-190), he nonetheless treats atheism, like belief, as a steady way of thinking about the world (p. 47). However, this overlooks the fact that belief and disbelief are not steady cognitive styles but rather social commitments and identities that develop and fluctuate across the life span. Like the above comments on ritual, this point does not challenge Norenzayan's argument but rather his overall story. If atheism is a social commitment and identity - instead of being a simple lack of belief - it may be on the rise today not because people are believing less in Big Gods, but rather they are finding new forms of social commitment and identities outside of traditional prosocial religions.

\section{The origins of belief}

Turning more closely to premise 2, Norenzayan argues that belief in Big Gods and the expansion of large-scale cooperation originated in the Near East around the Holocene (pp. 7, 19-32, 118-124). Above all, Norenzayan should be commended for delving into the archaeological record. However, despite finding compelling evidence for communal ritual practices at the Pre-Pottery Neolithic A-B (PPNA-B) site of Göbekli Tepe, the debate over whether early religion drove the transition to farming or the opposite is far from settled. Archaeologists have long debated the drivers of this major turning point in human history. These range from climatic change (Childe, 1971; Richerson et al., 2001) to demographic pressure (Binford, 1968; Bocquet-Appel, 2011; Flannery et al., 1969) and increased social demands (Cauvin, 2002).

Ritual practices documented at PPN archaeological sites at the time of the agricultural transition, such as Göbekli Tepe, are thought to reflect a new ideological system often cited as the harbinger of established formal religious systems to come (Cauvin, 1994). Norenzayan references Cauvin (1994), who proposed that the birth of the gods likely predated plant and animal domestication, because he believed that agriculture would not have been possible without a prior mental transformation allowing people to conceive of controlling their environment. However, other archaeologists argue that humans were active in the construction of their environments long before domestication occurred (Miller, 2011; Stiner et al., 2000). Likewise, several lines of evidence suggest that domestication may have already begun in the surrounding region by the time that Göbekli Tepe was occupied. Because human control over local species, especially plants, had likely already started by the time that rituals were practiced at Göbekli Tepe, Cauvin's argument that religion came first may not fit Norenzayan's application.

Norenzayan finds that the "early stirrings to worship Big Gods" (p. 120) came before agriculture at the unprecedented ritual center of Göbekli Tepe based on the lack of domesticated species at the site, but this does not necessarily mean that early religion predates the early stirrings of agriculture in the region. It is difficult to detect the earliest phases of the domestication process that lasted about 4000 years (Zeder, 2011). Göbekli Tepe was first used at the early date of 11,500 years ago (BP) and the earliest evidence for fully (morphologically) domesticated wheat from the nearby site of Nevali Çori (c. $50 \mathrm{~km}$ from Göbekli Tepe) dates to 10,500 BP (Nesbitt, 2002). This may seem to support the interpretation that plants were domesticated in the region after the Göbekli Tepe rituals took place. However, the early stages of domestication are not marked by morphological change and are often difficult to detect in the archaeological record. Humans began 
managing the movements of wild animals and cultivating strands of wild plants to control the availability of dietary resources thousands of years before morphological changes occurred. Thus, non-morphological markers must be used to assess whether the communities practicing communal rituals at Göbekli Tepe engaged in animal management (i.e., human control over the movement and culling of animal herds; see Zeder \& Hesse, 2000) and the selective cultivation of plants. The earliest evidence of animal management found near to Göbekli Tepe is also from Nevali Çori (10,500 cal. BP; see Arbuckle \& Özkaya, 2006), but more distantly, interesting finds on Cyprus indicate that animals were sufficiently controlled by humans to have been transported to the island by boat as early as about 11,400 cal. BP (Vigne et al., 2011). This establishes that the management of animals on the mainland began earlier than the current evidence suggests, closer to the time when rituals were practiced at Göbekli Tepe.

The early stages of the animal domestication process (management) occur before morphological changes appear and are best detected using demographic (age/sex) methods. However, demographic methods may not be appropriate to investigate management at Göbekli Tepe due to the ritual nature of the site. The population structure of sheep from Göbekli Tepe favors prime-aged animals, the expected pattern for a hunted wild population (Peters et al., 2013) where humans are expected to preferentially target the largest and fattest animals. However, according to the ethnographic record, specific animals of certain ages and sexes are often selected for ritual activities, in particular adult animals that can feed more people and often have increased symbolic importance (Twiss, 2008). Therefore, the faunal evidence may correctly indicate that fully domesticated animals were not used at the site, but the use of animals in the early stages of animal management or the intentional selection of wild animals over managed animals for ritual activities cannot be ruled out based on the current evidence.

Regardless of the problems associated with assessing the stage of plant and animal domestication at Göbekli Tepe, the site clearly "attracted pilgrims from a wide range of locations" (p. 120), as indicated by the stone tools that came from as far west as Cappadocia and as far east as Lake Van (c. $600 \mathrm{~km}$ range; see Carter et al., 2013), so settlement sites where the pilgrims lived should be examined to assess whether they had started the shift from foraging to farming. Evidence of early plant cultivation within a 200 $\mathrm{km}$ radius indicates that the transition to agriculture had already begun in communities that likely used the site for ritual activities beginning by 11,500 BP, including Hallan Cemi (11,500 BP), Demirkoy (11,400 BP), and Queramel (11,500 BP) (Tanno \& Willcox, 2012). These sites were within the range of eastern stone sources that were exploited to make the tools found at Göbekli Tepe (Carter et al., 2013). Cultivated plants or knowledge of the domestication process would likely have been brought to Göbekli Tepe along with the materials for stone tools that originated near these sites. Even earlier evidence for weedy species shows that fields were under cultivation by 13,000-12,000 cal. BP at the more distant sites of Abu Hureyra and Mureybet in modern-day Syria (Zeder, 2011). Thus, several indicators establish that the management and cultivation of wild plant species had long been underway in the greater region by the time that rituals occurred at Göbekli Tepe. Even though only wild species have been found at the site thus far, knowledge of the early agricultural processes of plant and animal management was available to communities that used Göbekli Tepe and wild species may have been preferred for their symbolic value in ritual activities, which likely differed from that of domesticated varieties (Arbuckle, 2009; Shanklin, 1985).

One additional problem with Norenzayan's discussion of early belief is that although ideological change could potentially predate agriculture, belief in Big Gods is nearly 
impossible to detect in the archaeological record. The shift to Big God beliefs may be better documented by focusing on the later shift to the doctrinal mode of religiosity that Whitehouse and Hodder (2010) documented after the forager-to-farmer transition, but before the advent of writing at the site of Çatalhöyük. Göbekli Tepe may be situated too early to examine the Big God beliefs that concern Norenzayan, because rituals there likely reflect the imagistic mode. Although a significant increase in the visibility of ritual activity reflecting larger-scale and increasingly public ritual practice appears in the archaeological record during the PPN period when Göbekli Tepe was used (GoringMorris \& Belfer-Cohen, 2011) and this generally indicates that changes in ritual practices occurred during the shift to agriculture, Big God beliefs are more likely associated with doctrinal mode rituals (Atkinson \& Whitehouse, 2011), which appear later with fullfledged farming and thus, were not likely a part of the mode of religiosity present at Göbekli Tepe.

In sum, Norenzayan's discussion of the rise of large-scale, cooperative groups that practice prosocial religion and agriculture is appealing, but the origin of this shift is difficult to pinpoint using only one narrow time frame from one ritual-use site. Other permanent habitation sites in the surrounding region provide better contexts to track the state of domestication during the PPNA when rituals were practiced at Göbekli Tepe. Moreover, the success of religion in facilitating the high level of cooperation needed to practice agriculture may be better studied not by examining the early origins of this transition, but rather the end of the PPN culture. A hiatus in the archaeological record beginning c. 8500 BP indicates that the PPN culture eventually collapsed and was replaced by full-fledged agriculturalists practicing rituals characteristic of the doctrinal mode of religiosity c. 1000 years later. Perhaps the type of religion documented at Göbekli Tepe did not produce a level of cooperation that could fully overcome the many challenges documented during this period, such as climate change, deforestation, and disease (Goring-Morris \& Belfer-Cohen, 2010). Even if religion could have driven the shift to agriculture, in its early form it was not enough to sustain early farming groups in the long run.

\section{Conclusion}

As mentioned, Norenzayan's text presents a timely and synthetic account of CSR and ESR that, with further considerations to the soundness of his argument, could become the paradigmatic outlook in the contemporary science of religion. For this reason we look forward to his reply, and the many discussions that will result from his important book.

\section{References}

Alcorta, C., \& Sosis, R. (2005). Ritual, emotion, and sacred symbols: The evolution of religion as an adaptive complex. Human Nature, 16, 323-359. doi:10.1007/s12110-005-1014-3

Arbuckle, B.S. (2009). The early management of cattle (Bos taurus) in Neolithic central Anatolia. Antiquity, 83,669 .

Arbuckle, B.S., \& Özkaya, V. (2006). Animal exploitation at Körtik Tepe: An early Aceramic Neolithic site in southeastern Turkey. Paléorient, 32(2), 113-136. doi:10.3406/paleo.2006.5193

Atkinson, Q.D., \& Whitehouse, H. (2011). The cultural morphospace of ritual form: Examining modes of religiosity cross-culturally. Evolution and Human Behavior, 32(1), 50-62. doi:10.1016/j.evolhumbehav. 2010.09.002

Barrett, J.L., \& Nyhof, M.A. (2001). Spreading non-natural concepts: The role of intuitive conceptual structures in memory and transmission of cultural materials. Journal of Cognition and Culture, 1(1), 69-100. doi:10.1163/156853701300063589 
Bateson, M., Nettle, D., \& Roberts, G. (2006). Cues of being watched enhance cooperation in a real-world setting. Biology Letters, 2, 412-414. doi:10.1016/S0960-9822(02)00890-4

Binford, L.R. (1968). Post-pleistocene adaptations. In L.R. Binford \& S.R. Binford (Eds.), New perspectives in archaeology (pp. 313-341). Chicago: Aldine.

Bocquet-Appel, J. (2011). The agricultural demographic transition during and after the agriculture inventions. Current anthropology, 52, S497-S510. doi:10.1086/659243

Boyer, P. (2001). Religion explained: The evolutionary origins of religious thought. New York, NY: Basic Books.

Bulbulia, J., \& Sosis, R. (2011). Signaling theory and the evolution of religions. Religion, 41, 363-388. doi:10.1080/0048721X.2011.604508

Carter, T., Grant, S., Kartal, M., Coşkun, A., \& Özkaya, V. (2013). Networks and Neolithisation: Sourcing obsidian from Körtik Tepe (SE Anatolia). Journal of Archaeological Science, 40, 556-569. doi:10.1016/j. jas.2012.08.003

Cauvin, J. (1994). The birth of the gods and the origins of agriculture. Cambridge: Cambridge University Press.

Cauvin, J. (2002). The symbolic foundations of the Neolithic Revolution in the Near East. In J. Cauvin (Ed.), Life in Neolithic farming communities (pp. 235-252). New York, NY: Kluwer Academic.

Childe, V.G. (1971). Origin of agriculture. New York, NY: Natural History Press.

Flannery, K.V., Ucko, P.J., \& Dimbleby, G.W. (1969). Origins and ecological effects of early domestication in Iran and the Near East. In P.J. Ucko \& G.W. Dimbleby (Eds.), The domestication and exploitation of plants and animals (pp. 73-100). New York, NY: Aldine.

Goring-Morris, A.N., \& Belfer-Cohen, A. (2010). 'Great expectations', or, the inevitable collapse of the early Neolithic in the Near East. In M.S. Bandy \& J.R. Fox (Eds.), Becoming villagers. Comparing early village societies (pp. 62-77). Tuscon, AZ: Amerind Studies in Archaeology, University of Arizona Press.

Goring-Morris, A.N., \& Belfer-Cohen, A. (2011). Neolithization processes in the Levant: The outer envelope. Current Anthropology, 52, S195-S208. doi:10.1086/658860

Henrich, J. (2009). The evolution of costly displays, cooperation and religion: Credibility enhancing displays and their implications for cultural evolution. Evolution and Human Behavior, 30, 244-260. doi:10.1016/j. evolhumbehav.2009.03.005

Miller, N. (2011). Reconciling nature and culture after "Naissance des divinites, naissance de l'agriculture". Paléorient, 37(1), 61-74.

Nesbitt, M. (2002). When and where did domesticated cereals first occur in southwest Asia? In R. Cappers \& S. Bottema (Eds.), The dawn of farming in the Near East (pp. 113-132). Berlin: Ex Oriente.

Norenzayan, A. (2013). Big Gods: How religion transformed cooperation and conflict. Princeton, NJ: Princeton University Press.

Norenzayan, A., \& Shariff, A.F. (2008). The origin and evolution of religious prosociality. Science, 322, 58-62. doi:10.1126/science. 1158757

Peters, J., Buitenhuis, H., Grupe, G., Schmidt, K., \& Pöllath, N. (2013). The long and winding road: Ungulate exploitation and domestication in early Neolithic Anatolia (10000-7000 cal BC). In S. Colledge, J. Conolly, K. Dobney, K. Manning, \& S. Shennan (Eds.), The origins and spread of domestic animals in southwest Asia and Europe (pp. 83-114). Walnut Creek, CA: Left Coast Press.

Rappaport, R. (1999). Ritual and religion in the making of humanity. New York, NY: Cambridge University Press.

Richerson, P.J., Boyd, R., \& Bettinger. R.L. (2001). Was agriculture impossible during the Pleistocene but mandatory during the Holocene? A climate change hypothesis. American Antiquity, 66, 387-411. doi: $10.2307 / 2694241$

Shanklin, E. (1985). Sustenance and symbol: Anthropological studies of domesticated animals. Annual Review of Anthropology, 14, 375-403. doi:10.1146/annurev.an.14.100185.002111

Sosis, R. (2003). Why aren't we all Hutterites? Costly signaling theory and religious behavior. Human Nature, 14(2), 91-127. doi:10.1007/s12110-003-1000-6

Sosis, R. (2005). Does religion promote trust? The role of signaling, reputation, and punishment. Interdisciplinary Journal of Research on Religion, 1, 1-30.

Stiner, M.C., Munro, N.D., \& Surovell, T.A. (2000). The tortoise and the hare. Current anthropology, 41(1), 3979. doi: $10.1086 / 300102$

Tanno, K., \& Willcox, G. (2012). Distinguishing wild and domestic wheat and barley spikelets from early Holocene sites in the Near East. Vegetation history and archaeobotany, 21(2), 107-115. doi:10.1007/ s00334-011-0316-0

Twiss, K.C. (2008). Transformations in an early agricultural society: Feasting in the southern Levantine PrePottery Neolithic. Journal of Anthropological Archaeology, 27, 418-442. doi:10.1016/j.jaa.2008.06.002

Vigne, J., Carrère, I., Briois, F., \& Guilaine, J. (2011). The early process of mammal domestication in the Near East: New evidence from the Pre-Neolithic and Pre-Pottery Neolithic in Cyprus. Current Anthropology, 52, S255-S271. doi:10.1086/659306

Whitehouse, H. (2004). Modes of religiosity: Towards a cognitive explanation of the sociopolitical dynamics of religion. Walnut Creek, CA: Altamira Press. 
Whitehouse, H., \& Hodder, I. (2010). Modes of religiosity at Çatalhöyük. In I. Hodder (Ed.), Religion in the emergence of civilization Çatalhöyük as a case study (pp. 122-139). Cambridge: Cambridge University Press.

Wilson, D.S. (2002). Darwin's cathedral. Chicago: Chicago University Press.

Zeder, M.A. (2011). The origins of agriculture in the Near East. Current Anthropology, 52, S221-S235. doi:10.1086/659307

Zeder, M.A., \& Hesse, B. (2000). The initial domestication of goats (Capra hircus) in the Zagros mountains 10,000 years ago. Science, 287, 2254-2257. doi:10.1126/science.287.5461.2254

\title{
Big Gods and the greater good
}

\author{
Hillary L. Lenfesty and Jeffrey P. Schloss* \\ Department of Biology, Westmont College, Santa Barbara, CA, USA
}

\begin{abstract}
Ara Norenzayan's proposal that "prosocial religions, with their Big Gods who watch, intervene, and demand hard-to-fake loyalty displays, facilitated the rise of cooperation in large groups of anonymous strangers" (p. 8) is one of the most plausible and promising general accounts on offer. But the "devil is in the details." And so are the gods. Here we argue that some details of Norenzayan's proposal appear to be internally inconsistent or are (as yet) not to be preferred over alternative accounts in light of available data. We should start by saying - lest we be smitten from above - that our goal is not to win an intellectual contest but to clarify contours of the playing field. Indeed, we ourselves are agnostic on many of the following questions that we raise.
\end{abstract}

\section{Adaptation and the arrow of religious history}

Norenzayan's claim is that moralizing gods are a cultural adaptation that arose in the Holocene and facilitated levels of group cooperation that competitively displaced other religions. We think that this is probably right, but the following questions remain unresolved.

To begin with, it is not completely clear that the historical arrow actually flies in this direction. As Norenzayan acknowledges, current foragers do not necessarily represent religions of the late Pleistocene. Moreover, neither extant forager nor cosmopolitan religions are as divergent as he describes. It is not uniformly the case that forager religions have "no religious morality, no belief in an afterlife - theirs is nothing like the major religions" (p. 8). (Indeed, if dualism is a native cognitive disposition as Bloom (2005, 2007) proposes and Norenzayan endorses, it would be surprising if afterlife beliefs are cultural innovations of the last few millennia. This alone seems to pose a problem for Norenzayan's position.) Nor is it agreed that the gods of large-scale societies were moral deities. Baumard and Boyer (2013) characterize the gods of cosmopolitan Greek, Roman, Mayan, Aztec, Chinese, and Hindu religions as generally uninterested in human morality. And leaving aside the issue of Eastern or classical religious traditions, Semitic textual scholarship would not affirm that "everywhere in the Hebrew Bible... it is asserted that God sees everything" (p. 24). There are many Gods in the Hebrew Bible, commanding allegiance of the henotheistic Hebrew people at different times, not all of whom

*Email: schloss@westmont.edu 
(and early on, arguably none of whom) were omniscient (Noll, 2001; Smith, 2002). Importantly, this is not just an issue of limitations, outliers or variance in empirical data, but it entails an underlying conceptual problem in describing the trajectory of evolutionary change in a complex, socially mediated behavioral trait: avoiding "arbitrary agglomeration" and discerning "the correct topology of description, the natural suture lines along which the phenotype of the individual is to be divided" (Lewontin, Rose, \& Kamin, 1984, p. 247). Religion, even if we avoid its taxonomic reification, is not melanism in pepper moths.

But if one grants, as we are wont to do, that there is a phylogenic trend in religious evolution, questions remain about the cause of that trend. First is the issue of selection versus drift: adaptively salient differential reproduction versus chance fixation or contingent elimination of (usually small) populations. This is actually a very difficult methodological problem in evolutionary biology, even when it comes to simple and experimentally manipulable anatomical phenotypes (Abrams, 2007; Brandon, 2005, 2006; Millstein, 2002, 2008); all the more so when it comes to manifold cultural variants for which we do not have complete histories and which cannot be experimentally controlled at present. There have been thousands of religions, most of which have died out; Mormonism survives from among numerous other religions generated in a period of exuberant innovation; multiple religions are born and die daily; the life expectancy of religious communes is a generation or less (Sosis, 2000); Abrahamic monotheism started out in a small population of nomadic herders and has become the world's dominant religious tradition (but only two of the three variants ascended to this status). All these facts are cited by Norenzayan, and all are amenable to a drift interpretation. Count your lucky stars?

Second, if there is indeed selectively mediated differential reproduction of religious variants, it does not follow that Big Gods are the adaptative driving force. Big Gods may hitchhike on or themselves be an outcome of another adaptive cultural innovation. Of course one prominent option is agriculture, which Norenzayan recognizes as the "conventional wisdom." He cites the example of Big Gods religion in Göbekli as lacking evidence of agriculture, which if confirmed, would "turn on its head" the view that Big Gods arose out of the agricultural transition. But unlike finding a mammal in the Cambrian, a precocious cultural anomaly is not in principle impossible and need not overturn the prevailing paradigm. Another, related option is that the sequence from small foraging bands, to chiefdoms, to large kingdoms was not driven by but rather informed the notion of Big Gods: humans anthropomorphically endowed their gods with the properties that they saw in their own societies, from numerous co-equals, to eminent chiefs, to all-powerful kings. Yet a third option is one of concomitant variability: social organization and religious concepts were jointly facilitated by the emergence of "proportionality based morality" as embodied in some version of the golden rule, and in the conviction that the universe is a cosmos rather than a chaos - that is, that life itself is morally structured so that goodness leads to flourishing and wrongdoing leads to perishing (Baumard \& Boyer, 2013).

To his credit, Norenzayan is clear to "emphasize that we should be careful about interpretations of [these] historical data, which cannot conclusively determine causal direction" (p. 133). Indeed, the transition into large-scale social organization may involve moral monitoring by Big Gods, interacting with other causal factors. But the specific cooperative content of the morality ascribed to such gods - such as the "Great Commandment" - is important, and this morality may exist independently of god beliefs 
in the axial worldviews of cosmopolitan populations." This does not mean that Big Gods merely hitchhiked on other factors. The above options are not mutually exclusive: Big Gods could contribute to adaptive synergism or constitute adaptations in their own right.

This opens up the third question: what is the specific fitness-related challenge to which Big Gods constitute an adaptation? One option is that belief in life-ordering, moral gods is not fundamentally a social but an individual homeostatic adaptation (Paloutzian \& Kirkpatrick, 1995): that is, God may be a surrogate attachment figure (Kirkpatrick, 2005), or a motivation for greater impulse control and reduced future discounting, and so on.

Another option - the one that we favor and that Norenzayan advocates - is that "prosocial religions" are indeed just that: adaptations related to social cooperation. But even here, there are at least two differing accounts of the adaptive salience of moralizing religions (Schloss \& Murray, 2011). Norenzayan acknowledges differences between his own Big Gods proposal and the Supernatural Punishment Hypothesis (Johnson, 2009, 2011; Johnson \& Bering, 2009). But we think that he both under- and overstates the differences. He understates them in claiming that they "both see supernatural punishment as a key driver of human prosociality" (p. 41). Actually, this is not the case. The Big Gods proposal posits religion as a driver of prosociality; the Supernatural Punishment Hypothesis sees religion as being driven by it. In the former case, moralizing gods facilitate cooperation where existing means of social enforcement are inadequate; in the Supernatural Punishment Hypothesis, moralizing gods prevent individuals from suffering the consequences of being punished by peers for defection, where social enforcement is already highly adequate. These are important differences that involve not only alternative assessments of when supernatural punishment arose and how efficacious nonreligious mechanisms of social coordination are, but also the level of selection at work and the contribution of genetic and cultural replicators selected. On the other hand, Norenzayan also somewhat overstates differences between the proposals in claiming that the Supernatural Punishment Hypothesis entails "an innate fear of divine retribution that is a genetic adaptation" (p. 136, original emphasis). Being framed as a "gene only hypothesis" (p. 136) is not a necessary entailment of the Supernatural Punishment Hypothesis. Supernatural punishment could be a cultural innovation, or a culturally influenced modification of native dispositions, that constituted a Pleistocene adaptation to punishment avoidance rather than a Holocene promoter of large-scale cooperation. And even if one construes it as "genetic," since all phenotypes are gene-by-environment interactions, the proposal does not require supernatural punishment beliefs to be universal or invariant. If faced with a choice, we would go with Big Gods. But given recent demonstrations of what appear to be innate cognitive biases toward moralizing gods independent of culturally variable theological attributions (Purzycki, 2013), considerations of theoretical parsimony, and the lability of religious culture over time that may modify the expression of native dispositions, it is not clear that we are faced with a choice.

Finally, if we go all the way with Norenzayan and accept that Big Gods "facilitated the rise of cooperation in large groups of anonymous strangers," there remains the question: what kind and scale of cooperative dilemma did Big Gods (and their costly displays) help solve? One-shot dyadic exchanges between strangers personally encountering one another in the cosmopolitan marketplace? Long-distance exchange across networks of commerce? Very large-scale collective action problems? Norenzayan rightly mentions all of these. But each may favor different interactive strategies, and each entails distinctive nonreligious solutions to the risks of defection: 
- Theoretical proposals for dyadic exchanges suggest (Frank, 1988; Schloss, 2008) and empirical studies demonstrate (Brown, Palameta, \& Moore, 2003; Sylwester, Lyons, Buchanan, Nettle, \& Roberts, 2012) that nonreligious, hard-to-fake nonverbal cues can reliably signal commitment to strangers.

- Trading networks may be facilitated by $2^{\circ}$ or higher-order indirect reciprocity along with the social norms and cognitive/affective systems for managing moral reputation (Alexander, 1987). Interestingly, the motivational salience of feeling "guilt" is mentioned just once in Big Gods; "shame" and "conscience" not at all.

- Many large-scale collective endeavors - Norenzayan cites Hume's (1888) account of a 1000-person project - require a sophisticated social infrastructure for coordination. Once that exists, it may also serve a policing function. It is not clear that Big Gods can facilitate such collective action in the absence of social hierarchy; and in the presence of organizing social structures, it is not entirely clear that Big Gods are necessary.

None of this means that the Big Gods model does not supplement the above nonreligious mechanisms. Indeed, we think that it does. And the Big Gods hypothesis is not only made plausible by, but also provides a unifying account of data from an impressive range of anthropological field studies and human subjects experiments cited by Norenzayan. The remaining fine-grained questions involve the extent to which Big Gods are necessities for or merely enhancements to the expansion of social cooperativity, and whether their function is primarily one of social control through ritualized reminders of and belief in supernatural punishment. To this we now turn our attention.

\section{Divine surveillance and punishment}

Two of Norenzayan's key principles are "watched people are nice people" and "hell is stronger than heaven" (p. xiii). Given the overwhelming abundance of supporting empirical data, it is virtually mandatory to endorse some version of these principles. But we think that they are too simple and too general. It might be more accurate to say "watched people are more likely to be as nice as they have to be," and "hell is stronger than heaven... in constraining some kinds of social decisions." Importantly, we question Norenzayan's conclusion that when it comes to evolutionary accounts of Big Gods religion or large-scale cooperation, "the action is in the fear of supernatural punishment" (p. 45).

\section{Surveillance}

That monitored individuals are less likely to defect is beyond question. But there are two problems with distilling this well-documented observation to "watched people are nice." First is the issue of colinearity. Most studies reporting this phenomenon - including subliminal or consciously visible eyes, tales of ghosts or invisible princesses, religious word-primes, and comparing behaviors on church versus non-church days - do not actually assess the sense of being monitored, and the few that do, do not assess the (likely-to-be-related) sense of being connected to the other. Both of these stand to influence prosociality.

Norenzayan argues against an ideomotor effect of priming, or being motivated to act more lovingly because one is presented with the idea of a loving god. He supports this 
with the observation that "many nonbelievers are immune to religious priming" (p. 45). However, in other places he maintains that the effects of religious priming are almost invariably insensitive to religious commitment. What is the appropriate characterization of the literature, and how many atheists who are unresponsive to priming would it take to unscrew the ideomotor light bulb? Whatever the answer, we would maintain that provoking a sense of "connection" is not an ideomotor effect due to being primed with the idea of a personal attribute anyway. Rather, it may be due to an experience of connectedness (as some religious and other group rituals may provide; Konvalinka et al., 2011), or to the ability of some religious or nonreligious social cues to provoke empathy or theory of mind (Pichon, Boccato, \& Saroglou, 2007).

The second question regarding the impact of surveillance involves the distinction between making people "nice" and merely making them less likely to violate prevailing behavioral norms. As Norenzayan notes, some norms have little to do with cooperation, such as proscriptions against pornography, which are less frequently violated on church days (Edelman, 2009). Other norms may actually subvert cooperation and in this sense are dubbed "antisocial"" (Herrmann, Thoni, \& Gachter, 2008).

Thus, being "nice" (a saccharine term in the most significant moral contexts) may involve violating social norms in a variety of cultural settings, as in the case of the Underground Railroad or Holocaust rescuers. The relationship between the varied elaborations of Big Gods religions and the deepest manifestations of "prosociality," compassionate sacrifice, or cooperative exchange with strangers is complicated. On the one hand, Big Gods religions (although not religions exclusively) share an affirmation of golden-rule morality (Baumard \& Boyer, 2013). They also provide a fulcrum to resist socially authorized deviations from that morality: "as Thomas More famously affirmed, 'I am the King's good servant, but God's first." Moreover, there are manifold but interpretively disputed correlations of religious commitment with planned versus spontaneous, sustained rather than one time, and private rather than public giving (Myers, 2012). On the other hand, there is little evidence that the most radical or even consistent implementations of cooperative morality are related to religious cues of being watched, but rather to an enduring sense of being connected. ${ }^{2}$ The most extensive studies of Holocaust rescuers, for example, indicate that sustained risk on behalf of others (in contrast to one-shot instances of guards allowing prisoners to escape) was weakly correlated to religious commitment or setting, but strongly related to an abiding "perception of shared humanity" (Monroe, 1996; Oliner, 1992).

Norenzayan cites a fascinating study by Zhong, Bohns, and Gino (2010) that demonstrates that people cheat more when provided with a sense of being anonymously cloaked. The paper begins with a quote from Emerson (1860): "As gaslight is the best nocturnal police, so the universe protects itself by pitiless publicity." But Emerson does not stop there. He goes on to explore the interplay between and transition from being monitored to being connected:

\footnotetext{
There was never a man born so wise or good, but one or more companions came into the world with him, who delight in his faculty, and report it. I cannot see without awe, that no man thinks alone, and no man acts alone, but the divine assessors who came up with him into life, - now under one disguise, now under another, - like a police in citizens' clothes, walk with him, step for step, through all the kingdom of time... We have another sight, and a new standard; an insight which disregards what is done for the eye, and pierces to the doer 1860 , pp. 140-141.
} 


\section{Reward versus punishment}

Here we will just briefly mention both an affirmation and a reservation comparable to what we have said above. Empirical findings and theoretical considerations leave little question that the specter of supernatural punishment is efficacious in constraining certain kinds of norm violations. An omniscient, incorruptible, morally concerned deity who does not have to be paid (at least for monitoring activities) is an economical solution to the 20 defection and detection challenges endemic to all policing systems (Schloss \& Murray, 2011).

But it is not clearly the case that hell is "stronger" than heaven. Punishment may deter people from being mean to each other; but whether it can motivate them towards genuine care for each other is not the same issue. It may be that hell restrains and heaven sustains. ${ }^{3}$ Indeed, the most notable manifestations of religious prosociality - vows of poverty for the sake of charity, celibate orders of service, widespread commitment to nonviolence, egalitarian movements, and ministries of reconciliation - do not show evidence of being motivated by the fear of punishment for failing to seek a supererogatory level of moral attainment. It is, rather, a sense of invitation to the good: Martin Luther King's "Dream," Mother Theresa's "call within a call," Dag Hammarskjöld's "enduring yes," and the widely shared sense of an "absorbing errand." Our goal here is not to settle science by schmaltz, but rather to avoid prematurely capping inquiry into the wellspring of human virtue.

\section{Atheist mistrust}

Norenzayan proposes that belief in a watchful, morally interested deity who punishes wrongdoers promotes prosocial behavior because, at the very least, it inhibits antisocial behavior. However, atheists are perceived to pose a special threat to cooperative groups, Norenzayan claims, because they are assumed to lack an inhibition toward moral transgression since they do not believe that reality is so constituted as to punish wrongdoing. Emerson again: "Skepticism is unbelief in cause and effect... the police and sincerity of the Universe are secured by God's delegating his divinity to every particle." (1860, pp. 140-141).

Explaining widespread distrust of atheists must begin with the question: where do expectations about others' behaviors come from? Behavioral inferences about other people could certainly arise from the second-order theory of mind reasoning process that Norenzayan proposes. That is, distrust may result from one's belief about another's belief (or rather, disbelief) in the intentions of a supernatural agent. However, there are equally plausible and less cognitively demanding ways of accounting for atheist distrust. These include: (1) psychological essentialism as a cognitive process for attributing particular internal motivations and dispositions to members of a social category, which explain (past-looking) and create expectations (forward-looking) about their behavior; and (2) the process of dehumanization.

Psychological essentialism is a developmentally early-emerging and culturally ubiquitous psychological process that seems to motivate and underlie stereotyping (Gelman, 2003). One of the first psychological studies to investigate the question of atheism as a social stereotype was recently conducted by Wright and Nichols (2014) who found that both Christian and atheist participants' moral appraisals of atheists were more negative than those of Christians who performed the same moral and immoral actions. In addition, participants also reported moral behavior as more consistent for Christians and 
immoral behavior as more consistent for atheists. One could expect that the same stereotype underlying moral appraisals of past actions of atheists (and Christians) would generate expectations about future behavior of atheists. But the question remains: from where does this atheist stereotype originate? Does it arise from the belief that atheists do not believe in a deity who will punish them, or does it arise from attributing essence of general moral depravity to this social group? If and where we find cultures that essentialize the moral capabilities of groups of persons, then distrust of those persons would not depend on a belief about that person's disbelief in a punishing god.

Theory-of-mind reasoning processes may actually explain distrust of atheists, but not exactly as Norenzayan describes. Deep skepticism of atheists could arise simply from the fact that they do not believe in a supernatural mind, which serves as an indication of their (presumed deficient) abilities to reason about the minds of conspecifics. Individuals or groups who lack fundamental social-cognitive capacities such as mentalizing abilities would carry low social utility or impose a threat. Furthermore, atheist minds - not unlike psychopaths - could be perceived to lack certain mentalizing capacities but not others; for example, they may be able to deceive but unable to empathize or have remorse. These kinds of minds are anti-, not prosocial.

A complementary explanation here is that atheists are distrusted because they are dehumanized. According to Haslam's (2006) psychological model, dehumanization involves either: (1) the denial of characteristics to persons that are uniquely human, such as a moral sensibility; and (2) the denial of characteristics to persons that constitute human nature, including emotional responsiveness and interpersonal warmth. The former "animalistic" form of dehumanization results in representations of persons as animal-like, while the latter "mechanistic" form results in representations of persons as objects or automata. The dehumanization of atheists in either form could result in notions of atheists as being unresponsive to the "other." Distrust of atheists therefore arises from lack of confidence in their basic human social capacities alongside a perceived disconnect to fundamental human intuitions. The fact that this commentary was written collaboratively by an atheist and theist indicates that such distrust is not unbreachable.

\section{Funding}

This work was funded by John Templeton Foundation [grant number 15371].

\section{Notes}

1. But to the extent that those who evidence cooperative behavior violate prevailing norms, their prosocial behavior is considered antisocial. In describing behavioral phenotypes, the terms "antisocial" and "prosocial" are even more ambiguous than the varied employments of "cooperation" and "altruism," to the point of being nearly forlorn.

2. Indeed, the effects of being monitored under some circumstances may be short-lived, (Sparks \& Barclay, 2013).

3. Norenzayan himself judiciously makes this point elsewhere: "Punitive deities may be more effective at keeping anonymous strangers from cheating each other, whereas rewarding deities may be more effective at encouraging more trust and cooperation within groups of people who interact recurrently" (Shariff \& Norenzayan, 2011, p. 94). However, the trust-building effect of Big Gods would not have to be restricted to iterative interactions if cooperation in one-shot anonymous exchanges cultivated internalized signals of commitment with downstream benefits when engaging others (Frank, 1988). 


\section{References}

Abrams, M. (2007). How do natural selection and random drift interact? Philosophy of Science, 74, 666-679. doi: $10.1086 / 525612$

Alexander, R.D. (1987). The biology of moral systems. New Brunswick: Transaction Books.

Baumard, N., \& Boyer, P. (2013). Explaining moral religions. Trends in Cognitive Sciences, 17, 272-280. doi:10.1016/j.tics.2013.04.003

Bloom, P. (2005). Descartes' baby: How the science of child development explains what makes us human. New York, NY: Random House.

Bloom, P. (2007). Religion is natural. Developmental Science, 10(1), 147-151. doi:10.1111/j.1467-7687.2007. 00577.x

Brandon, R.N. (2005). The difference between selection and drift: A reply to Millstein. Biology and Philosophy, 20, 153-170. doi:10.1007/s10539-004-1070-9

Brandon, R.N. (2006). The principle of drift: Biology's first law. The Journal of Philosophy, 103, 319-335.

Brown, W.M., Palameta, B., \& Moore, C. (2003). Are there nonverbal cues to commitment? An exploratory study using the zero-acquaintance video presentation paradigm. Evolutionary Psychology: An International Journal of Evolutionary Approaches to Psychology and Behavior, 1, 42-69.

Carter, E.C., McCullough, M.E., Kim-Spoon, J., Corrales, C., \& Blake, A. (2012). Religious people discount the future less. Evolution and Human Behavior, 33, 224-231. doi:10.1016/j.evolhumbehav.2011.09.006

Edelman, B. (2009). Markets: Red light states: Who buys online adult entertainment? Journal of Economic Perspectives, 23, 209-220. doi:10.1257/jep.23.1.209

Emerson, R.W. (1860). Worship. In R.W. Emerson (Ed.), The conduct of life (pp. 191-230). Cambridge, MA: Riverside Press.

Frank, R.H. (1988). Passions within reason: The strategic role of the emotions. New York, NY: WW Norton.

Gelman, S. (2003). The essential child: Origins of essentialism in everyday thought. New York, NY: Oxford University Press.

Haslam, N. (2006). Dehumanization: An integrative review. Personality and Social Psychology Review, 10, 252-264. doi:10.1207/s15327957pspr1003 4

Herrmann, B., Thoni, C., \& Gachter, S. (2008). Antisocial punishment across societies. Science, 319, 1362-1367. doi:10.1126/science. 1153808

Hume, D. (1888). A treatise of human nature. Oxford, UK: Clarendon Press.

Johnson, D.D.P. (2009). The error of God: Error management theory, religion, and the evolution of cooperation. In Games, groups, and the global good (pp. 169-180). Berlin and Heidelberg: Springer.

Johnson, D.D.P. (2011). Why God is the best punisher. Religion, Brain \& Behavior, 1(1), 77-84. doi:10.1080/ 2153599X.2011.558714

Johnson, D.D.P., \& Bering, J. (2009). Hand of God, mind of man. In J.P. Schloss \& M.J. Murray (Eds.), The believing primate: Scientific, philosophical, and theological perspectives on the origin of religion (pp. 26-44). Oxford: Oxford University Press.

Kirkpatrick, L.A. (2005). Attachment, evolution, and the psychology of religion. New York, NY: Guilford Press.

Konvalinka, I., Xygalatas, D., Bulbulia, J., Schjodt, U., Jegindo, E.-M., Wallot, S., ... \& Roepstorff, A. (2011). Synchronized arousal between performers and related spectators in a fire-walking ritual. Proceedings of the National Academy of Sciences, 108, 8514-8519. doi:10.1073/pnas.1016955108

Lewontin, R.C., Rose, S.P.R., \& Kamin, L.J. (1984). Not in our genes: Biology, ideology, and human nature (p. 24). New York, NY: Pantheon books.

Millstein, R.L. (2002). Are random drift and natural selection conceptually distinct? Biology and Philosophy, 17(1), 33-53. doi:10.1023/A:1012990800358

Millstein, R.L. (2008). Distinguishing drift and selection empirically: "The great snail debate" of the 1950s. Journal of the History of Biology, 41, 339-367. doi:10.1007/s10739-007-9145-5

Monroe, K.R. (1996). The heart of altruism: Perceptions of a common humanity. Princeton, NJ: Princeton University Press.

Myers, D.G. (2012). Reflections on religious belief and prosociality: Comment on Galen. Psychological Bulletin, 138, 93. doi:10.1037/a0029009

Noll, K.L. (2001). Canaan and Israel in antiquity: An introduction (Vol. 83). London: Continuum International Publishing Group.

Oliner, S.P. (1992). Altruistic personality: Rescuers of Jews in Nazi Europe. New York, NY: Simon and Schuster.

Paloutzian, R.F., \& Kirkpatrick, L.A. (1995). Introduction: The scope of religious influences on personal and societal well-being. Journal of Social Issues, 51(2), 1-11. doi:10.1111/j.1540-4560.1995.tb01320.x

Pichon, I., Boccato, G., \& Saroglou, V. (2007). Nonconscious influences of religion on prosociality: A priming study. European Journal of Social Psychology, 37, 1032-1045. doi:10.1002/ejsp.416

Purzycki, B.G. (2013). The minds of gods: A comparative study of supernatural agency. Cognition, 129, 163-179. doi:10.1016/j.cognition.2013.06.010

Schloss, J. (2008). He who laughs best: Involuntary religious affect as a solution to recursive cooperative defection. In J. Bulbulia, R. Sosis, C. Genet, R. Genet, E. Harris, \& K. Wyman (Eds.), The evolution of religion: Studies, theories, and critiques (pp. 197-207). Santa Margarita, CA: Collins Foundation Press. 
Schloss, J.P., \& Murray, M.J. (2011). Evolutionary accounts of belief in supernatural punishment: A critical review. Religion, Brain \& Behavior, 1(1), 46-99. doi:10.1080/2153599X.2011.558707

Shariff, A.F., \& Norenzayan, A. (2011). Mean gods make good people: Different views of God predict cheating behavior. The International Journal for the Psychology of Religion, 21(2), 85-96. doi:10.1080/ 10508619.2011.556990

Smith, M.S. (2002). The early history of God: Yahweh and the other deities in ancient Israel. Grand Rapids: Wm. B. Eerdmans Publishing.

Sosis, R. (2000). Religion and intragroup cooperation: Preliminary results of a comparative analysis of utopian communities. Cross-Cultural Research, 34(1), 70-87. doi:10.1177/106939710003400105

Sparks, A., \& Barclay, P. 2013. Eye images increase generosity, but not for long: The limited effect of a false cue. Evolution and Human Behavior, 34, 317-322. doi:10.1016/j.evolhumbehav.2013.05.001

Sylwester, K., Lyons, M., Buchanan, C., Nettle, D., \& Roberts, G. (2012). The role of theory of mind in assessing cooperative intentions. Personality and Individual Differences, 52(2), 113-117. doi:10.1016/j. paid.2011.09.005

Wright, J.C., \& Nichols, R. (2014). How perceived religiosity influences moral appraisal: The social cost of atheism. Journal of Cognition and Culture, 14, 115-137.

Zhong, C.-B., Bohns, V.K., \& Gino, F. (2010). Good lamps are the best police: Darkness increases dishonesty and self-interested behavior. Psychological Science, 21, 311-314. doi:10.1177/0956797609360754

\title{
Products of cultural evolution are baroque and hard to analyze
}

\author{
Lesley Newson* \\ School of Psychology, University of Exeter, Exeter, UK
}

Humans often behave irrationally and destructively and a fair proportion of such behavior is motivated or justified by religious belief. Ara Norenzayan grew up in Lebanon in the 1980s and so has had considerable personal experience of negative consequences of religious behavior. After immigrating to the West, he began to study psychology and was disappointed that psychologists had not devoted more effort to understanding religious behavior. He sees "religion" to be a family resemblance construct rather than a natural kind. We may know religious behavior when we see it but it is nevertheless a very large and diverse family of behaviors. This diversity may be one explanation for psychologists' reluctance to try to come to grips with it. Every sub-discipline of psychology could potentially contribute to the study of religion but the insight gained by approaching the topic with one group of theories and methods might be considered so incomplete that it would not be worth the effort. Norenzayan believes the topic to be too important not to tackle. He developed an idea about the possibility of a relationship between belief in "Big Gods" and the ability to maintain big societies and set out to test it.

When a graduate student in the 1990s, Norenzayan was "captivated" by Boyer's (1994) book The Naturalness of Religious Ideas and he followed the subsequent work of other behavioral scientists taking an evolutionary approach to religion. The evolutionary process that equipped our species with a mind that supports complex societies also supports religion. The idea that religious behavior is a "cognitive byproduct" of our social abilities is compelling. It is incomplete, however, for two reasons. First, it does not begin to explain the vast diversity of religious behavior. Our evolved genes may help explain why humans sometimes find it easier to believe information that is improbable rather than information that is supported by evidence. But humans believe a vast range of

*Email: lgnewson@ucdavis.edu 
different bits of improbable information. Why does any given individual believe some bits and not others? And why are there patterns to this diversity? The answers cannot lie in our genes because there is not enough genetic diversity in the human population to account for the vast diversity seen in religious behavior. Humans are actually very similar genetically. Second, the cognitive byproduct explanation cannot account for the extent to which individuals suffer handicap or setback as a consequence of their religious behavior. It is not uncommon for humans to suffer the ultimate biological setback when participating in religious conflict. If religious behavior were not bringing some benefits to balance these costs, natural selection would surely have favored the genes of individuals who were less religiously inclined. Skeptics would have enjoyed greater "fitness."

Norenzayan assumes that readers will consult the literature that he cites if they want to examine arguments about basic evolutionary theory, read about how selection on genes compares with selection on cultural traits, and learn the conditions under which selection between groups can play an important role in evolution. He concentrates instead on explaining how and why a "cultural evolutionary" approach provides a useful way of investigating the complex question posed by religion and on providing examples to support his arguments. He argues that behaviors that we categorize as "religious" are common because, although they are often costly to the individual, they benefit the group to which the individual belongs by encouraging cooperation among group members. Individual group members may not behave competitively but their group competes successfully against groups with less cooperative members. As a result, the cooperative group members enjoy a net benefit. They and/or their relatives produce more offspring and perhaps recruit members from other groups who adopt their kindly ways.

This is not a new idea and its essence was stated by Charles Darwin (1874) in his book The Descent of Man, but Norenzayan's work to develop and test evolutionary models of religion is a valuable contribution. For this book he has gathered together the results of his own work and findings of scholars from many disciplines outside psychology (such as history, anthropology, and economics) to argue a central idea. He sees the package of religious traits shared by any population as continuously evolving, but if certain of the traits increase the effectiveness of cooperation, then these traits will coalesce in populations as the moral circle expands and a larger group of people feel that they can trust one another. To develop into a big complex society, he argues, it helps if your culture includes belief in a Big God. This cultural evolutionary argument is not to be confused with "evolutionary" theories of human behavior, which consider the role of the evolved genes. There is no suggestion of a "Big God" gene. The religious traits being considered here are cultural traits, not genetic traits. Our genetic traits are with us for our whole lives. Our religious traits are much more labile.

The book discusses a wide range of cultural traits and behaviors. For example, it recounts the research that has shown that in some populations individuals who receive a slight hint that they are being watched are more inclined to behave in a prosocial way. Some populations of religious people are more inclined to behave prosocially after being reminded that an omniscient God is watching over them. Another way of promoting prosocial behavior is more physical. It has been found in a number of populations that people are more likely to cooperate on economic games after performing a set of behaviors in unison. When some populations of religious people gather, they spend a great deal of time performing a number of rituals in unison. Such cooperation-promoting behaviors are more likely to be seen in populations that enjoy the benefits of cooperation and coordination on a wide scale. Thus, we observe patterns consistent with the suggestion that the populations who best managed to 
sustain cooperation on a large scale are the ones whose religious customs obliged them to include more behaviors that encourage prosociality, such as a belief in a "Big God."

This finding does not require us to believe that useful religious customs were cynically invented by meddling clerics any more than it requires us to believe that they were inspired by an omniscient Big God. Cultural evolution can explain the effectiveness of these traits. Customs and beliefs were handed down the generations with many handovers per generation. With each handover, changes were introduced. Sometimes the change was the result of careful thought, sometimes it happened by accident or through laziness. A new variant may have been found that most people just felt better about. The collection of behaviors being handed down at any one moment in a population is limited to the ones that at least one member of the population thinks is worthwhile. Culture is an inheritance system analogous to the genetic inheritance system. Just as genetic traits compete through the birth and death of the living things that carry them, cultural traits compete in the "marketplace of ideas" as some individuals get listened to more than others, some cultural variants get remembered better than others, and some culturally defined and culturally different groups do better than others.

I found this book interesting and useful and a good read, but I am such a strong believer in the usefulness of cultural evolutionary approaches that I worry about my fitness to judge the book. It may be that some people who are just being introduced to cultural evolutionary approaches will find it less convincing. Religions, like everything cultural, have the characteristics of an evolved system, which means that they do not lend themselves easily to analyses that everyone will find convincing. Norenzayan is proposing a simple explanatory model of a complex thing. If this thing had been designed by a human or human-like engineer, there would be a "right" model that we could search for the model or idea that the designer had started with. But when the thing being studied is the product of evolution, there is no idea behind it and so there is no right model. There are likely to be many models that could help us understand it, some more useful than others.

Products of evolution can look as though they were designed, at least to modern people. We might see them as analogous to one of the many complex and ingenious devices that we use. Closer study of an evolved system, however, reveals many whimsical flourishes, unexpected elegance, and clumsy mistakes. There may be ingenuity to an evolved system but it is not the work of a human genius. Consider the eye, for example. We might "explain" the eye simply as the device for collecting, focusing, and detecting light that allows the brain to perceive images of its surroundings. This is a useful verbal model of the eye but it is far from perfect. It does not explain the large variation in eye performance among individuals and species. Why are there fish with nonfunctioning eyes living in complete darkness? Our model also neglects to mention the other roles that the eye plays. I can immediately think of two others: (1) the eyes are the source of information about light levels used to set an animal's biological clock each day; and (2) eyes are used by many animals, including humans, to signal emotion. And our simple model also fails to explain exceptions to the use of the eye. Why do some animals detect sonar instead of light in order to visualize their environment?

If religion is an evolved system, we should expect the same sorts of difficulties in definition and explanation as we do with an evolved biological system like the eye. To design the experiments reported in this book, Norenzayan and his colleagues obviously struggled with such difficulties. The nature of many experimental methods demands the creation of false dichotomies and distorted categories. "Cooperation" is compared to "defection"; "atheist" experimental subjects are compared to "religious" ones; "smallscale" societies are compared with "modern" ones. Subjects are given small experiences 
designed to "prime" them to see how their behavior is affected. Inevitably, each prime will affect each subject slightly differently but the experiments are only designed to detect certain responses. I can imagine some readers of this book howling at the simplicity of the interpretations made and models proposed. Anyone with a broad knowledge of religion can likely suggest several glaringly obvious counter-examples that show the model to be wrong. Such criticism is valid, of course, but as statisticians George Box and Norman Draper (1987, p. 74) said: "Remember that all models are wrong; the practical question is how wrong do they have to be to not be useful."

The "Big Gods" model is useful and the publication of this book will make it more useful still if it stimulates scholars to contribute research and insight to developing the model or creating new competing models. This is not criticism but encouragement. I am sure that Norenzayan will agree with me that more research needs to be performed that has non-Westerners as subjects. The reliance on data from experiments performed on people from one country, the USA, is too great. As he himself points out, the religiosity of the USA makes it an outlier among Western countries. I also would recommend more attention to research on how children pick up information. A great deal of religious information is transmitted from older people to children. How does that influence the nature of the message?

Finally, I would advise taking a closer look at the change from small- to large-scale societies. The net effect of the last 5000 years has been an increase in the size of societies and an increase in the size of their gods. But the evolution has not been smooth. The moral circle has expanded in fits and starts, with nearly as many contractions as expansions (Shennan et al., 2013). At the same time, religious behavior has been far from static or easily defined. In populations defined as "Christian," magic was practiced, witches were tortured, and heretics burned (Thomas, 1971). The timing and links between these variations can provide information that will further test the model.

It seems likely that the social lives of most Europeans in the seventeenth century would not have been much different from those of early Holocene horticulturalists. Although medieval and early modern Europeans benefited from technology shared with a much larger population, most of them spent their lives in small isolated communities seeing the same people day after day (Anderson, 1991; Watkins, 1991). People would seldom have been called upon to cooperate with strangers. It was only with the beginning of the Industrial Revolution that large masses of people began to leave their natal villages and hamlets and migrate to join larger populations seeking employment. This transition to modernity must have been a time when the need for cultural tools to encourage cooperation was acute. The Big Gods model predicts that this time will coincide with a rise in participation in organized "Big Gods" religion. Historical accounts provide evidence that this was the case. It was, for example, a time when church attendance in the USA and Britain rapidly increased (Chadwick, 1966; Finke \& Stark, 2005). Do similar changes in religious behaviors occur in other populations when they are rapidly urbanizing, such as in the Middle East today? Today's American population may be more religious than the population of other Western countries because it includes more recent immigrants and more of its immigrants are from small villages that have not evolved the cultural tools for cooperation among strangers (Newson \& Richerson, 2014).

\section{References}

Anderson, B. (1991). Imagined communities: Reflections on the origin and spread of nationalism (Rev. and extended ed.). London: Verso. 
Box, G.E., \& Draper, N.R. (1987). Empirical model-building and response surfaces. Hoboken, NJ: John Wiley \& Sons.

Boyer, P. (1994). The naturalness of religious ideas: A cognitive theory of religion. Berkeley: University of California Press.

Chadwick, O. (1966). The Victorian Church. London: A \& C Black.

Darwin, C. (1874). The descent of man and selection in relation to sex (2nd ed.). New York, NY: American Home Library.

Finke, R., \& Stark, R. (2005). The churching of America, 1776-2005: Winners and losers in our religious economy. New Brunswick, NJ: Rutgers University Press.

Newson, L., \& Richerson, P.J. (2014). Religion: The dynamics of cultural adaptations. In F. Watts \& L. Turner (Eds.), Evolution, religion, and cognitive science (pp. 192-218). Oxford: Oxford University Press.

Shennan, S., Downey, S.S., Timpson, A., Edinborough, K., Colledge, S., Kerig, T., ... Thomas, M.G. (2013). Regional population collapse followed initial agriculture booms in mid-Holocene Europe. Nature communications, 4. doi:10.1038/ncomms3486

Thomas, K. (1971). Religion and the decline of magic. Oxford: Weidenfeld \& Nicholson.

Watkins, S.C. (1991). From provinces into nations: Demographic integration in Western Europe, 1870-1960. Princeton, NJ: Princeton University Press.

\title{
Big Gods: religion in the beginning
}

\author{
Hervey C. Peoples* and Frank W. Marlowe \\ Department of Archaeology and Anthropology, University of Cambridge, Cambridge, UK
}

Ara Norenzayan's Big Gods (2013) is an engaging synthesis of history, experimental research, and theory that seeks to explain the emergence and role of morally punishing gods in the growth of human society. Much of that answer is based on the author's research into the psychology of social dynamics, and a general premise that "Religious beliefs and rituals arose as an evolutionary by-product of ordinary cognitive functions that preceded religion" (p. 8).

Norenzayan's approach to the "puzzle" (p. 3) of prosocial religions is no less bold as he links their success in promoting cooperation and stabilized growth of society to the belief in morally supportive deities who are active in human affairs. Big Gods describes the psychological and social effects that historically have buttressed institutionalized belief in gods whose omniscient policing of human behavior carries with it the threat of supernatural punishment. Norenzayan's Big Gods vary in power and level of interest in human affairs, and appear to be similar in concept to the creator deities termed "High Gods" by Guy Swanson (1960) in his classic work Birth of the Gods.

Until the advent of agriculture, all humans foraged for wild food by hunting, gathering, and fishing. Norenzayan points out that the religions of today's forager societies, like that of the Hadza of Tanzania, are often hard to define, consisting only of a simple cosmology and possibly the concept of a creator being (Marlowe, 2010). In other forager groups there may be many gods and spirits, but generally a striking absence of Big Gods who take an active interest in human affairs (pp. 121-123).

As I emphasized in chapter 1, we now live in a world where the vast majority of human beings are the cultural descendents of Big Gods. If modern hunter-gatherer groups clue us to the ancestral conditions, even in a limited and oblique fashion, then we can conclude that these beliefs started as rare forms of cultural beliefs. If so, then how did we get here from

*Corresponding author. Email: hervey@humanquestion.com 
there? What role did this cultural change play in the growth and stabilization of large-scale cooperation? (p. 123)

Norenzayan suggests that the answer to these questions can be found in his "seventh principal of supernatural monitoring" (p. 124): Big Gods for Big Groups. This list describes specific changes in the character of religion as small societies scaled up to become very large and complex. As religion evolved it incorporated more Big Gods, more direct connections between religion and morality, more highly structured worship and demanding ritual, and an increase in the power and reach of supernatural monitoring of human activities. These are certainly the results of religious evolution, but what were the socio-ecological dynamics driving them? What were the characteristics of Big Gods that ensured that they would be culturally accepted and maintained? In answer to these basic questions of emergent dynamics of Big Gods, we would like to fill in the "puzzle" by adding the point of view of individual selection to Norenzayan's otherwise comprehensive and powerful discussion. We ask: "What could have prompted individuals of our highly successful species to obey unseen beings who told them what they should and should not do?"

Norenzayan suggests several conditions that prompted humans to accept the watchful presence and moral meddling of unseen beings. These include an increase in anonymous crime and violence in larger groups, enhanced threat of free-riding, intensified competition for resources, and the related issues of a host of collective-action problems. The presence of Big Gods has also been shown to be positively correlated with the number of levels of jurisdictional hierarchy, population size, keeping of herd animals, and scarcity of water resources. We would add to that list the archaeological evidence for a cause/effect relationship between economic determinants and emergence of religion uncovered at dozens of Neolithic sites in the Near East. There the timing of the appearance of utilitarian grave goods related to economic surplus consistently precedes evidence for animal sacrifice or goods related to wealth and social complexity (Fuller \& Grandjean, 2001; Rodrigue, 1992). This suggests that changes in subsistence economy may have preceded and shaped many Neolithic social institutions, including religion.

Despite recurring themes in the literature associating the presence of Big Gods with broad measures of economic and social complexity, few attempts have been made to clarify competing explanations, or to suggest a causal direction through which Big Gods evolved. How did a rare concept among ancestral human foragers evolve culturally "from there to here" (p. 124) and become nearly universal among today's large, complex societies?

In order to paint a clearer picture of the selective forces at work in the evolution of religion and morally supportive gods, we focused on social evolution that begins with mode of subsistence (Peoples \& Marlowe, 2012). We take a dynamic view of subsistence by comparing and contrasting specific ecological criteria, population stresses, and social structures that distinguish among the four modes of subsistence: foragers, pastoralists, horticulturalists, and intensive agriculturalists. These modes have been linked to other findings regarding the evolution of social norms and institutions (Borgerhoff Mulder et al., 2009; Henrich et al., 2010). What circumstances could have triggered a belief in gods that affect the lives of humans, or one all-powerful god of morality? What characteristics of High Gods ensured that they would be culturally sustained?

We propose that religious behavior is linked to individual selection operationalized by specific ecological factors and population stresses. The result would be enhanced individual reproductive success, increased group strength through population growth, 
and success in competition with others for resources. The relationship between Big Gods and the subsistence technology of a society is mediated by the dynamics of natural selection and cultural evolution.

In a recent cross-cultural study we measured the differential effect of subsistence mode, total population, and social stratification on the presence and nature of Swanson's "High Gods" among the 186 societies in the Standard Cross-Cultural Sample (Murdock \& White, 1980). We investigated which of those factors best explain where societies sit along a continuum from no High God (absent) to a High God present but inactive in human affairs, to a High God that is active in human affairs and may or may not be morally punishing. We made and confirmed three predictions.

First, the presence and activity of High Gods will generally increase on a continuum of increasing productivity from foragers to horticulturalists to intensive agriculturalists, with pastoralists occupying a unique position among the four subsistence modes owing to their moveable but defendable resource base and heightened mobility.

Subsistence activities occurring in different environments, using different technologies, would benefit differentially from the presence of a High God who encouraged cooperation and moral constraint. For example, simple foragers are mostly egalitarian and live in small, mobile groups of individuals who are usually capable of acquiring food for themselves using simple technologies. When disputes arise, they are solved by individuals moving from one camp to another, making social-action problems less of an issue among foragers. Simple foragers would be the least likely to accept or benefit from the personal constraints of High Gods. It is mainly among foragers that High Gods are absent, or are inactive if present at all. In our sample, a High God was absent among $58 \%$ of forager societies, and $88 \%$ had either no High God or one that was inactive.

In contrast, horticulturalists, agriculturalists, and complex foragers vary in degree of stratification. Some groups would have no leaders and no moral gods, while others might have both moral High Gods and leaders who could use the threat of supernatural punishment to solve collective-action problems (Atkinson \& Bourrat, 2011; Johnson, 2005; Sosis, 2000). As plant domestication brings with it increased food production, higher fertility, and larger populations, horticulturalists and intensive agriculturalists encounter new problems of collective action not faced by foragers. Horticulturalists often combine cultivation with some foraging, and are close to foragers on the productivity continuum, but less mobile. Increased food production among horticulturalists leads to larger villages as well as the related social problems (crime, disease) that reduced mobility exacerbates. Beginnings of stratification appear among horticulturalists (and some complex foragers) in the form of entrepreneurial community leaders ("big men") who begin to establish conventions that institutionalize social controls (Johnson \& Earle, 2000). The result would have been increased group cohesion leading to larger populations, greater stratification, and greater cooperative success when competing against other groups for resources. These leaders would gain personal power and enhanced reproductive success from their association with High Gods. In our sample, a High God was absent among $48 \%$ of horticulturalist societies, and $83 \%$ had either no High God or one that was inactive.

Agriculturalists reside at the far end of the productivity continuum, excelling in production of resources while being sedentary. Emergence of early agricultural societies benefited from the success of cooperative labor in building the communal storage facilities, defensive perimeters, and irrigation networks that overcame limits to growth. This made possible the population booms that also led to big city problems (Boone, 
1992). These societies were highly stratified and their leaders would gain the most from moral conventions, backed by High Gods, that reduce chances of fissioning and ensure high levels of cooperation. The population as a whole would eventually benefit as the society expands at the expense of other competing groups. High Gods were present in $73 \%$ of agricultural societies in our sample, and $62 \%$ of those were active or moral.

Pastoralists do not fit easily on the productivity continuum from foragers to horticulturalists to agriculturalists. They are more stratified and mobile than foragers, moving in small groups sparsely scattered throughout vast areas of land. Their most important and often main source of subsistence exists in the form of large, divisible amounts of energy and wealth that can be stolen: their herd animals. Among pastoralists, the ecological (drought and disease) and sociological (tend and defend) stresses are highest. In our sample, pastoralists have the largest percentage of active or moral High Gods (94\%).

We confirmed the differential effect of mode of subsistence on the presence of High Gods through Mann-Whitney pairwise comparisons of the four modes against High Gods. The greatest numerical difference in the presence of High Gods is between foragers and pastoralists $(U=133, p<.0005)$, followed by horticulturalists and pastoralists $(U=298.5, p<.0005)$, then foragers and agriculturalists $(U=501, p<.0005)$, and then horticulturalists and agriculturalists $(U=1113.5, p=.002)$. Animal husbandry is by far the strongest subsistence-related predictor of High Gods $(\rho=0.429, p<.0005)$.

Second, Norenzayan and others have noted that the likelihood of the presence of High Gods will increase with society size. The presence in a society of a moral High God, with new codes of conduct that reduce intragroup conflict and fissioning, and stabilize stratification, would allow further population growth and domination over smaller societies. In our sample, the prevalence of active or moral High Gods increases in direct proportion to population size $(\rho=0.387, p<.0005)$. High Gods are absent or inactive in more than $95 \%$ of the smallest populations (between 10 and 999), which consist of the forager societies.

Finally, as pressures of increasing population result in stratification, there is a greater likelihood that active or moral High Gods will be found in those societies with more social stratification.

In our sample, $80 \%$ of egalitarian societies have either inactive High Gods or none at all. Active or moral High Gods are present in nearly $40 \%$ of societies with either wealth distinctions or classes. The effect of increased population size on stratification $(B=0.502$, $p<.0005$, df $=4)$ is greater than that of stratification on population size $(B=0.402$, $p<.0005, \mathrm{df}=4$ ) when controlling for subsistence mode. This suggests that increased population leads to stratification, which makes it easier to handle the greater number of collective-action problems and reduces the likelihood of fissioning. Once stratification stabilizes it would allow further growth in population, with stratification and increased population acting in a feedback loop, and population being the more fundamental (Boone, 1992). As populations grow and wealth accumulates, skillful political entrepreneurs emerge as de facto leaders who aggrandize their power, prestige, and authority by manipulating social inequality to attain personal goals. Promotion of commitment to belief in a High God who enforces inequality by threat of supernatural punishment would be an appealing tool for such an individual (Irons, 2001).

We applied ordinal logistic regression to tease apart the effects of closely related predictor variables mode of subsistence, stratification, and total population on High Gods, and to specifically address the ranked nature of our dependent variable that 
measures increasing power of supernatural meddling and coercion in a society. In this regression, both subsistence and population are significant predictors of the presence and type of High Gods. Any effect of stratification on High Gods drops out in the presence of mode of subsistence and total population. The usual interpretation is that the effect of population size on High Gods overwhelms that of stratification, or that stratification has little or no independent predictive power on the presence of High Gods. But the dynamic and close relationship between population increase and stratification suggests that any independently large predictive effect of stratification on High Gods might only be found in those hard-to-find cases where large populations are not involved.

One scenario for achieving the levels of cooperation and prosociality needed to stabilize larger populations (or growing ones) suggests the emergence of an authority figure. Heightened environmental threat, such as that encountered among pastoralists, has been shown empirically to be a primary contributor to the manifestation of the authoritarian personality and the social psychology that engenders coalitions, cooperation, and religiosity (Hastings \& Shaffer, 2008). Even among fiercely independent horticulturalists or complex foragers, one individual often stands out as more influential than the others and will assume leadership. Under extraordinary pressure to survive, this type of individual would likely recognize the value of coercing others into mounting a cohesive defense against external threat or banding together to build and maintain new subsistence technology. The concept of a morally supportive High God would have been an appealing tool to use as leverage (Irons, 2001).

Our results suggest that a significant selective force promoting the concept of a morally supportive High God was the herding and keeping of animals. What specific attributes of pastoralism and the economies of animal husbandry could have stimulated the birth of moral High Gods? Pastoralists are in constant and direct contact with their main source of subsistence and livelihood in a landscape filled with moment-to-moment contingencies. Situations can quickly become unstable (herds scattering) or dangerous (attacks by marauders or wild animals). Pastoralists have the highest frequency of warfare across the four modes of subsistence (Marlowe, 2011), which increases the need for collective action. Recurring environmental and ecological threats take on enhanced importance because of the self-generating wealth embodied in herded animals. When drought, disease, or constant violence becomes unrelenting, cooperation within one group, enforced by the moral codes of an active High God, would provide a survival advantage when challenged by other feuding groups.

Similar environmental threats are faced by settled agriculturalists due to reliance on controlled production of resources within a circumscribed area. Group size will grow with increased food production, which may depend on cooperative efforts. If the costs of cooperation outweigh the benefits, groups will fission as individuals leave for lesscompetitive resource environments. When leaving is not a good alternative, a population may remain intact even though some individuals are at a disadvantage. The result is inequality and exploitation of others by certain individuals or kin groups (Boone, 1992). Achieving stable inequality is more difficult as large populations continue to grow larger, and requires incentives beyond those of reciprocity or mutualism, and costly sanctions that punish free-riders. Activities related to "public goods" present cooperative challenges (Boone, 1992). Everyone benefits, but the costs of maintaining them are very high.

The conceptual seed of a paternalistic High God that meddles in human affairs and promises social order probably originated several times in many societies. This type of god found fertile ground in the threatening landscape of pastoralism and the 
environmental vagaries of settled agriculture. Success of the new cultural variant of "god" would compete with other religions, spreading through imitation and diffusion (Richerson \& Boyd, 2005).

We suggest that conditions promoting belief in High Gods included challenges encountered by individuals employing modes of subsistence that demanded the effective manipulation and cooperation of others in order to produce, manage, and defend vital resources. The coercive power of religion was used to facilitate cooperation for the benefit of higher-status individuals, which in turn benefited the whole group. The success of this strategy was copied, and it led to the transformation of human societies into higher levels of collective, economic organization that sustained larger populations.

\section{Conclusion}

We have described a pattern of evolution of Big Gods based on individual selection and adaptation in which Norenzayan's patterns of supernatural monitoring fit easily. This congruence suggests that cognitive bias may allow humans to be receptive to supernatural monitoring, but the concept and nature of a Big God is culturally determined. Its emergence and maintenance is strongly influenced by the subsistence economy of a society within the dynamics of individual selection.

\section{References}

Atkinson, Q.D., \& Bourrat, P. (2011). Beliefs about god, the afterlife and morality support the role of supernatural policing in human cooperation. Evolution and Human Behavior, 32(1), 41-49. doi:10.1016/j. evolhumbehav.2010.07.008

Boone, J.L. (1992). Competition, conflict, and the development of social hierarchies. In E.A. Smith \& B. Winterhalder (Eds.), Evolutionary ecology and human behavior (pp. 301-337). New York, NY: Aldine de Gruyter.

Borgerhoff Mulder, M., Bowles, S., Hertz, T., Bell, A., Beise, J., Clark, G., ... Wiessner, P. (2009). Intergenerational wealth transmission and the dynamics of inequality in small-scale societies. Science, 326, 682-688. doi:10.1126/science.1178336

Fuller, J.E., \& Grandjean, B.D. (2001). Economy and religion in the Neolithic Revolution: Material surplus and the proto-religious ethic. Cross-Cultural Research, 35, 370-399. doi:10.1177/106939710103500402

Hastings, B.M., \& Shaffer, B. (2008). Authoritarianism: The role of threat, evolutionary psychology, and the will to power. Theory \& Psychology, 18, 423-440. doi:10.1177/0959354308089793

Henrich, J., Ensminger, J., McElreath, R., Barr, A., Barrett, C., Bolyanatz, A., ... Ziker, J. (2010). Markets, religion, community size, and the evolution of fairness and punishment. Science, 327, 1480-1484. doi:10.1126/science. 1182238

Irons, W. (2001). Religion as a hard-to-fake sign of commitment. In R. Nesse (Ed.), Evolution and the capacity for commitment (pp. 292-309). New York, NY: Russell Sage Foundation.

Johnson, A.W., \& Earle, T. (2000). The evolution of human societies: From foraging group to agrarian state (2nd ed.). Stanford: Stanford University Press.

Johnson, D.D.P. (2005). God's punishment and public goods. Human Nature-an Interdisciplinary Biosocial Perspective, 16, 410-446. doi:10.1007/s12110-005-1017-0

Marlowe, F.W. (2010). The Hadza: Hunter-gatherers of Tanzania. Berkeley: University of California Press.

Marlowe, F.W. (2011). The behavioral ecology of warfare. Keynote presented at the fortieth annual meeting of the Society for Cross-Cultural Research, February, Charleston, S.C.

Murdock, G.P., \& White, D.R. (1980). Standard cross-cultural sample. In H. Barry \& A. Schlegel (Eds.), Crosscultural samples and codes (pp. 3-43). Pittsburgh: University of Pittsburgh Press.

Norenzayan, A. (2013). Big gods: How religion transformed cooperation and conflict. Princeton, NJ: Princeton University Press.

Peoples, H.C., \& Marlowe, F.W. (2012). Subsistence and the evolution of religion. Human Nature, 23, 253-269. doi:10.1007/s12110-012-9148-6

Richerson, P.J., \& Boyd, R. (2005). Not by genes alone: How culture transformed human evolution. Chicago: University of Chicago Press.

Rodrigue, C.M. (1992). Can religion account for early animal domestications? A critical assessment of the cultural geographic argument, based on Near Eastern archaeological data. The Professional Geographer, 44, 417-430. doi:10.1111/j.0033-0124.1992.00417.x 
Sosis, R. (2000). Religion and intragroup cooperation: Preliminary results of a comparative analysis of utopian communities. Cross-Cultural Research, 34(1), 70-87. doi:10.1177/106939710003400105

Swanson, G.E. (1960). The birth of the gods: The origin of primitive belief. Ann Arbor: University of Michigan Press.

\title{
Supernatural, social, and self-monitoring in the scaling-up of Chinese civilization
}

\author{
Hagop Sarkissian*
}

Department of Philosophy, Baruch College, The City University of New York, New York, NY, USA

In Book II of Plato's Republic, there is an extended dialogue between Socrates and Glaucon on the nature of justice. In the course of this dialogue, Glaucon recounts to Socrates the legend of the ring of Gyges. As the legend has it, generations prior, in the land of Lydia, a shepherd was tending his herd when a sudden violent earthquake split the earth around him. Climbing down into the newly formed chasm, the shepherd discovers a bronze horse containing within its hollow core the corpse of a large, human-like figure wearing nothing save a ring on one hand. The shepherd pockets the ring. Later, he puts it on and sets on his way to meet with his friends, only to discover that, once in their midst, they do not seem to notice his presence. He is invisible to them. He realizes that the ring has granted him the power of invisibility - of anonymity. Soon, this otherwise unassuming and unremarkable shepherd, with no prior history of wickedness, sets off for the royal palace of Lydia, seduces the queen, contrives to murder the king, and assumes royal power for himself.

As a philosopher, I was reminded of this ancient tale while reading Ara Norenzayan's Big Gods: How Religion Transformed Cooperation and Conflict, for it contains the seed of the idea that anchors the book: monitoring spurs prosocial behavior, and in the absence of monitoring, prosociality is compromised. In the legend, the ring cloaks the shepherd of Lydia in anonymity, and once free from the fear of reprisal his behavior devolves into depraved pursuit of self-interest.

What has kept any of us, after all, behaving in prosocial ways? Norenzyan's account posits different answers depending on the size of one's social group. In small-scale societies, where individuals can keep track of one another, where reputations count and anonymity is scarce, social pressures are sufficient to ensure that individuals cooperate with one another and act in prosocial ways. Transparency abounds. The gaze (and thus the potential repercussions) of others is hard to evade. Social monitoring, kin bonds, reciprocal altruism, and related cultural norms and practices are enough to ensure that individuals are able to build trust in one another, which in turn allows for cooperative projects to get off the ground (pp. 124-126). Without such trust, the costs involved in undertaking cooperative endeavors, coupled with the risks of being exploited by anonymous, unrelated others, would be prohibitive. Groups risk losing stability in proportion to their size. What, then, allows for large-scale cooperation? How did our ancestors scale up from smaller groups to large societies? Norenzayan focuses on one

*Email: hagop.sarkissian@baruch.cuny.edu 
prominent solution that serves to both remove anonymity and raise the stakes for defection - namely, supernatural monitoring.

Supernatural monitoring has its roots in the older, earthly notion of social monitoring. Yet, supernatural watchers fill in gaps where social monitoring falls short; Big Gods are always watching, and they have vast powers to enforce prosociality. Social monitoring is limited, after all, because:

[I]t depends on the actual or implied presence of others; it also depends on keeping track of others' reputations, which is severely limited by group size. As the number of interactions increase, anonymity creeps back into the situation and reputational mechanisms break down. (p. 23)

Social surveillance is a powerful and reliable mechanism to promote prosocial behavior for small groups; however, when societies scale up and interactions among strangers become commonplace, supernatural observation can arise to induce cooperation and render individuals trustful of one another.

Norenzayan's account is compelling. But there is an elephant in this room, and it is from China - one of the largest and most enduring civilizations on the planet, yet one also lacking a rich tradition of belief in Big Gods or supernatural monitoring. Does the scaling-up of Chinese civilization mark a counter-example to the book's main thesis? Norenzayan is careful in presenting his theory, noting in several places that belief in supernatural monitoring is not a necessary (nor perhaps sufficient) feature for societies to successfully scale up (e.g., pp. 9, 134-135). He also notes that supernatural monitoring can work in concert with other factors to promote cooperation among strangers. Nonetheless, I would like to make some brief comments about Norenzayan's own brief comments concerning the question of China. For while I agree with him that supernatural monitoring exists at the outset of ancient Chinese civilization, I believe it plays a very small role in explaining how it scales up. Monitoring itself is central, but it is of the more mundane kind.

What should we expect to find when assessing whether a group or society has struck upon supernatural monitors as a solution to large-scale cooperation? Norenzayan claims that in scaling up from small groups to large and complex societies, certain general patterns emerge, which can be summarized in four points (p. 124):

(1) Big Gods go from rare to common.

(2) Morality and religion become more intertwined.

(3) Rituals and faith displays become more organized, uniform, and regular.

(4) Supernatural punishment (a) centers on violations of group norms and (b) increases in potency (e.g., salvation, eternal damnation, eons of karma, hell).

Do we find these patterns in early China? In making his case that China falls under the rubric of his theory, Norenzayan focuses largely on the first point - that is, he focuses on the question of whether we find evidence of Big Gods in early China. Here, he is correct in claiming that Shang Di (Lord on High) plays the role of a supernatural monitor during the Shang Dynasty (1600-1046 BCE), the earliest dynasty for which we have significant historical records. Shang Di is depicted as approving or disapproving, supporting or abandoning, and otherwise rewarding or punishing sovereigns for excelling in royal virtue on the one hand, or failing on the other. (This theme is found, for example, in the Book of Odes - the earliest extant collection of folk songs and poems c. 1000-600 BCE.) So early China does have Big Gods in its earliest records. The evidence concerning 
Shang Di also suggests a positive answer to Norenzayan's second point: moral considerations are indeed intertwined with Shang Di's approval and disapproval (e.g., Thote, 2009). The head of the Shang royal clan, for example, receives Shang Di's approval or disapproval to the extent that he carries out his duties of protecting the people and allowing them to flourish.

However, after the conquest of the Shang by the Zhou (1045 BCE), Shang Di is replaced by the notion of Tian (or heaven). Tian appears, at the outset, as the progenitor or chief ancestral deity of the Zhou royal line, and is identified as the same entity as the former Shang Di. Yet with Tian we have a mitigation in monitoring and punishment. Tian loses its anthropomorphic characteristics and becomes less interested in human affairs. Eventually, Tian is significantly naturalized, taken to refer as much to the patterns and propensities inherent in the natural world as to any deity. A similar general pattern emerges with regards to Norenzayan's third point. Rituals do become more organized, uniform, and regular. However, they are also increasingly neglected. Moreover, there is a growing theory of ritual itself in the classical period recognizing its instrumental value: participation in ritual is important because it tames selfish tendencies and strengthens interpersonal ties, thus promoting beneficial consequences (e.g., Puett, 2013). With Norenzayan's second and third points, then, there are questions as to how large a role they play in scaling up Chinese society.

What about the fourth point? Norenzayan discusses the Mohists (p. 206), who constitute a prominent example of a manifestly religious movement railing against the cultural elites of their time (c. fifth to third centuries BCE) for rejecting supernatural monitoring and punishment, for neglecting the will of heaven (Tian), and for denying the efficacy of ghosts. The Mohists emerged during a time when old, kinship-based political structures were becoming more open and meritocratic, and when the various kingdoms and fiefdoms comprising the classical Chinese world were scaling up through alliances and warfare. The Mohists attributed much of the chaos and immorality of their time to the waning of religious beliefs. (They found disbelief among the political and cultural elite to be especially pernicious, as their attitudes would infect the masses.) The way to restore order is to demonstrate the existence of ghosts with the power to punish and reward. There can be no misreading the following Mohist passage:

If the ability of ghosts and spirits to reward the worthy and punish the wicked could be firmly established as fact throughout the empire and among the common people, it would surely bring order to the state and great benefit to the people. (Ivanhoe \& Van Norden, 2005, p. 104)

Here we do have explicit discussion of supernatural monitoring as a phenomenon. Yet the Mohists' protestations signal its demise rather than its vigor. The Mohists, after all, found it difficult to convince others of the efficacy of ghosts and spirits, and Tian. Furthermore, the type of punishing invoked throughout the Mohist corpus is not quite everlasting or hellish. (A prominent example of the kind of supernatural punishment that the Mohists had in mind is the ghost of a slain person coming back to exact justice by slaying the person who had brought about his or her demise.) The Mohists have no concept of salvation in the hereafter, nor do they believe that there is some other realm to which we go after earthly demise (Fraser, 2007). The rewards and punishments, such as they are, are meant to accrue to one during one's lifetime. In this light, it is not difficult to see why this belief would strike others as entirely lacking credibility; after all, there is abundant 
virtue that goes unrewarded, and vice unpunished, to have serious doubts as to whether supernatural punishment were credible.

We can speculate that the lack of eternal damnation on the one hand, and salvation on the other, might help to explain why belief in Big Gods stalled. Supernatural punishment and reward of the type discussed by the Mohists seem insufficient to induce cooperation beyond what is available through more mundane measures. Heaven is described as observing, rewarding, and punishing, but the rewards and punishments are left unspecified. Ghosts and spirits are invoked with greater detail and with stories of revenge after death, but these anecdotes fail to convince. So we do not find anything like Norenzayan's fourth point among the Mohists. Nor do we find it in the earlier Shang period.

When supernatural monitoring falls short, social monitoring steps in. And we do indeed find it to be a prevalent aspect of the Mohists' program of promoting prosocial behavior. The Mohists maintained that heaven (Tian) provided the ultimate ethical standard (a cluster of notions including order, abundance, and care), and that everyone ought to conform to this standard. Doing so, however, required constant social monitoring. Heaven itself cannot induce cooperation to its own ethical standard. Instead, individuals must "conform upwards" by evaluating one another and report any defections away or deviations from the ultimate ethical standard. Good old social monitoring, then, was a key cog to prosocial behavior - even for the Mohists.

The sense of being monitored and of conforming one's behavior to others' expectations is itself an old idea in China - older and more widespread than the Mohists. As Norenzayan himself has pointed out, the rice agriculture found in ancient China (particularly in the south) required much extensive coordination and cooperation in order to succeed (Nisbett, 2003; Nisbett, Peng, Choi, \& Norenzayan, 2001). Hierarchical, centralized organization arrives early in China for this reason, and along with it comes a commitment to acting in ways conducive to communal flourishing. This leads to harmony being a central moral value in the classical period (e.g., Li, 2006). Maintaining harmony requires being attuned not only to one's responsibilities and relationships to others, but also to how one's actions might be impacting the group. This requires a sense of selfawareness, including sensitivity to oneself as a social actor, to what others' expectations are, and to how one's behavior may be interpreted by others (Sarkissian, 2010).

This brings us to a final form of monitoring in early China - self-monitoring. Supernatural monitors fill an important gap by making sure that one does not defect or violate group norms when no one else is around. Big Gods are there "to watch even when no one is watching, to care when no one cares, to threaten when no one can threaten" (p. 27). But, of course, even when there is no one else present (supernatural or otherwise), one can monitor oneself. This notion is central to early Confucian ethical practice. For example, a famous passage from the first chapter of the "Doctrine of the Mean," a section of the Record of Ritual, claims: "There is nothing more visible than what is secret, and nothing more manifest than what is minute. Therefore the superior man is watchful over himself, (even) when he is alone (Legge, 1930, p. 350)." The idea is simple enough: one can be habituated into taking an external viewpoint on one's own behavior - that is, to become a self-monitor. One could then serve as a role model to others, especially those lower in the social hierarchy (Munro, 1969). This tendency to monitor oneself, to be aware of others' expectations, and to mind one's impact on others is not only found in a number of classical texts, but also persists today in societies that inherit Confucian cultural values (Heine, Takemoto, Moskalenko, Lasaleta, \& Henrich, 2008; Sarkissian, 2014). 
So I believe that Norenzayan is correct in claiming that there are supernatural monitors in ancient China. However, they likely play a minor role in explaining the scaling-up of classical Chinese civilization. Supernatural monitoring is parasitic upon social monitoring, and the latter seems a more prominent theme in the classical texts themselves. "Perhaps," Norenzayan writes, "the Chinese managed to create secular alternatives to religion earlier and more successfully than Western civilization" (p. 135). This seems closer to the truth. As the classical period approaches the founding of the Qin Dynasty and the unification of the Chinese world $(221 \mathrm{BCE})$, there is widespread emphasis on building efficient and reliable institutions, of promulgating clear laws backed with punishment, and of centralizing governing structures based on meritocratic criteria, all as ways to incentivize cooperative and prosocial behavior within rapidly expanding societies. As China scales up, Big Gods get left behind.

\section{References}

Fraser, C. (2007). Mohism. In E.N. Zalta (Ed.), Stanford encyclopedia of philosophy (Winter 2007 ed.). Retrieved from http://plato.stanford.edu/archives/win2007/entries/mohism/

Heine, S.J., Takemoto, T., Moskalenko, S., Lasaleta, J., \& Henrich, J. (2008). Mirrors in the head: Cultural variation in objective self-awareness. Personality and Social Psychology Bulletin, 34, 879-887. doi:10.1177/ 0146167208316921

Ivanhoe, P.J., \& Van Norden, B.W. (2005). Readings in classical Chinese philosophy. Indianapolis, IN: Hackett.

Legge, J. (1930). The four books. Shanghai: Chinese Book Company.

Li, C. (2006). The Confucian ideal of harmony. Philosophy East and West, 56, 583-603. doi:10.1353/ pew.2006.0055

Munro, D.J. (1969). The concept of man in early China. Stanford: Stanford University Press.

Nisbett, R.E. (2003). The geography of thought. New York, NY: The Free Press.

Nisbett, R.E., Peng, K., Choi, I., \& Norenzayan, A. (2001). Culture and systems of thought: Holistic versus analytic cognition. Psychological Review, 108, 291-310. doi:10.1037/0033-295X.108.2.291

Puett, M. (2013). Critical approaches to religion in China. Critical Research on Religion, 1(1), 95-101. doi:10.1177/2050303213476115

Sarkissian, H. (2010). Minor tweaks, major payoffs: The problems and promise of situationism in moral philosophy. Philosopher's Imprint, 10(9), 1-15.

Sarkissian, H. (2014). Is self-regulation a burden or a virtue? A comparative perspective. In N. Snow \& F. Trivigno (Eds.), The philosophy and psychology of virtue: An empirical approach to character and happiness (pp. 181-196). New York, NY: Routledge.

Thote, A. (2009). Shang and Zhou funeral practices: Interpretation of material vestiges. In J. Lagerwey \& M. Kalinowski (Eds.), Early Chinese religion: Part one: Shang through Han (1250 BC-22 AD) (pp. 103-142). Boston, MA: Brill.

\section{RESPONSE}

\section{Big questions about Big Gods: response and discussion}

Ara Norenzayan*

Department of Psychology, University of British Columbia, Vancouver, BC, Canada

\section{Introductory remarks}

I am grateful to my colleagues for their generosity of engagement in this book symposium on Big Gods (BG) (Norenzayan, 2013).

Let me start by laying out my perspective and priorities in writing $B G$, which will give context to my response. Most of us who study religion were trained in a specific

*Email: ara@psych.ubc.ca 
home discipline, with a unique set of perspectives, research tools, and interests. We are like the six blind men and the elephant in that old Indian parable. "Religion" is the elephant, and we the blind men get a glimpse of one part of the big beast - the thick skin, the tusk, the trunk, and so on - and are tempted to conclude that what we touch is the whole elephant. "It's like a wall!" "A spear!" "No, it's like a rope!" And just like in the parable, each of us is partly in the right, and all of us are in the wrong. As I see it, the great promise of the evolutionary perspective is that, through triangulation, it provides a vehicle that consolidates different perspectives and facts, so that the contours of the whole elephant begin to emerge, bringing about some measure of consilience that E. O. Wilson (1998) has called for (see also Campbell, 1990; Slingerland \& Collard, 2012). In this regard, I am appreciative of Rich Sosis's wider role in promoting discussion, dialogue, and integration in the evolutionary studies of religion. He is that wise man in the parable who, as he wanders by the six blind men, and noticing the comedy, gets the conversation flowing among them.

And now, I have a confession to make: I am guilty of changing my mind. $B G$ brings home the fact that, over the years, I have updated my thinking on key issues in the evolutionary study of religion. I got started on this journey steeped in the cognitive byproduct perspective working with Scott Atran, and in cultural psychology with Richard Nisbett. As can be seen throughout this book, I still think the insights of the cognitive byproduct account are foundational to any grand evolutionary explanation of religion, but I have come to the conclusion that it cannot do the job alone. When it is fused with a cultural evolutionary framework, we get a powerful, and more comprehensive evolutionary synthesis that explains both recurrent features and cultural and historical variability found in religion. We can then say goodbye to the misguided idea, popular in some influential corners of the evolutionary sciences, that culture is a shallow appendage, a mere side effect of evolved psychology. We can also say goodbye to the equally mistaken idea in some parts of the humanities and social sciences that culture is somehow opposed to or outside of human evolution. Culture is a core part of the human evolutionary lineage. Both genetic and cultural changes obey their own distinctive evolutionary principles, run parallel and mutually shape each other in profound ways. In Big Gods, I explore the implications of this emerging evolutionary picture to make sense of religion's footprints in human nature.

Elaborating on these points, religious beliefs and practices are a natural byproduct of how minds work. That is a deep insight but the story does not end there; it only gets more interesting. Some cultural variants have powerful downstream effects for individuals and human societies. Another shift in my thinking was the result of appreciating a major puzzle: the spectacularly different survival rates of religious movements or groups as a whole (not the individuals), with just a handful of them accounting for most of the world's believers. I know this is a controversial idea and breaks with dogma among some mainstream evolutionists, but I would argue that it is hard to explain this fundamental feature of the spread of religions unless we incorporate intergroup competition in our existing models in a cultural multilevel selection (or cultural group selection) framework. These updated views are reflected in $B G$ and throughout my response.

\section{Key themes and questions}

The 10 commentaries contain a rich set of questions and issues coming from fields as diverse as evolutionary biology, psychology, anthropology, archaeology, philosophy, and history. They raise specific and important challenges, make key elaborations, or ask new 
questions. Given the large number of commentaries and the limited space, I organize my response thematically. In the next three sections, I sharpen and clarify the core argument in $B G$. This lays the foundation to address a broad range of interrelated issues that have been raised by the commentators.

\section{There is a suite of features assembled by cultural evolutionary pressures that promote large-scale cooperation}

First, despite the title, the logic of the idea that I develop in the book is that cultural evolutionary pressures selected for a suite of myriad solutions that facilitated large-scale cooperation. These include complexes of culturally transmitted traits - beliefs, values, practices, and rituals that (1) sustain within-group solidarity and (2) promote success in competition with other social groups, by increasing group size, cooperative intensity, fertility, economic output, and superiority in warfare, among other features that allow groups to survive and outcompete other groups. Thus, any cultural traits (whether connected to the supernatural or not) that directly or indirectly promote in-group solidarity or parochial prosociality (Bowles, 2006) in expanded groups could be selected. Therefore, the idea is that prosocial religions were an important part of these suite of complexes, not that they constitute the entirety of them (Atran \& Henrich, 2010; Norenzayan et al., 2014), and that Big Gods are a potent element of prosocial religions, not that they are the only religious solution to the problem of large-scale cooperation.

I start with this key clarification because it addresses a common thread of critiques that runs throughout the commentaries. Lenfesty and Schloss, Kiper and Meier, Johnson, and Atkinson, Latham, and Watts all emphasize that there likely are features of religions other than Big Gods that promote large-scale cooperation. I agree completely. I do not claim that Big Gods are the single magic bullet. Like streams of water that converge into a river, what $I$ have in mind is a complex process that draws on a suite of solutions that are bundled together over historical time. Typically, we researchers play favorites and focus our attention on one element or another (which is why we have a poor understanding of how these various elements that get labeled "religion" converge and energize each other; see Sosis, 2009). I discussed this in some detail in chapters 6 and 8 , and again in chapter 10, where I explored secular solutions to large-scale cooperation. If only I could have a nineteenth-century-esque title for this book, I would call it Big Gods, Loyalty Displays and Extreme Rituals in the Form of CREDs and Commitment Signals, Practices that Encourage Self-Restraint, Suppress Selfishness, and Promote High Fertility, Fictive Kinship, Synchronous Rituals, Karma, Meddling Ancestor Spirits, and other Powerful Mechanisms such as Third-Party Punishment and Norm-Enforcing Institutions that Gave Rise to Large-Scale Cooperation. Alas, my editor would have balked at this more accurate and comprehensive, but 50-word title.

Building on this above point, the idea in $B G$ is that prosocial religions facilitated large-scale cooperation - nowhere in the book do I endorse the idea that Big Gods or prosocial religions are a necessary condition for cooperation of any scale, as some commentators seem to think or imply (Baumard \& Boyer; Fuentes; Kiper \& Meier). I make this point explicit in pages 134-135, although I could have given it greater attention throughout the book. To reiterate, the thesis is that of a statistical causal relationship, where prosocial religions facilitate the rise and sustenance of large-scale cooperation (for a more detailed discussion of this point, see Norenzayan, 2014). This thesis allows for: (1) the obvious likelihood that there are myriad other factors that 
promote large-scale cooperation (e.g., Seabright, 2004); and (2) that the arrow can also go in the other direction (see next point).

\section{Prosocial religions and large-scale cooperation are autocatalytic}

Are Big Gods a consequence, rather than a cause, of large-scale cooperation? Atkinson, Latham, and Watts, Baumard and Boyer, and Johnson raise this important question. But this idea is most clearly expressed by Lenfesty and Schloss, who say:

Another, related option is that the sequence from small foraging bands, to chiefdoms, to large kingdoms was not driven by but rather informed the notion of Big Gods: humans anthropomorphically endowed their gods with the properties that they saw in their own societies...

Here it is important to distinguish between two versions of this argument. The weak version is that Big Gods are not only a cause, but also a consequence of large-scale cooperation - the effects are bidirectional, an autocatalytic process of mutual galvanization. The strong version is that Big Gods are a byproduct of societal complexity but they have no causal power in the scaling-up of human cooperation.

Let us start with the easy part: I fully endorse the first (weak version); in fact, I consider it co-extensive with the main thesis of $B G$. For example, on page 8 , where the core argument is introduced, I talk about "mutual rise to prosocial religions and largescale cooperation." At several points in the book, and particularly in chapters 7 and 8, I discuss the question of causal arrows going in both directions, creating autocatalytic processes, as would be expected from a cultural evolutionary process.

But which came first, prosocial religions or large-scale cooperation? This is an interesting question for future research (see next section), but it could very well be that there is no simple answer to such a chicken-and-egg question. The answer could be different in different places and historical periods. As Newson points out, the trajectories of cultural evolution are complex, crisscrossing, and often circular.

Consistent with this, it is also important to clarify another cultural evolutionary point related to the historical trajectories of Big Gods. They are not "all or none." We would expect that they emerged gradually - there could be plenty of "intermediate" cases of gods who are somewhat omniscient about some things but not others, and morally concerned in some respects but not others. Over time, both the gods and the cooperative scale get larger in a bootstrapping process. Chiefdoms, both in the ethnographic and historical records, appear to fit this intermediate pattern. Their gods are more powerful and moralizing than those of foragers, but not as powerful as full-fledged Big Gods of states and empires (Bellah, 2011).

What about the second version, that Big Gods are merely a reflection of the social milieu, a causally inert cultural ornament? Some version of this appears to be the prevailing view in anthropology ever since Swanson's (1960) groundbreaking crosscultural work. Since then, the body of research has grown considerably. This hypothesis is increasingly strained by the evidence, and here is why. First, this view contradicts the experimental evidence on religious priming. We know that the arrow of causality clearly goes from certain aspects of religion to cooperation. Second, this view splinters into several sub-explanations for the cross-cultural patterns, as I explain below.

Let us discuss the religious priming evidence that allows us to make causal inferences. Since the book was written, my colleagues and I have completed a comprehensive 
meta-analysis of all known religious priming experiments with a wide range of outcome measures (Shariff, Willard, Andersen, \& Norenzayan, 2014). We found an overall religious priming effect across a broad range of relevant dependent measures, summarizing 66 studies (Hedges' $\mathrm{g}=0.36$ ). The religious priming effect emerged also for prosocial behaviors only, summarizing 25 studies (Hedges' $g=0.27$ ). The effect in both analyses gets stronger for self-reported believers and is on average not statistically different from zero for nonbelievers. The effect is reduced but stays robust and statistically significant when we correct for the estimated publication bias in psychology (that non-significant results are less likely to be published). Finally, these priming effects are comparable to the average effect size in social psychology over a 100-year period, summarizing 25,000 studies (Richard, Bond, \& Stokes-Zoota, 2003).

The experimental priming literature also gives us some important clues about the underlying mechanisms, which also addresses concerns and questions by the commentators. First, we know that the same religious primes that increase prosocial tendencies also increase believers' perceptions of being under social surveillance (Gervais \& Norenzayan, 2012). This is consistent with a wide range of experimental evidence, in both laboratory and field studies, that cues of social surveillance increase prosociality and decrease cheating, and conversely, the illusion of anonymity has the opposite effect (this evidence is reviewed in $B G$ in chapter 2; see also Norenzayan, Henrich, \& Slingerland, 2013).

Furthermore, belief in a punishing God causes less punishing behavior toward freeriders, since participants believe that they can offload punishing duties to God (Laurin, Shariff, Henrich, \& Kay, 2012). Here, people who are reminded of God are not acting like God - they are doing the opposite of what they think God is doing. Third, Purzycki et al. (2012) examined reaction times and found that believers are faster when they think about God knowing about norm-violating behaviors compared to when they think about God knowing norm-consistent behaviors. Faster reaction times are a good measure of intuitive pull, and these results show that intuitively, believers associate God's moral involvement with deeds worthy of punishment rather than deeds worthy of praise. Together these findings do not seem to suggest that religious virtue or the desire for benevolence are a key explanation for why some religious beliefs and practices encourage prosocial tendencies, as Lenfesty and Schloss, Barrett and Greenway, and Fuentes think. I do not dismiss this idea altogether; it could be part of the overall picture (see below for more discussion on this). However, the pattern of evidence from the experimental literature at least, does not support this view. Moreover, these findings contradict the alternative hypothesis that already prosocial individuals spontaneously imagine conceptions of prosocial deities.

In their rich commentary, Lenfesty and Schloss ask: "What is the appropriate characterization of the literature, and how many atheists who are unresponsive to priming would it take to unscrew the ideomotor light bulb?" At the time that I wrote $B G$, I did not have a clear answer, but with the meta-analysis, an answer does emerge: religious priming produces no consistent effect on the nonreligious. This null finding suggests that responsiveness to religious cues depends to a significant extent on cultural transmitted beliefs, and is not merely the result of low-level associations (Norenzayan et al., 2013). Put another way, the religious primes appear to capitalize on the situational activation of existing beliefs, rather than on society-wide stereotypes about religious benevolence (which are presumably known to believers and nonbelievers alike). 


\section{Revisiting the cross-cultural patterning of Big Gods}

Atkinson, Latham, and Watts provide a thoughtful critique of one of the main pillars of the argument in $B G$ : that across cultures, there is a robust association between the prevalence of Big Gods and indicators of social scale. First, let me outline the points of agreement. I agree completely that this association should be interpreted with care. To be precise, the theory in $B G$ predicts these cross-cultural correlations, but does not infer causality from them. I draw on the experimental psychology evidence (which uses random assignment) to infer the causal direction. They are also right that more in-depth exploration of the cross-cultural patterns, historical data, as well as carefully implemented cultural phylogenetic analyses that Atkinson and his colleagues have been pioneering, can help us adjudicate between various interpretations of the data. These research directions are exciting and important for the future agenda of the field. I also agree that the measure of "High Gods" commonly used in the cross-cultural databases is coarse. We need additional and more precise measures. To add to Atkinson and colleagues' list of concerns, this variable does not account for karmic religions (with overall one billion faithful practitioners), where supernatural monitoring and punishment are clearly at play (norm violations in one's lifetime now have consequences in the afterlife).

The third point of agreement: Big Gods are bundled together with other religious beliefs and practices (remember the nineteenth-century title of $B G$ ). Correlational findings alone do not conclusively tell us that Big Gods are the potent cause of large-scale cooperation. Agreed, but: (1) the argument is that cultural evolution selected for the co-evolution of large-scale cooperation and a suite of features that include Big Gods; and (2) we have other causal evidence that Big Gods indeed are part of this package of causes. The message that I take from this commentary is that we should do more to tease apart the various elements of the religious bundle as we try to understand these converging processes.

With these areas of agreement in mind, let me address Atkinson, Latham, and Watts's concern that this association does not adequately solve Galton's problem or independence of cross-cultural observations. I fail to see why we should eliminate the role of spatial diffusion in our statistical models, when in fact the theory that we are working with says that prosocial religions spread by a variety of processes, many of which entail spatial diffusion: population expansions and absorption of neighboring groups (whether through war, coercion, or cultural influence). Brown and Eff's (2010) finding, which Atkinson and colleagues cite, is an important one, but to me it does not depart from the story that I was telling in $B G$; rather, it reinforces an important point by quantifying it. On the other hand, I am puzzled as to why Atkinson and colleagues want to control for world religion (Christianity, Islam, Hinduism, Buddhism), when at stake is to explain how these world religions spread so successfully to the point that most of the world adheres to one of these traditions. Controlling for the world's most successful religions leaves little variance left to explain. As to the Abrahamic religions, there are two issues here. One is that, with over two billion members, they are indeed a very big chunk of the puzzle; therefore, again, diffusion predicts precisely what Atkinson and colleagues find: the Abrahamic religions account for a major proportion of the variance. However, another methodological issue to consider is that this result might be partly due to problems with the High Gods variable, which favors the Abrahamic religions. Additional and more nuanced measures of supernatural monitoring and punishment might yield results that are not as skewed toward the Abrahamic traditions. 
I regret that I saw Peoples and Marlowe's (2012) paper only after $B G$ was completed. Had I seen it earlier, it would have been an important point of discussion and a more nuanced interpretation of the cross-cultural data. In $B G$, I focused on group size and to some extent water scarcity, but now I am beginning to see that there are a broader set of conditions that co-evolve with prosocial religions and Big Gods. Peoples and Marlowe find several independent predictors of High Gods: society size, agricultural mode of subsistence, animal husbandry, and stratification.

These broader patterns also pose an interesting challenge to explanations that argue that Big Gods are byproducts of social scale but not a cause. Different accounts have to be generated as to why large anonymous groups, herders, agricultural societies, and societies with water scarcity independently imagine or create Big Gods in their own image. In contrast, in the Big Gods $\rightarrow$ large-scale cooperation account, there is one parsimonious explanation as to why Big Gods are widespread in all these conditions: every one of these circumstances pose collective actions problems, and the Big Gods complex contributes to solutions to them. I elaborate on this point in the next section.

Several other analyses also match the finding that High Gods are positively correlated with political and economic inequality. This latter point made only a minor appearance in $B G$, but Peoples and Marlowe are right that it is an important piece of the puzzle. Small foraging groups thrive and maintain harmony in an egalitarian structure (e.g., Boehm, 1999), but as groups expand and extract more and more resources from their environment, they have to figure out ways to "scale up" without splintering. One common solution to this problem that cultural evolution has stumbled on is hierarchical organization, which enhances cooperation but has the important side effect of inequality (Turchin, 2011). However, this opens the door for exploitation, creating opportunities for the elite to manipulate the masses. A question ripe for study is how religion is implicated in these processes. In this regard, Johnson's point is well taken: religious leadership plays an important role in these processes. As Peoples and Marlowe explain, religious systems reify these hierarchies as a way of maintaining group solidarity. However, when too much inequality undermines group harmony, cultural selection may favor shifts in religious traditions toward suppressing unequal distribution of power and resources. For example, Henrich, Boyd, and Richerson (2012) cite the spread of monogamy as an example of this. Despite the fact that polygynous marriage is the common pattern in the anthropological record, monogamy first made inroads in Europe along with the spread of Christianity, and then across the rest of the globe. The idea is that monogamy reduces intrasexual competition and so shrinks the pool of unmarried young men, who are the typical demographic group behind high rates of within-group violence. Monogamy clashes with the powerful interests of the men on top, but Christianity overcame this obstacle by making it a divinely ordained sacred value. Similarly, Islam, while not prescribing strict monogamy, enforced practices that reduced rampant polygyny that again favor powerful, wealthy men (Henrich et al., 2012).

In concluding this section, I should say that I am struck by how robust these associations are despite the great deal of noise in measurement. They remain after controlling for a variety of potential confounds and even after some adjustments are made for non-independence of the observations. They are weakened only when sample sizes are drastically reduced or variables that are part of the explanatory package are statistically accounted for. Nevertheless, I echo Atkinson and colleagues' call for crosscultural and historical work that goes beyond correlations, by for example, drawing on techniques from cultural phylogeny. However, these techniques, derived from modeling genetic evolution, must be recalibrated to cultural evolutionary theory that in important 
respects is quite unlike genetic evolution. In addition, the models must incorporate the rich theoretical knowledge that we already have about the spread of world religions. The list is long, but includes, among other considerations, biased transmission (the theoretical process that we want to model erases the independence of data points) and asymmetric cultural diffusion that is the result of intergroup competition (missionaries from world religions are far more likely to transmit supernatural beliefs to local groups than acquire new ones from them).

\section{Greece, Rome, Egypt, Babylon, China, and India}

Referring to the "pre-axial" ancient gods of the Maya, Greece, Rome, Egypt, China, and India, Baumard and Boyer assert: "There is little or no evidence that people in these societies represented the gods as concerned with people's own cooperative or prosocial behavior toward fellow members of their groups."

I find this reading of the historical record problematic. First, as I argued earlier, it is a mistake to treat this question as "all or none." In previous work, Baumard and Boyer (2013) seem to claim a vast chasm between pre-axial amoral gods and axial-age moral religions. I struggle to see how this accords with the historical record as I read about the gods and religions of the ancient world (I am partly relying here on Bellah's (2011) ambitious and detailed account and his sources regarding the continuities between preaxial and axial religions). Historically, chiefdoms, predating the axial age by thousands of years (the earliest ones in the Middle East first emerged at the dawn of the Holocene), had anthropomorphized deities who intervened in social relations and punished norm violations, although their moral scope was more groupish than the "universalist" axial gods. This is also true in contemporary chiefdom societies, such as Fiji (McNamara, Norenzayan, \& Henrich, in press). Axial religions did not emerge out of a vast black hole of completely amoral gods. More plausibly, there has been a co-evolution of two gradual processes: an escalation of gods' powers and the scope of their moral concern, and an expansion of the cooperative sphere. The axial age represents the historical tip of this iceberg. This is more precisely the testable claim that I would like evaluated and debated.

If pre-axial gods cared only about themselves, and showed no concern with how people treated each other, what, then, is Hammurabi's code, which at approximately 1772 BCE, emerged at least a 1000 years before the start of the so-called axial age? The fact that the written record emerged relatively recently is not evidence of the absence of interventionist gods dating back to before the invention of writing. Hammurabi's code is the best-preserved written document we have of a divinely inspired moral system that is precisely about how people should treat each other, but it is hardly the oldest one. And there is little doubt that the code was seen as having supernatural origins. Hammurabi capitalized on the peoples' fear of Marduk, patron god of Babylon, and invoked Shamash, god of justice. He wrote: "When (my god) Marduk had given me the mission to keep my people in order and make my country take the right road, I installed in this country justice and fairness in order to bring well-being to my people" (Bottéro, 2001, p. 168; for more on moralizing Mesopotamian gods, see Bellah, 2011, pp. 221-224)

In their commentary and elsewhere (Baumard \& Boyer, 2013), the axial religions are contrasted with the gods of the highly organized Greek city states and later Imperial Rome, which, it is argued, were fickle, amoral deities. But are Greek and Roman religions not a paradigm case of the axial age, and therefore religions that concerned themselves with public morality? True, the gods of the Greek city states were portrayed to be more human-like than the Abrahamic God, but that does not imply that they lacked powers and 
moral concern. In fact, personified gods are seen to be more strongly involved in the moral domain than impersonal, abstract gods (Atkinson \& Bourrat, 2010; Morewedge \& Clear, 2008), and more willing to punish norm violations (McNamara, Willard, Norenzayan, \& Henrich, 2014), rendering even believers in the Abrahamic faiths to anthropomorphize a highly moralizing God despite theological discouragement (Barrett, 2004). The Greek and Roman gods were worshipped by the populace, demanded extravagant sacrifices, and elicited elaborate rituals. In doing so they played an active role in enforcing oaths and supporting public morality (Mikalson, 2010, pp. 150-168). This pattern is seen in Greek city states and even more starkly in the case of the deities of Imperial Rome (Rives, 2007, pp. 105-131). Even the spatial layouts of Roman cities were designed around its temples dedicated to the major gods (Rives, 2007, pp. 110-111). In $B G$, I discuss how cults dedicated to Mercury and Hercules in the second- and firstcentury BCE Delos leaned heavily on supernatural surveillance in order to overcome cooperation dilemmas in long-distance trade relations (Rauh, 1993). Delos was an important maritime trade center during the axial age, and is well-documented. In earlier periods, Greek, Roman, Sumerian, and Egyptian gods were also deeply involved in regulating the economic sphere, and these patterns are found throughout the Mediterranean (see Silver, 1995, chapter 1). In fact, Silver starts his book, Economic Structures of Antiquity, with the role of the gods in economic exchange. He writes: "The economic role of the gods found important expression in their function as protectors of honest business practices. Some deities openly combated opportunism (self-interest pursued with guile) and lowered transaction costs by actively inculcating and enforcing professional standards" (Silver, 1995, p. 5).

Now, let us revisit China. Sarkissian accepts the evidence that I discuss in $B G$ that supernatural monitoring and punishment existed and played a role in early China, but sees a less important role than secular alternatives to religious morality relative to Middle Eastern and European civilizations. Others have disputed this claim (e.g., Clark \& Winslett, 2011; Slingerland, 2013). I welcome debate on this point. If it turns out that the evidence is closer to Sarkissian's position, it would add an important nuance to the overall argument in $B G$. Sarkissian's point about China, and East Asia more broadly, also highlights a crucial gap in current experimental research on religious beliefs and practices there. Addressing this gap might give us some answers to complement the historical analyses.

What about India, and more broadly, the so-called karmic religions (Hinduism, Buddhism, Jainism, Taoism)? These traditions, important in over a billion people in the world, are another casualty of the WEIRD (Western, educated, industrialized, rich, and democratic) problem in psychology and the behavioral sciences. In a comparative analysis of religious traditions in the world, Obeyesekere (2002) finds that the notion of rebirth is present in many small-scale societies but disconnected from morality. Birth is a re-entry into a new life, but what one did in a previous lifetime has no effect on prospects in the next life. Then, something interesting happens: "rebirth eschathologies" are transformed into "karmic eschathologies" as societies scale up. Rebirth links up with the idea of ethical causation across lifetimes, and begins to play a central role in the cooperative sphere. Karmic religions are world prosocial religions. As such, they are compatible with the broad explanatory framework developed in $B G$. As far as I know, there are no experimental studies that have tested the effects of karmic beliefs or reminders on prosocial behavior. Nevertheless, Xygalatas and his colleagues have shown that participation and observation of extreme Hindu rituals such as the Cavadee, practiced among devotees of the Tamil war god Murugan, increase prosocial behavior (Xygalatas 
et al., 2013), and religious location priming has prosocial effects among Hindus (Xygalatas, 2013). We do not know yet if the mechanisms are similar to those found in Abrahamic religions, but the karmic religions remind us again that there is no need to tie religion to a procrustean bed. There is no single mechanism underlying religion's prosocial effects, therefore the processes could easily be different in different places. To me, the cultural differences can be as illuminating and important as the shared features of religions. So, karmic religions are not counter-examples to the thesis in $B G$. Rather, they illustrate another set of cultural evolutionary trajectories that connect some cultural variants of religion with large-scale cooperation.

\section{The religious person versus the religious situation}

Barrett and Greenway, Lenfesty and Schloss, and Fuentes raised objections to the second principle of Big Gods, which says that Religion is more in the situation than in the person. Why would religious norms about being nice to other co-religionists not be internalized and become part of virtuous behavior toward others? And relatedly, what about religion acting through love, compassion, guilt, and what is often called the "conscience?" Sarkissian also raises this issue when he cites the following passage from the "Doctrine of the Mean" found in Confucian virtue ethics, which seems to imply that the best form of social monitoring is self-monitoring: "There is nothing more visible than what is secret, and nothing more manifest than what is minute. Therefore the superior man is watchful over himself, (even) when he is alone."

While I am sympathetic to their argument, I have two broad answers. One is that the current empirical evidence is more in line with this situationist interpretation (for a recent review of the evidence, see Norenzayan et al., 2013). Religious reminders, but not selfreported religiosity, predict more prosocial tendencies. Put another way, without being cued with religious reminders, believers and nonbelievers show similar levels of prosocial behavior, as seen, for example, in the Sunday Effect (Malhotra, 2008). Moreover, the extant evidence shows that supernatural punishment is implicated in prosociality. Supernatural benevolence, if anything, backfires (for discussion of the evidence, see $B G$, pp. 43-47). Third, one of the few well-designed series of studies, looking directly at empathy-driven prosociality, found that if anything, empathy predicted higher levels of prosociality among nonbelievers than among believers (Saslow et al., 2013; for a discussion of these studies, see $B G$ pp. 72-73). But this is one paper in one cultural context (the USA). More studies along these lines are needed to reach firmer conclusions about whether and how the "conscience" plays a role in religiously motivated prosociality.

Second, I hypothesize that this pattern may be accentuated in cultural contexts with strong secular institutions. The theory in $B G$ is consistent with the observation that strong secular institutions crowd out religion's role in cooperation. When people live in societies with a strong rule of law, institutions raise the bar of trust and cooperation for everyone believers and nonbelievers alike (Herrmann, Thoni, \& Gaechter, 2008). In these WEIRD societies (Henrich, Heine, \& Norenzayan, 2010), the signal from religion is weak and priming techniques are needed to discover religion's influence on prosocial tendencies. Conversely, the idea is that in places with weak institutions (most of the non-WEIRD world), levels of prosociality and trust are generally lower and the signal from religion is stronger. This prediction does not contradict the second principle of Big Gods but adds an important nuance to it. This is yet another reason why we need experimental studies of religion in non-WEIRD contexts, as Newson also calls for. 


\section{The cultural evolution-cognitive byproduct framework: between adaptationism and byproduct-only accounts}

I have already addressed many of the key issues raised by Johnson as well as Baumard and Boyer, but in this last section I revisit these two commentaries and tackle them more directly. Johnson objects that $B G$ does not offer anything new beyond the adaptationist stance of the Supernatural Punishment Hypothesis (SPH). On the other end of the spectrum, Baumard and Boyer appear to stick to a "byproduct-only" account and dispute the line of reasoning in $B G$, including the key argument that prosocial religions facilitated large-scale cooperation. Perhaps this was to be expected, given that the theory in $B G$ straddles these two divergent positions, and in doing so integrates key elements of both perspectives. It would be interesting to see a debate between these two opposing views.

Johnson's critique starts by arguing that the idea in $B G$ is identical to the SPH; in other places, it shifts to saying that the two are compatible (including a useful table that illustrates how), and yet in other places it seems to argue against the main idea in $B G$. I admire Johnson and Bering's work on the evolution of religion (e.g., Johnson \& Bering, 2006; Bering, 2011), which is why $B G$ draws from it quite extensively. And I do not see $B G$ as an attack on SPH. Rather, I wrote $B G$ partly to shift the conversation beyond the "adaptationism versus byproduct" debate (for a discussion, see Sosis, 2009), and to explore additional theoretical possibilities. I cannot do full justice to the important divergences between these two approaches here. Readers can consult Shariff, Norenzayan, and Henrich (2010) for a critical discussion of the similarities and differences between the SPH and the main idea in $B G$.

Is the argument in $B G$ just another version of the SPH? No. The two theories are overlapping, but distinct. This is not uncommon, where two theories that are about the same class of phenomena make many similar predictions, yet the explanatory precision of theories can be tested when they diverge in a few, but critical respects. If fear of supernatural punishment is a mind-guard suppressing cheating, it is therefore part of an evolved psychology, as the SPH proposes. Therefore, it should be clearly visible among foraging groups, and moreover, would not lead to the prediction that belief in supernatural punishment is more likely, or more uniformly present, in large anonymous communities. My reading of the ethnographic evidence does not encourage the first claim, and there is wide agreement among the commentators with ethnographic expertise on this point. Moreover, the evidence strongly supports the claim that the prevalence of supernatural punishment increases with social scale where anonymity is more common, and therefore the threat of getting caught is weaker (not stronger). But this remains an open empirical question. Better and more systematic cross-cultural studies could be conducted to further refine and test these hypotheses, and to tell us whether predictions from both theories are supported, which would suggest compatibility (here Schloss and Murray's (2011) analysis would serve as a useful guide).

In $B G$, I drew extensively from Boyer's insights on the cognitive biases that push human minds toward religious intuitions. Baumard and Boyer seem to accept the priming evidence that supernatural monitoring has prosocial effects, but draw a sharp line and stop there. Whereas Johnson is convinced that various forms of supernatural punishment beliefs are found everywhere, including among foragers, Baumard and Boyer raise the opposite concern: that the linking of morality with the supernatural is a recent invention of the axial religions. I have already discussed in some detail (see sections 2 and 4 ) why I think the historical evidence shows otherwise. 
Baumard and Boyer then argue against the idea that societies with Big Gods cooperate more than societies without, by downplaying the religious priming evidence because "this evidence comes from places where gods are construed as, precisely, interested in people's prosocial behavior." But that is precisely the cultural evolutionary argument in $B G$. The theory says that there should be religious priming effects in groups with Big Gods, but minimal or no effects of religious primes where gods have minimal or no moral concern (the latter part of the hypothesis remains to be tested). The direct implication therefore is that, all else being equal, individuals in groups with Big Gods cooperate more than those in groups with small gods, and the available evidence supports this (e.g., Henrich et al., 2010; contrary to Baumard and Boyer's claim, these are sizable effects considering the narrow ranges in offers in the economic games and the fact that confounding variables were controlled for). And I am puzzled as to why they think that the greater potency of supernatural punishment relative to supernatural benevolence is a problem for my account. This asymmetry is entirely compatible with the cultural evolutionary account as well as the SPH, and shows that religions obey a well-known principle in human psychology (that the stick is often stronger than the carrot).

Next point: Baumard and Boyer claim that cultural group selection lacks empirical evidence. There are several lines of converging evidence: laboratory studies (Gurerk, Irlenbusch, \& Rockenbach, 2006), global surveys (Bell, Richerson, \& McElreath, 2009), archaeology (Flannery \& Marcus, 2000; Spencer \& Redmond, 2001), history (Turchin, 2003; Turchin, Currie, Turner, \& Gavrilets, 2013), and ethnography (Atran, 2002; Currie \& Mace, 2009; Kelly, 1985; Soltis, Boyd, \& Richerson, 1995; Wrangham \& Glowacki, 2012). Space limitation precludes a detailed discussion here, but interested readers can decide the validity of the evidence for themselves by consulting the published literature. These empirical findings are consistent with evolutionary modeling (a bedrock of any evolutionary argument), showing broad conditions under which cultural group selection can influence the trajectory of cultural evolution (e.g., Boyd, Gintis, \& Richerson, 2003; Guzman, Rodriguez-Sickert, \& Rowthorn, 2007). Multilevel selection is a hotly debated topic, but why not move beyond the heated rhetoric and treat it as a scientific hypothesis, and test its explanatory power alongside other contenders?

The explanatory power of cultural group selection, and the supporting evidence, has been outlined most recently in Smaldino (2014) and Baldini et al. (2014). Coming back to the topic at hand - explaining religion - there are several considerations that encourage a cultural multilevel selection framework in combination with (not necessarily in substitution of) existing insights from cognitive and other evolutionary approaches (Atran \& Henrich, 2010; for an account that combines intergroup competition with costly signals, see Wildman \& Sosis, 2011; for an earlier argument, see also Wilson, 2002). I started $B G$ with a striking fact, the evidence of which is all around us: the differential group survival rates of religious groups and movements have produced an extremely nonrandom cultural distribution. Since the data are about the differential survival and stability of the group, not the individuals who make up the group (the individuals are replaceable), the selective advantage of the successful groups is an emergent group-level cultural feature that is hard to account for without cultural multilevel selection. Moreover, it is not obvious to me how a purely genetic evolutionary account (whether considering between-group variation or not) would explain differences in the longevity of cultural groups over historical time, in some cases spanning just a few generations (consider the worldwide spread of the Pentecostal movement, reaching almost 300 million members in about 100 years). Another issue is that many religious elements are group-level traits (not something about the individuals). These features elicit strict norm-following and mark 
group boundaries, such as the taboo on eating pork among Jews and Muslims, or monogamous marriage enforced among early Christian communities in the Roman Empire. Many rituals or practices that are widespread or even universal in one religious community are entirely absent in others.

Baumard and Boyer do not see large-scale cooperation as a puzzle because institutions can do the job and people are likely to find reputable partners and repeatedly interact with them. If this is all that is needed to unleash cooperation among strangers, then what explains the massive cultural variability in cooperation and trust, with downstream effects on economic outcomes, even under the same or similar institutions (e.g., Zak \& Knack, 2011)? The answer that a growing body of economic literature points to is the importance of culturally transmitted traditions, beliefs, and norms (Algan \& Cahuc, 2010; Fukuyama, 1995; Guiso, Sapienza, \& Zingales, 2009; Nunn, 2009). And Baumard and Boyer's claim - that cooperation can flourish without trust - is an extremely narrow and problematic reading of the evidence amassed by economists, including the ones that they cite. Studies show high positive intercorrelations between the strength of institutions, trust levels, and cooperative tendencies (Ensminger \& Henrich, 2014; Herrmann et al., 2008; Zak \& Knack, 2011). This is the same powerful cultural package that leads to secularization (Norris \& Inglehart, 2004). Moreover, institutions themselves break down when trust disappears, for example, when some West African ethnic groups were raided in the slave trade, eroding trust toward their neighbors (e.g., Nunn \& Wantchekon, 2011).

Finally, there are several lines of evidence showing that, all else being equal, groups with prosocial norms outcompete their less prosocial counterparts. Studies show that group size has an obvious selective advantage in intergroup competition and predicts more prosocial behavior in economic games, including more willingness to punish unfair offers (Henrich et al., 2010; Henrich, Ensminger, Barr, \& McElreath, 2014). These findings accord with studies showing that ethnic groups that are culturally spreading, as observed by ethnographers, in fact play more fairly in the Ultimatum Game than stagnating ethnic groups in the same geographical area (Paciotti \& Hadley, 2003). Sosis and Bressler (2003) found that the more costs religious communes impose on their members, the longer they last. This is instructive because we know that extreme behaviors such as restrictions on diet and possessions, fasts, and painful rituals are correlated with in-group solidarity (Iannacone, 1994; Sosis \& Alcorta, 2003) and prosociality (Xygalatas et al., 2013). International comparisons also offer a different kind of evidence: participants coming from nation states with stronger economic potential and rule of law are more prosocial and less antisocial in economic games (Herrmann et al., 2008). All these empirical findings are also supported by simulation studies showing that selection pressures favor cultural groups with stronger prosocial tendencies when intergroup competition escalates (Boyd, Richerson, \& Henrich, 2011).

In concluding, I see $B G$ as the beginning of an evolving argument, and an invitation to continuous debate. So I could not agree more with Newson, who quoted Box and Draper saying: "Remember that all models are wrong; the practical question is how wrong do they have to be to not be useful." Only time will tell how wrong relative to how useful the ideas in $B G$ will prove to be. The good news is that, as a young field, the evolutionary study of religion is vibrant, intellectually diverse, and dynamically changing. What is needed is more integration. Those who are looking for one monolithic evolutionary account of religion will be disappointed. Most of what we can know lies ahead. 


\section{Acknowledgements}

The writing of this article was supported by the Cultural Evolution of Religion Research Consortium, funded by a generous partnership grant [895-2011-1009] from the Social Sciences and Humanities Research Council of Canada.

\section{References}

Algan, Y., \& Cahuc, P. (2010). Inherited trust and growth. American Economic Review, 100, 2060-2092. doi:10.1257/aer.100.5.2060

Atkinson, Q.D., \& Bourrat, P. (2010). Beliefs about God, the afterlife and morality support the role of supernatural policing in human cooperation. Evolution and Human Behavior, 32, 41-49. doi:10.1016/j. evolhumbehav.2010.07.008

Atran, S. (2002). In Gods we trust: The evolutionary landscape of religion. Oxford: Oxford University Press.

Atran, S., \& Henrich, J. (2010). The evolution of religion: How cognitive by-products, adaptive learning heuristics, ritual displays, and group competition generate deep commitments to prosocial religions. Biological Theory: Integrating Development, Evolution, and Cognition, 5, 18-30.

Baldini, R., Bell, A., Demps, K., Frost, K., Hillis, V., Mathew, S., ... Richerson, P.J. (2014). A sketch of the evidence for selection on inter-group cultural variation in humans. Manuscript under review. Davis: University of California.

Barrett, J.L. 2004. Why would anyone believe in God? Walnut Creek, CA: AltaMira Press.

Baumard, N., \& Boyer, P. (2013). Explaining moral religions. Trends in Cognitive Sciences, 17, 272-280. doi:10.1016/j.tics.2013.04.003

Bell, A.V., Richerson, P., \& McElreath, R. (2009). Culture rather than genes provides greater scope for the evolution of large-scale human prosociality. Proceedings of the National Academy of Sciences of the United States of America, 106, 17671-17674. doi:10.1073/pnas.0903232106

Bellah, R.N. (2011). Religion in human evolution: From the Paleolithic to the axial age. Cambridge, MA: Harvard University Press. doi:10.4159/harvard.9780674063099

Bering, J. (2011). The belief instinct. New York: W. W. Norton.

Boehm, C. (1999). Hierarchy in the forest: The evolution of egalitarian behavior. Cambridge, MA: Harvard University Press.

Bottéro, J. (2001). Religion in Ancient Mesopotamia. Chicago: University of Chicago Press. doi:10.3366/ edinburgh/9780748613878.001.0001

Bowles, S. (2006). Group competition, reproductive leveling, and the evolution of human altruism. Science, 314 , 1569-1572. doi:10.1126/science. 1134829

Boyd, R., Gintis, H., \& Richerson, P.J. (2003). The evolution of altruistic punishment. Proceedings of the National Academy of Sciences of the United States of America, 100, 3531-3535. doi:10.1073/pnas.0630443100

Boyd, R., Richerson, P.J., \& Henrich, J. (2011). Rapid cultural adaptation can facilitate the evolution of largescale cooperation. Behavioral Ecology and Sociobiology, 65, 431-444. doi:10.1007/s00265-010-1100-3

Brown, C., \& Eff, E.A. (2010). The state and the supernatural: Support for prosocial behavior. Structure and Dynamics, 4(1), 1-21.

Campbell, D.T. (1990). Levels of organization, downward causation, and the selection-theory approach to evolutionary epistemology. In G. Greenberg \& E. Tobach (Eds.), Theories of the evolution of knowing (pp. 1-17). Hillsdale, NJ: Lawrence Erlbaum.

Clark, K.J., \& Winslett, J.T. (2011). The evolutionary psychology of Chinese religion: Pre-Qin high Gods as punishers and rewarders. Journal of the American Academy of Religion, 79, 928-960. doi:10.1093/jaarel/ 1 fro18

Currie, T.E., \& Mace, R. (2009). Political complexity predicts the spread of ethnolinguistic groups. Proceedings of the National Academy of Sciences, 106, 7339-7344. doi:10.1073/pnas.0804698106

Ensminger, J., \& Henrich, J. (2014). Experimenting with social norms: Fairness and punishment in crosscultural perspective. New York, NY: Russel Sage.

Flannery, K.V., \& Marcus, J. (2000). Formative Mexican chiefdoms and the myth of the "mother culture". Journal of Anthropological Archaeology, 19(1), 1-37. doi:10.1006/jaar.1999.0359

Fukuyama, F. (1995). Trust: The social virtues and the creation of prosperity. New York, NY: Free Press.

Gervais, W.M., \& Norenzayan, A. (2012). Like a camera in the sky? Thinking about God increases public selfawareness and socially desirable responding. Journal of Experimental Social Psychology, 48, 298-302. doi:10.1016/j.jesp.2011.09.006

Guiso, L., Sapienza, P., \& Zingales, L. (2009). Cultural biases in economic exchange? Quarterly Journal of Economics, 124, 1095-1131. doi:10.1162/qjec.2009.124.3.1095

Gurerk, O., Irlenbusch, B., \& Rockenbach, B. (2006). The competitive advantage of sanctioning institutions. Science, 312, 108-111. doi:10.1126/science.1123633

Guzman, R.A., Rodriguez-Sickert, C., \& Rowthorn, R. (2007). When in Rome, do as the Romans do: The coevolution of altruistic punishment, conformist learning, and cooperation. Evolution and Human Behavior, 28, 112-117. doi:10.1016/j.evolhumbehav.2006.08.002 
Henrich, J., Boyd, R., \& Richerson, P.J. (2012). The puzzle of monogamous marriage. Philosophical Transactions of the Royal Society B: Biological Sciences, 367, 657-669. doi:10.1177/106939710003400205

Henrich, J., Ensminger, J., Barr, A., \& McElreath, R. (2014). Chapter 4: Empirical results—markets, community size, religion and the nature of human sociality. In J. Henrich and J. Ensminger (Eds.), Experimenting with social norms: Fairness and punishment in cross-cultural perspective (pp. 89-148). New York, NY: Russell Sage.

Henrich, J., Ensimger, J., McElreath, R., Barr, A., Barrett, C., Bolyanatz, A., ... Ziker, J. (2010). Markets, religion, community size, and the evolution of fairness and punishment. Science, 327, 1480-1484. doi:10.1126/science. 1182238

Henrich, J., Heine, S.J., \& Norenzayan, A. (2010). The weirdest people in the world? Behavioral and Brain Sciences, 33, 61-135. doi:10.1017/S0140525X0999152X

Herrmann, B., Thoeni, C., \& Gaechter, S. (2008). Antisocial punishment across societies. Science, 319, 1362-1367. doi:10.1126/science. 1153808

Iannacone, L. (1994). Why strict churches are strong. American Journal of Sociology, 99, 1180-1211. doi:10.1086/230409

Johnson, D.D.P., \& Bering, J.M. (2006). Hand of God, mind of man: Punishment and cognition in the evolution of cooperation. Evolutionary Psychology, 4, 219-233.

Kelly, R.C. (1985). The nuer conquest: The structure and development of an expansionist system. Ann Arbor: University of Michigan Press.

Laurin, K., Shariff, A.F., Henrich, J., \& Kay, A.C. (2012). Outsourcing punishment to god: beliefs in divine control reduce earthly punishment. Proceedings of the Royal Society B:Biological Sciences, 279, $3272-3281$.

Malhotra, D. (2008). (When) Are religious people nicer? Religious salience and the "Sunday effect" on prosocial behavior. Judgment and Decision Making, 5, 138-143.

McNamara, R.A., Norenzayan, A., \& Henrich, J. (in press). Supernatural punishment, in-group biases, and material insecurity: Experiments and Ethnography from Yasawa, Fiji. Religion, Brain, \& Behavior.

McNamara, R.A., Willard, A., Norenzayan, A., \& Henrich, J. (2014, February). God's mind on morality: A knowing God is a punishing God. Poster presented at the 15th Annual Meeting of the Society for Personality and Social Psychology, Austin, TX, USA.

Mikalson, J. (2010). Ancient Greek religion. Malden, MA: Blackwell.

Morewedge, C.K., \& Clear, M.E. (2008). Anthropomorphic god concepts engender moral judgment. Social Cognition, 26(2), 182-189. doi:10.1521/soco.2008.26.2.182

Norenzayan, A. (2013). Big Gods: How religion transformed cooperation and conflict. Princeton, NJ: Princeton University Press.

Norenzayan, A. (2014). Does religion make people moral? Behaviour, 151, 365-384.

Norenzayan, A., Henrich, J., \& Slingerland, E. (2013). Religious prosociality: A synthesis. In P. Richerson \& M. Christiansen (Eds.), Cultural evolution (pp. 365-378). Cambridge, MA: The MIT Press.

Norenzayan, A., Shariff, A.F., Gervais, W.M., Willard, A., Slingerland, E., \& Henrich, J. (2014). The cultural evolution of prosocial religions. Manuscript under review.

Norris, P., \& Inglehart, R. (2004). Sacred and secular: Religion and politics worldwide. New York: Cambridge University Press.

Nunn, N. (2009). The importance of history for economic development. Annual Review of Economics, 1(1), 65-92. doi:10.1146/annurev.economics.050708.143336

Nunn, N., \& Wantchekon, L. (2011). The slave trade and the origins of mistrust in Africa. American Economic Review, 101, 3221-3252. doi:10.1257/aer.101.7.3221

Obeyesekere, G. (2002). Imagining karma: Ethical transformation in Amerindian, Buddhist, and Greek rebirth. Berkeley: University of California Press. doi:10.1525/california/9780520232204.001.0001

Paciotti, B., \& Hadley, C. (2003). The ultimatum game in Southewestern Tanzania: Ethnic vatiation and institutional scope. Current Anthropology, 44, 427-432. doi:10.1086/374903

Peoples, H.C., \& Marlowe, F.W. (2012). Subsistence and the evolution of religion. Human Nature-an Interdisciplinary Biosocial Perspective, 23, 253-269. doi:10.1007/s12110-012-9148-6

Purzycki, B.G., Finkel, D.N., Shaver, J., Wales, N., Cohen, A.B., \& Sosis, R. (2012). What does god know? Supernatural agents' access to socially strategic and non-strategic information. Cognitive Science, 36, 846-869. doi:10.1111/j.1551-6709.2012.01242.x

Rauh, N.K. (1993). The sacred bonds of commerce: Religion, economy, and trade society at Hellenistic Roman Delos, 166-187. B.C. Gieben.

Richard, F.D., Bond Jr., C.F., \& Stokes-Zoota, J.J. (2003). One hundred years of social psychology quantitatively described. Review of General Psychology, 7, 331-363. doi:10.1037/1089-2680.7.4.331

Rives, J. (2007). Religion in the Roman Empire. Malden, MA: Blackwell.

Saslow, L.R., Willer, R., Feinberg, M., Piff, P.K., Clark, K., Keltner, D., \& Saturn, S.R. (2013). My brother's keeper? Compassion predicts generosity more among less religious individuals. Social Psychological and Personality Science, 4(1), 31-38. doi:10.1177/1948550612444137

Schloss, J.P., \& Murray, M. (2011). Evolutionary accounts of belief in supernatural punishment: A critical review. Religion, Brain \& Behavior, 1, 46-99. doi:10.1080/2153599X.2011.558707 
Seabright, P. (2004). The company of strangers: A natural history of economic life. Princeton, NJ: Princeton University Press.

Shariff, A.F., Norenzayan, A., \& Henrich, J. (2010). The birth of high Gods: How the cultural evolution of supernatural policing agents influenced the emergence of complex, cooperative human societies, paving the way for civilization. In M. Schaller, A. Norenzayan, S.J. Heine, T. Yamaguishi, \& T. Kameda (Eds.), Evolution, culture and the human mind (pp. 119-136). New York: Lawrence Erlbaum Associates.

Shariff, A.F., Willard, A., Andersen, T., \& Norenzayan, A. (2014). Priming God: A meta-analysis of religious priming with a focus on religious prosociality. Unpublished manuscript under peer review.

Silver, M. (1995). Economic structures of antiquity. Westport, CN: Greenwood Press.

Slingerland, E. (2013). Body and mind in early China: An integrated humanities-science approach. Journal of the American Academy of Religion, 81(1), 6-55. doi:10.1093/jaarel/1fs094

Slingerland, E., \& Collard, M. (Eds.). (2012). Creating consilience: Integrating science and the humanities. Oxford: Oxford University Press.

Smaldino, P.E. (2014). The cultural evolution of emergent group-level traits. Behavioral and Brain Sciences, 37 , 243-295.

Soltis, J., Boyd, R., \& Richerson, P.J. (1995). Can group-functional behaviors evolve by cultural group selection? An empirical test. Current Anthropology, 63, 473-494. doi:10.1086/204381

Sosis, R. (2009). The adaptationist-byproduct debate on the evolution of religion: Five misunderstandings of the adaptationist program. Journal of Cognition and Culture, 9, 315-332. doi:10.1163/15677090 9X12518536414411

Sosis, R., \& Alcorta, C. (2003). Signaling, solidarity, and the sacred: The evolution of religious behavior. Evolutionary Anthropology, 12, 264-274. doi:10.1002/evan.10120

Sosis, R., \& Bressler, E. (2003). Cooperation and commune longevity: A test of the costly signaling theory of religion. Cross-Cultural Research, 37, 211-239. doi:10.1177/1069397103037002003

Spencer, C., \& Redmond, E. (2001). Multilevel selection and political evolution in the valley of Oaxaca. Journal of Anthropological Archaeology, 20, 195-229. doi:10.1006/jaar.2000.0371

Swanson, G.E. (1960). The Birth of the Gods. Ann Arbor: University of Michigan Press.

Turchin, P. (2003). Historical dynamics: Why states rise and fall. Princeton, NJ: Princeton University Press.

Turchin, P. (2011). Warfare and the evolution of social complexity: A multilevel selection approach. Structure and Dynamics, 4, 1-37.

Turchin, P., Currie, T.E., Turner, E.A.L., \& Gavrilets, S. (2013). War, space, and the evolution of old world complex societies. PNAS, 10(41), 16384-16389. doi:10.1073/pnas.1308825110

Wildman, W.J., \& Sosis, R. (2011). Stability of groups with costly beliefs and practices. Journal of Artificial Societies and Social Simulation, 14, 6.

Wilson, D.S. (2002). Darwin's cathedral: Evolution, religion, and the nature of society. Chicago: University of Chicago Press. doi:10.7208/chicago/9780226901374.001.0001

Wilson, E.O. (1998). Consilience: The unity of knowledge. New York: Random House.

Wrangham, R.W., \& Glowacki, L. (2012). Intergroup aggression in chimpanzees and war in nomadic huntergathers, evaluating the chimpanzee model. Human Nature, 23, 5-29. doi:10.1007/s12110-012-9132-1

Xygalatas, D. (2013). Effects of religious setting on cooperative behavior: A case study from Mauritius. Religion, Brain and Behavior, 3(2), 91-102.

Xygalatas, D., Mitkidis, P., Fischer, R., Reddish, P., Skewes, J., Geertz, A.W., ... Bulbulia, J. (2013). Extreme rituals promote prosociality. Psychological Science, 24, 1602-1605. doi:10.1177/0956797612472910

Zak, P., \& Knack, S. (2011). Trust and growth. The Economic Journal, 111, 295-321. doi:10.1111/14680297.00609 